\title{
8. SHALLOW-WATER LIMESTONES FROM THE BLAKE NOSE, SITES 390 AND 392
}

\author{
Paul Enos, Department of Geology, State University of New York, Binghamton, New York \\ and \\ Tom Freeman, Department of Geology, University of Missouri at Columbia, Columbia, Missouri
}

\begin{abstract}
Cores from the Lower Cretaceous shelf edge were obtained at DSDP Sites 390 and 392 (Leg 44) at the edge of the Blake Plateau. The shallow-water Lower Cretaceous limestones comprise three units which are, in ascending order: skelmoldic limestone $(107+\mathrm{m})$, oolitic limestone $(29 \mathrm{~m})$, and fenestral limestone $(114 \mathrm{~m})$.

The skelmoldic limestone consists of skeletal wackestone and muddy skeletal-pelletoidal packstone containing pelletoids, green algae, and small benthic foraminifers. It was probably deposited as a low-relief blanket near the shelf edge. Cement-reduced skeletal moldic porosity is pervasive with local development of vugs and caverns.

Grainstone and packstone with varying proportions of ooids, pelletoids, and calcareous algae predominate in the oolitic limestone. Sedimentary structures include coarse-fine layering, sheet cracks, and thin muddy intervals inferred to be incipient hard grounds; no cross-bedding was detected. Initially high interparticle porosity was partly occluded by diagenetic sediment and pendant cement, both inferred to be vadose features, and was later obliterated by extensive cement precipitation of probable phreatic origin.

The fenestral limestone is interlayered packstone and wackestone with pelletoids, fossils (miliolid foraminifers, gastropods, ostracodes, and algal filaments), and intraclasts. Abundant fenestra, fine laminations, ruptured laminae, desiccation polygons, and low fossil diversity indicate tidal-flat deposition. Voluminous fenestral porosity, the inferred product of extensive migration of fluids (gas and/or water), was occluded by syndepositional interval sediment and later cement with the same morphological sequence and cloudy early zones found in the two underlying units.

The three units are ascribed to a single regressive depositional sequence. They were subjected to extensive subaerial diagenesis which began during, or perhaps before, deposition of the oolitic and fenestral limestone and continued until the continental margin was submerged and deposition of pelagic calcareous oozes initiated in the Barremian (Lower Cretaceous). The earliest pelagic deposits probably accumulated extremely slowly with in situ formation of goethitic laminated crusts and ooids.
\end{abstract}

\section{INTRODUCTION}

Two sites were drilled on the Blake Nose, at the edge of the Blake Plateau (Figure 1), where the presence of Cretaceous reefs has been inferred from seismic profiles and dredge samples (Heezen and Sheridan, 1966; Sheridan, et al., 1971; Sheridan, 1974). Drilling at this locality was proposed to determine the nature of the Lower Cretaceous shelf edge that has been traced from Mexico around the U.S. Gulf Coast, and extrapolated into Cuba, the Bahamas, and up the Atlantic Coast (Paulus, 1972; Sheridan, 1974; Meyerhoff and Hatten, 1974). The possible extension of this shelf edge northward is significant to interpretation of oil reserves on the Atlantic shelf (U.S. Geological Survey, 1975a, b), although the DSDP sites were chosen where there is little chance of petroleum accumulation.
The deposits encountered at Sites 390 and 392 include a very condensed, but surprisingly complete, Eocene through Barremian section composed entirely of pelagic calcareous ooze. A thin interval of red-stained limestone occurs just above the top of lithified Lower Cretaceous shallow-water limestone at 99 meters sub-bottom in Hole 392A, 50 meters in Hole 392, and 161 meters in Hole 390. Recovery at Hole $392 \mathrm{~A}$ was adequate for recognition of three limestone units (units 2, 3, and 4 of Figure 2), characterized in ascending order as: skelmoldic limestone $(107+\mathrm{m})$, oolitic limestone $(29 \mathrm{~m})$, fenestral limestone $(114 \mathrm{~m})$. The limestones are probably Lower Cretaceous on the basis of a green alga (Acroporella cf. radoicicae) found in the oolitic limestone (Graham F. Elliot, letter of 9 December 1976). The algal flora in general is characteristic Old-World Tethyan (Elliot, letter, December 1976). 


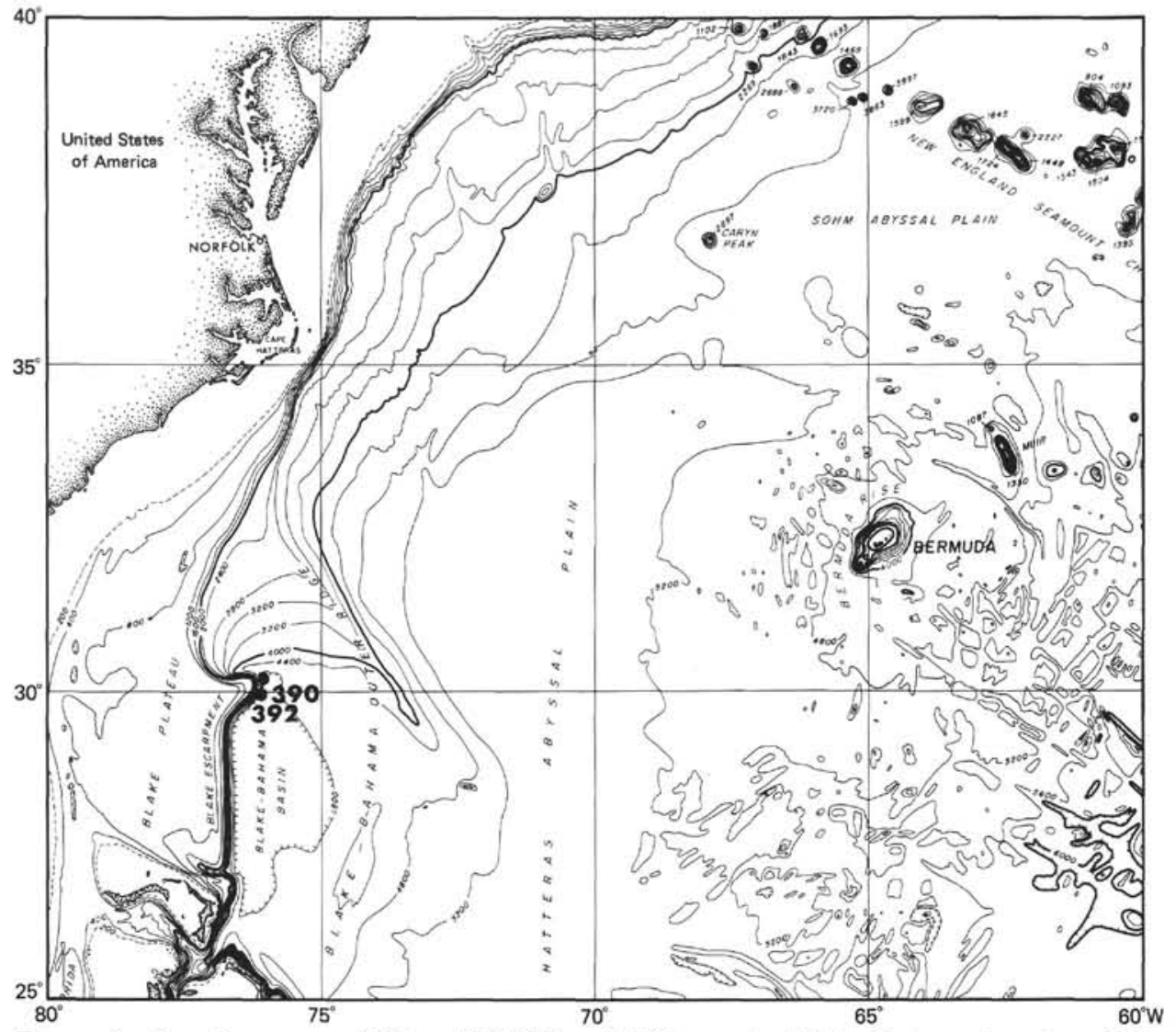

Figure 1. Location map of Sites 389-390 and 392, on the Blake Nose at the edge of the Blake Plateau. Bathymetric contours in meters.

The purpose of this study was to improve understanding of the depositional environments of these rocks and to investigate the diagenetic history, in particular the evolution of porosity. We examined 65 petrographic thin sections (mostly $50 \times 75 \mathrm{~mm}$ ) and companion core slabs. Our studies were supplemented by X-ray diffraction determinations of mineralogy, a few chemical analyses, and reconnaissance cathode luminescent petrography of cements. In the lithologic descriptions we use the depositional texture nomenclature of Dunham (1962), the authegenic calcite terminology of Folk (1965), and the porosity classification of Choquette and Pray (1970).

\section{SKELMOLDIC LIMESTONE}

The lowest unit penetrated on the Blake Nose has white microcrystalline limestone with sparse open molds of fossils (Figure 3). This diagenetic (solution) overprint is so pervasive that it serves to characterize the unit more than any specific depositional texture. At Hole 392A the unit is in excess of 100 meters thick; it extends from 241.6 meters sub-bottom to bottom-hole depth of 349 meters. (Cores 22-31; no samples were recovered below 335.5 meters in Cores 32 and 33.) Total recovery was only 3 percent of the cored interval and was limited to fragments severely rounded by the drill bit. Microcrystalline, moldic limestone was also present at the bottom of Hole 390 (Cores 9 and 10; Site 390 Report, this volume), although only 47.6 meters of limestone were penetrated before drilling was terminated.

\section{Lithology}

Skeletal lime wackestone is dominant at the base of this interval, and muddy skeletal-pelletoidal lime packstone gradually becomes dominant upward. Minor lithologies include pelletoidal-algal grainstone, oolitic-intraclastic grainstone, algal-oolitic grainstone, fenestral packstone, green-algal boundstone (?), and algal stromatolite wackestone. Grainstones are most common in the upper part of the interval, but occur sparsely throughout. The dominant color of slabbed samples is white to light gray, but a few pieces are very pale brown.

\section{Sedimentary Structures}

Because of poor recovery we could not distinguish bedding characteristics except for coarse-fine lamination and indistinct small-scale textural interbedding in a few intervals of grainstone and packstone. Algal stromatolites occur in one sample. Burrows were detected by muddy burrow linings in only one sample, although the general lack of sedimentary structures may reflect bioturbation.

\section{Constituents}

Pelletoids ranging up to $1 \mathrm{~mm}$ in diameter are present in all samples and abundant in most. Their sharp boundaries and local angularity suggest that many pelletoids, particularly the larger ones, were lithified prior to deposition. They also have the dark color and semi-opacity typical of hardened 


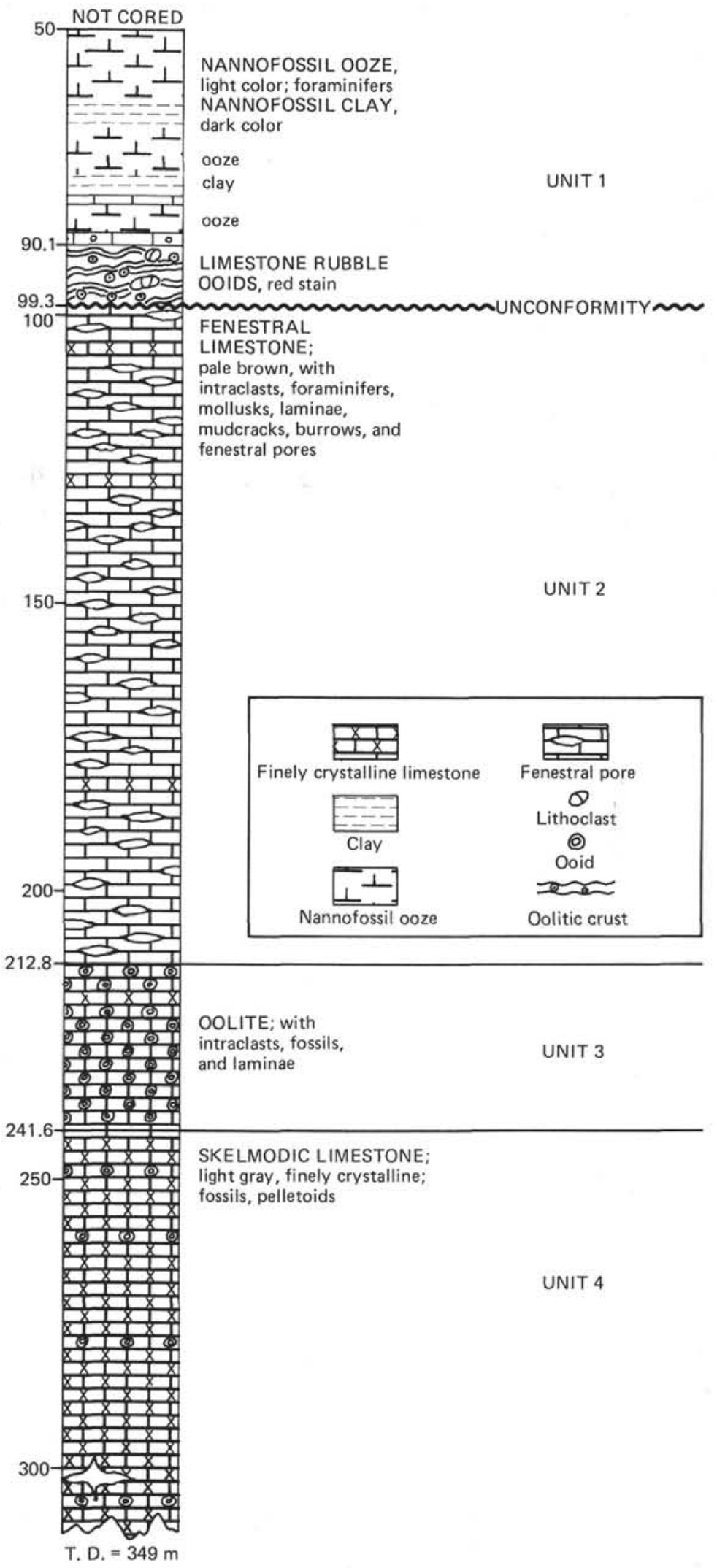

Figure 2. Stratigraphic column at Site 392, Blake Nose, showing lithified carbonate units described in this report (units 2-4). Modified from shipboard site reports, Site 392, Figure 9. 


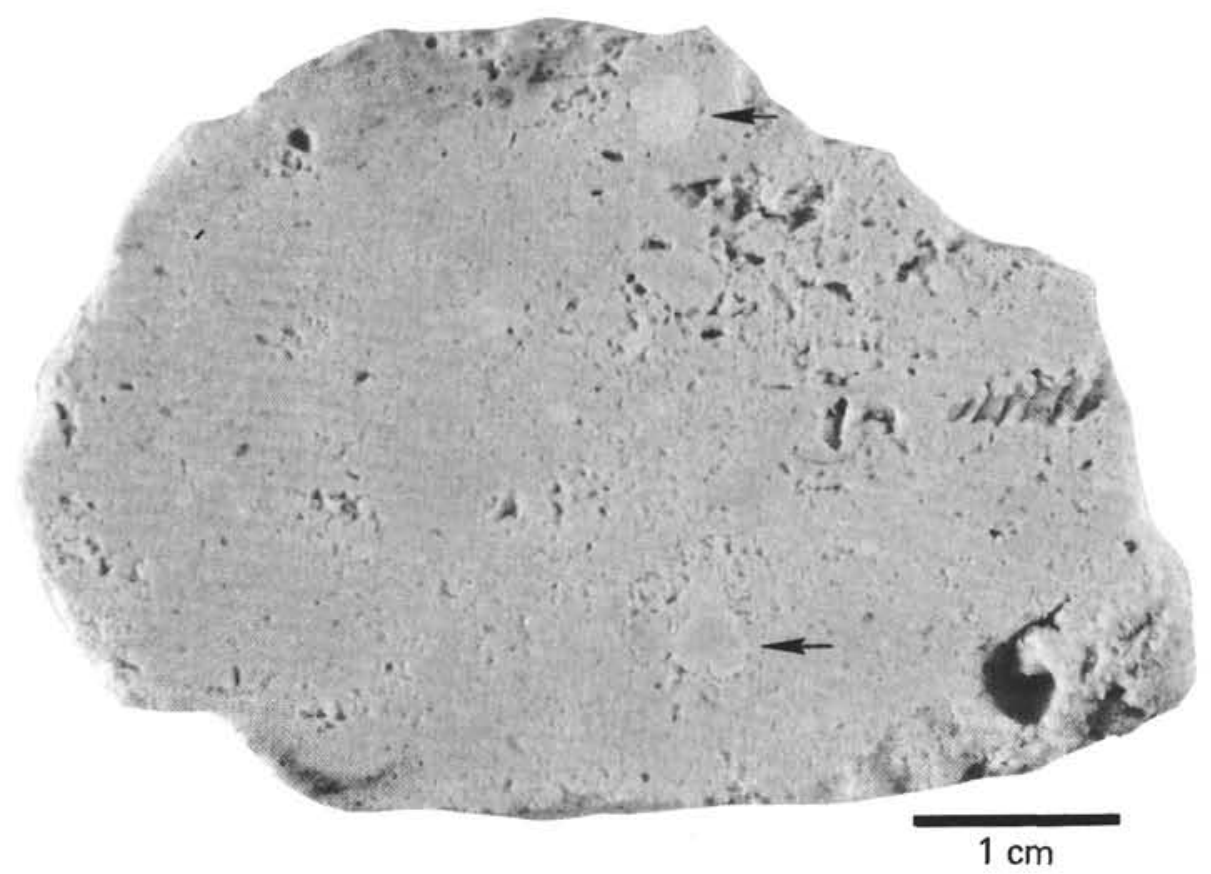

Figure 3. Skeletal-pelletoidal lime packstone from skelmoldic limestone unit. Large molds (lower right) were gastropods. Larger particles (arrows) are calcareous green algae (Cayeuxia spp.). Sample 392A-23-1, 95-98 cm. Depth 251 meters sub-bottom.

pelletoids in modern sediments. Traces of skeletal structure and, rarely, those of ooids show that many pelletoids originated through micritization of preexisting grains. Some smooth ovoid pelletoids include skeletal fragments, indicating that they are lithified fecal pellets or mud aggregates. Smaller (20-60 $\mu \mathrm{m}$ in diameter) and less regularly shaped, light gray, translucent, ovoid clots locally merge with the mud matrix. These were soft pelletoids, perhaps fecal in origin. Intraclasts occur in many samples and are normally muddier (or more highly micritized) than is the host sediment. Lithoclasts, which are indicated by the truncation of grains at the clast margins, are confined to a few grainy clasts, including some oolite. Ooids are very rare and highly micritized except in the oolitic grainstone interbeds.

Skeletal particles are predominately algae and foraminifers. Codiacian green algae, probably Cayeuxia, are common in the packstone (Figure 3). One blue-green algal wackestone or boundstone was recovered (Figure 4). Small dasyclad green algae are sparse to common throughout, but are preserved primarily as molds (Figure 5). Miliolids are the most commonly occurring foraminifer in most samples, but small, planispirally coiled or biserial forms, including Trocholina sp., are also present. Gastropods occur in small numbers throughout the interval. Other fossils include pelecypod fragments, ostracodes, and a single coral branch.

The matrix is uniformly 1-6 $\mu \mathrm{m}$ equant crystals of calcite. The larger crystals have irregular, but not interlocking, boundaries with some sharp corners. The smaller crystals are rounded, probably reflecting solution on smaller corners. This is micrite in the sense of Folk (1959). The particles have been recrystallized so that original particle shape and genesis cannot be determined.

\section{Depositional Porosity}

Initial interparticle porosity of the grainstone was about 35 per cent, but mud with matrix porosity of $65-75$ per cent filled in the interparticle space in the wackestone and most packstones. These values are estimated on the basis of cement-filled porosity and measurements in recent analogs (Enos, 1977). Most of the skeletal particles had some intraparticle porosity but this was minor, probably not more than 10 per cent of any sediment. Shelter voids beneath some of the larger grains and fenestral pores (Choquette and Pray, 1970 ) produced up to 15 or 20 per cent porosity in a few samples (Figures 4, 6).

\section{Depositional Environment}

The composition and texture of the skelmoldic limestone suggest a shallow-marine environment of deposition characterized by weak currents and thorough pelletization by organisms. Slow accumulation rates, for shallow-water carbonates, presumably allowed lithification of many fecal pellets and thorough micritization of skeletal grains, ooids, and other allochems. Depositional relief is indicated only by layers of fenestral and stromatolitic limestone, which suggest emergence on tidal flats, and by oolite which may have accumulated in sand waves.

A suitable modern analog for the skelmoldic microcrystalline limestone is the broad interior of the Great Bahama Bank where a blanket of pelletoidal lime sand is accumulating on level bottoms a few meters to 20 meters deep (Cloud, 1962; Purdy, 1963a, b; Ball, 1967; Traverse and Ginsburg, 1966; Enos, 1974). This blanket extends to the slope break in areas where marginal shoals (oolites, reefs, or 

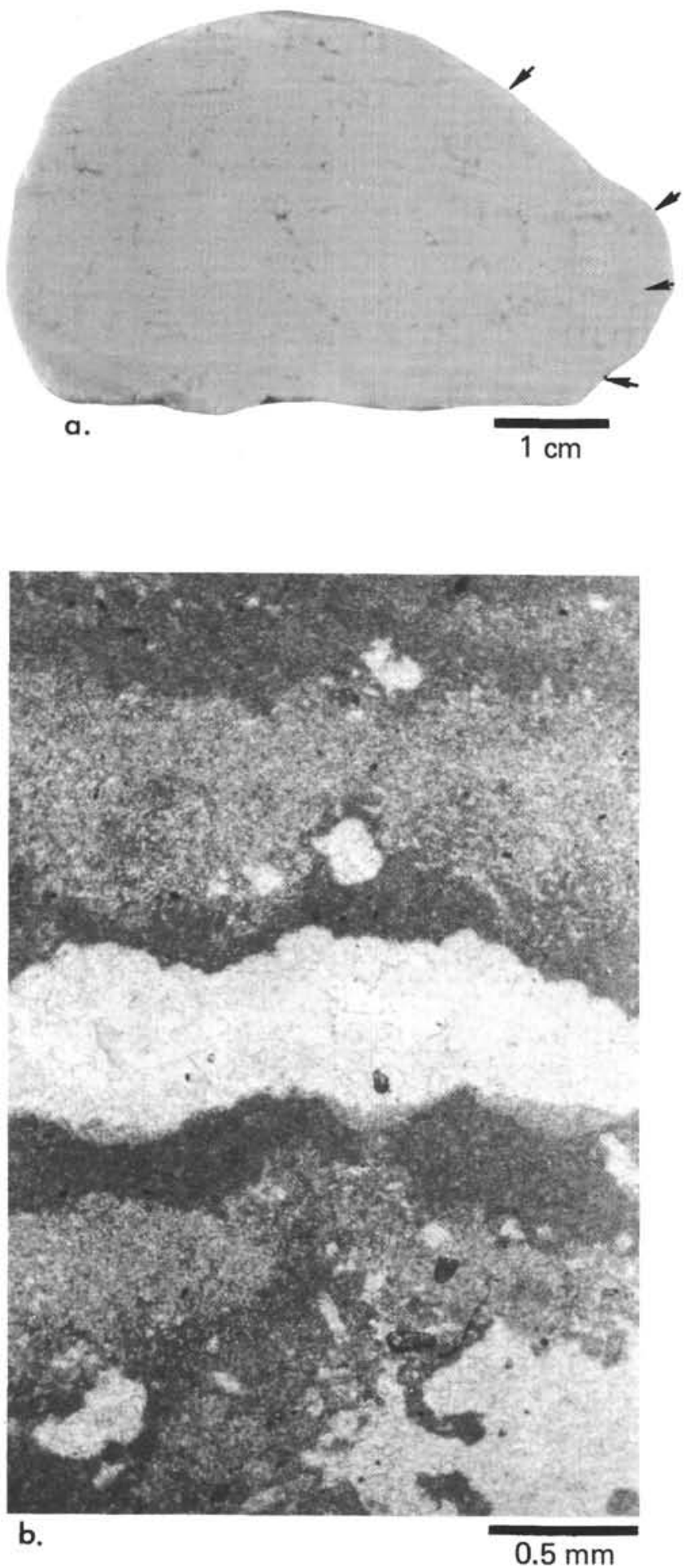

Figure 4. Algal stromatolite lime wackestone or boundstone. (a) Four light bands (arrows) are algal layers; a fifth is present but not clearly visible. Fenestral pores extend both horizontally and vertically. Sample 392A31, CC. Sub-bottom depth 326 meters slab. (b) Algal layers separated by fenestral pore. Thin section, of a; plane light. rock islands) are lacking, although skeletal components increase somewhat, at the expense of pelletoids, toward the platform edge. This marginal setting is perhaps the most precise analog for the skelmoldic limestone sampled at Site 392. The present shelf-margin location of the drill site (Figure 1) and the occurrence of pelagic Lower Cretaceous in cores seaward of the Blake escarpment (e.g., Site 391) support this interpretation. The superposition of oolitic and fenestral units, interpreted below as deposits of shelf-margin shoals, is compatible.

\section{Diagenetic History}

Diagenesis has converted the original locally porous sediment, probably composed largely of aragonite and magnesian calcite, to a well-lithified limestone, consisting entirely of calcite with generally reduced but more localized porosity. Most of the primary porosity has been occluded by diagenetic sediment (Dunham, 1969a) and pore-filling cement (Figure 6), but subsequent leaching has produced secondary porosity, in the form of molds and vugs, of up to perhaps 40 percent. Molds of skeletal particles, especially dasycladacian green algae and mollusks, occur in nearly all samples (Figures 2, 5). Leaching selected these particles whose original composition was aragonite, the more soluble calcium carbonate dimorph. Codiacean green algae, also originally aragonitic, were partially leached but escaped complete removal because of their large size. An undetermined number of vugs may be products of total solution of irregular codiacean fragments; mollusk and dasyclad molds are more easily recognized. The maximum extent of moldic porosity probably never exceeded 5 per cent at any time and cementation has since reduced it to 2 per cent or less. Still, it is the most persistent and obvious megascopic feature of this microcrystalline limestone.

Vugs, although patchily distributed, are more volumetrically important in present porosity which ranges up to 40 percent. Vugs show little or no preference for lithic types apart from being nearly absent in grainstones and most common lower in the section where wackestones predominate. Vugs range in size from a few tens of micrometers in diameter to more than $2 \mathrm{~cm}$ (Figure 7). Abrupt increases in drilling rate and sudden drops of the drill bit between 293 and 303 meters and from 322 to 326 meters sub-bottom at Hole 392A probably were the result of drilling through still larger vugs; that is, zones of cavernous porosity up to 10 meters thick with individual caverns perhaps 3 meters high. The edge of a small cavern partially filled with diagenetic sediment and cement was recovered in Core 24 (Figure 8).

Cement distribution and its morphology in the skelmoldic limestone are fairly simple. The degree of cementation ranges from nearly zero in some samples, through patchy pore linings, to complete occlusion of smaller pores and considerable reduction of the larger ones. Although the amount of cement differs among samples, the degree of occlusion of pores within any one sample appears to be a function of pore size; the smaller pores are more completely occluded. There does not appear to be a systematic relationship between the degree of cementation and type of 


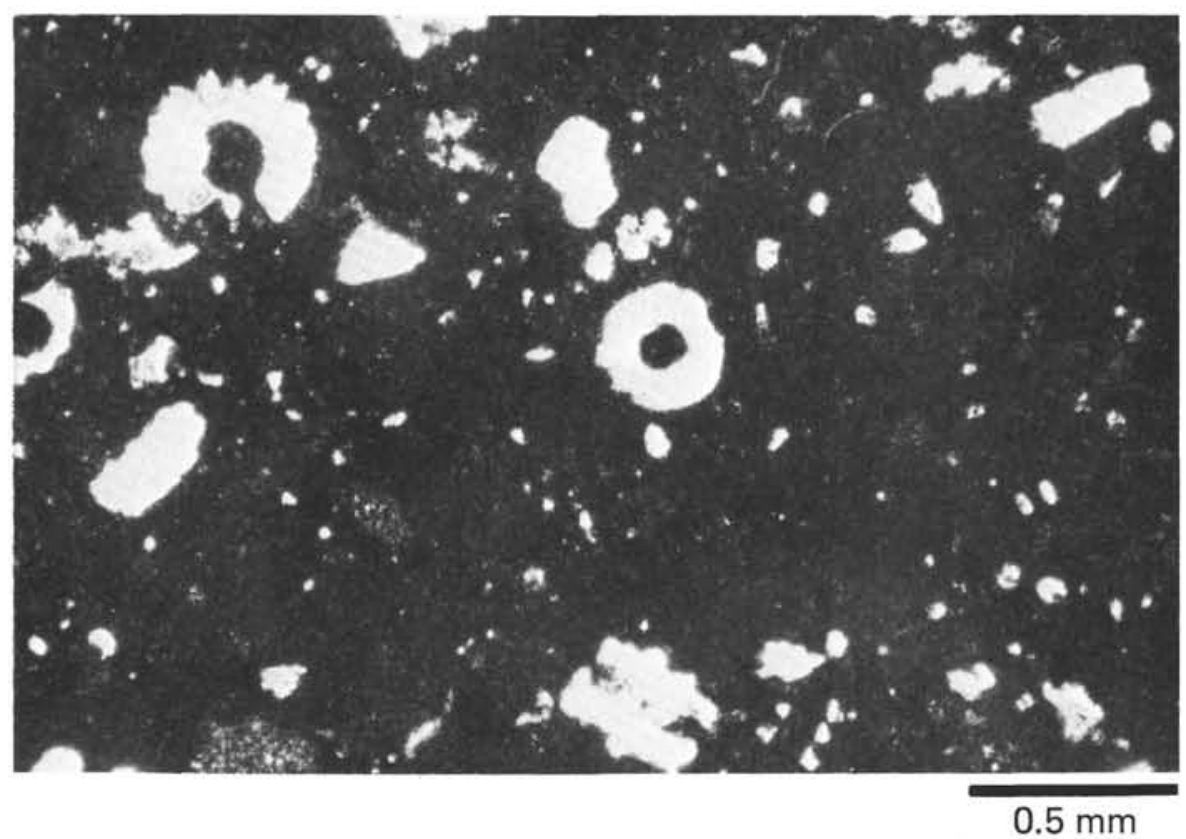

Figure 5. Molds of dasyclad green algae (?) in skeletal lime wackestone. Sample 392A-28, CC. Sub-bottom depth 298 meters. Thin section, plane light.

porosity that might illuminate the sequence of diagenetic events. One exception is a sample from Core 30 in which molds and vugs are less thoroughly cemented than are the primary pores, which suggests that these molds and vugs postdate most of the cement.

A specific sequence of cement morphologies is recognizable in most of the larger pores (Figures 9,10 ). The earliest cement is an irregular crust of equant crystals smaller than $16 \mu \mathrm{m}$. This crust is overlain by a fringe of bladed crystals (Folk, 1965) ranging from $65 \mu \mathrm{m}$ up to a millimeter in length. The crystals widen away from convex substrates to form fan-like crusts. The third and final cement consists of a mosaic of equant crystals up to a millimeter in size. Although the three cement morphotypes are readily recognizable, their mutual boundaries are gradational.

The crust of equant crystals and part or all of the bladed fringe contain numerous inclusions that impart a cloudy appearance in transmitted light (Figures 11, 12). In contrast, the final mosaic of equant crystals is relatively free of such inclusions and so is clear. The boundary between cloudy and clear cements is commonly more abrupt than is the boundary between crystal morphologies and the two are not coincident in some cases. The bladed crystals lack the distinctive features of "radiaxial fibrous calcite," i.e., convergent optic axes, diverging subcrystals and curved cleavages, outlined by Bathurst (1971) and Kendall and Tucker (1973, p. 367).

The intergradations between cement stages and the general crystal orientation with $\mathrm{C}$-axis normal to the pore walls suggest that competitive crystal growth may produce the apparent sequence of cement morphotypes. The earliest nucleated crystals tend to be equant. The most successful competitors for space are those oriented with $\mathrm{C}$-axis (the most rapid direction of growth) nearly perpendicular to the substrate. This gives rise to the bladed fringe. However, competition for spaces goes on in the third dimension as well as in the two dimensions seen in thin section. Thus a surface out of the plane of the thin section is likely to be closer to the apparent center of the pore than are the visible pore walls cut by the section (Figure 12A). This is especially true in skeletal and vuggy carbonates because of the many irregularities in their pore walls. Therefore, the ultimate pore-filling crystals are likely to be rooted outside of the plane of section and the cut of the thin section will be transverse to the $\mathrm{C}$-axis of these crystals. The widening of crystals away from the substrate, results in large, apparently subequant crystals as the final pore filling.

In a sample from Core 30 molds and vugs contain very little cement while primary pores are completely filled and display all three stages of crystal morphology. The thin crust of cement in the solution pores, although it must have been deposited concurrently with or later than the coarse, equant third-stage cement morphotype, is identical to the first-stage, fine-grained equant crust. Thus we cannot assume cements are time equivalent solely on the basis of similar morphology and sequence.

In summary, the diagenetic history of the skelmoldic limestone begins with syndepositional burrowing and micritization of grains, which did not greatly alter the sparse primary intergranular and intragranular porosity. The development of molds and vugs followed. There is no indication that cementation occurred before the limestones were leached (except in the sample from Core 30), although some degree of lithification was probably required to prevent collapse of the vugs as they formed. Finally, cementation partially filled the molds and vugs and almost completely filled the smaller primary pores. Three types of cement which differ both in morphology and degree of transparency probably represent a single episode of cementation, however lengthy or intermittent. 


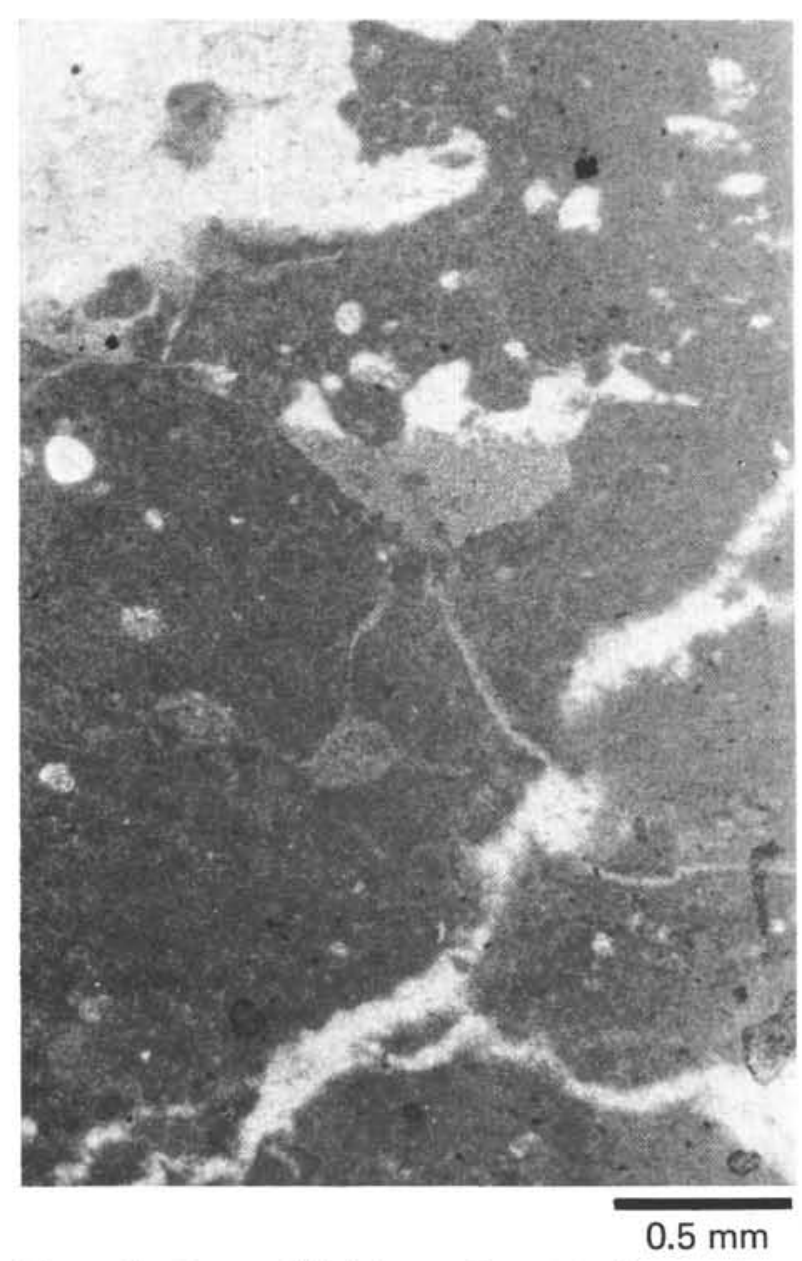

Figure 6. Cement-filled fenestral pores in lime wackestone. Early diagenetic sediment underlies the cement and fills narrow, irregular fractures linking the fenestral pores, indicating early formation of the fractures. Sample 392A-31, CC. Sub-bottom depth 326 meters. Thin section, plane light.

\section{Diagenetic Environment}

In some rocks, including some limestones from the Blake Nose, the existence of a unique diagenetic environment may be inferred from cement morphology, diagenetic sequence, and other clues. For the skelmoldic limestone we know only that the leached porosity was probably formed by chemically aggressive meteoric waters. Leached porosity is relatively rare in the overlying limestones, although some filled fossil molds occur. Thus, it is possible that exposure of the skelmoldic limestone to meteoric water preceded deposition of the overlying two units.

Because the molds are of aragonitic fossils, some less-soluble calcite cement was probably precipitated contemporaneously with leaching. This redistribution of calcium carbonate would sufficiently lithify the limestone to allow the formation of vugs as molds were enlarged beyond the original grain boundaries. It would also account for the lone sample (Core 30 ) in which molds and vugs appear to postdate cement. Both cementation and solution proceeded simultaneously, but in this sample one process, solution, proceeded slightly faster than the other. The mold-filling cement is, then, probably a precipitate from fresh, meteoric waters with some carbonate being derived through local leaching. These waters were probably near the top of the phreatic zone where leaching is favored by maximum water circulation. The fairly uniform distribution of cement and the lack of obvious vadose features are consistent with this upper phreatic-zone interpretation.

By extrapolation, the other morphologically identical cements may also be fresh-water, phreatic-zone products. Although correlation of events in time on the basis of the cement morphologies is probably unwarranted (see above), morphology may be a reliable indicator of diagenetic environment (cf. Folk, 1974).

Ostracode-bearing sediment occurs within the cavern shown in Figure 8 suggesting a possible incursion of sea water before much of the cementation was completed. As the cements in the limestone are indistinguishable from the

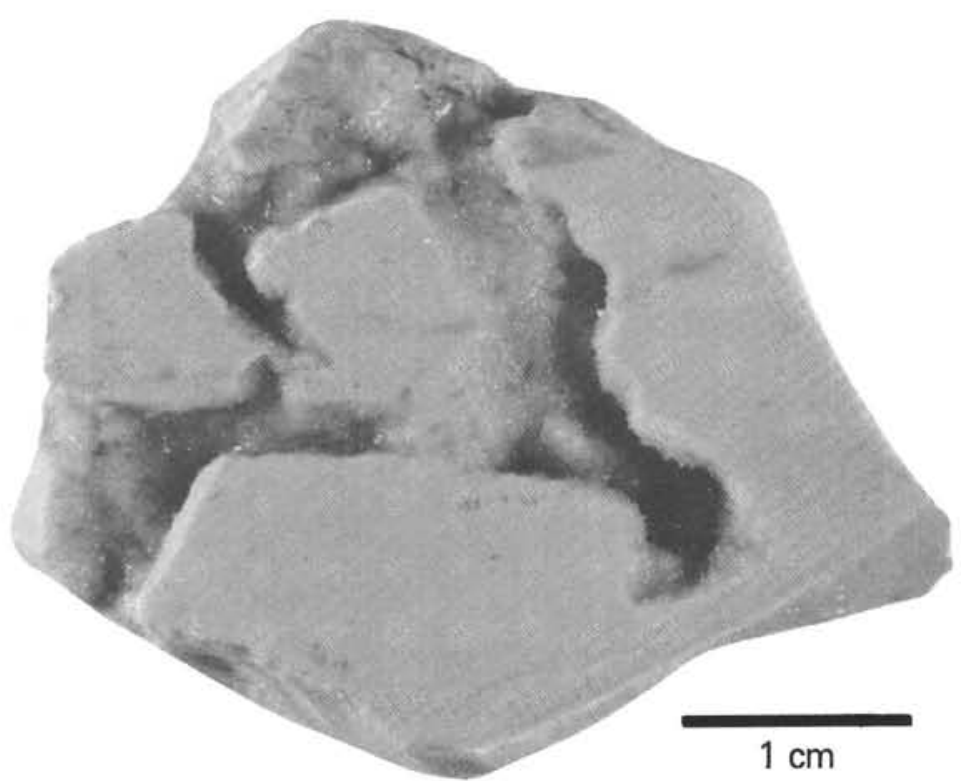

Figure 7. Vuggy porosity in crystalline skeletal lime wackestone. Sample 392A-27, CC. Sub-bottom depth 326 meters. Thin section, plane light. 


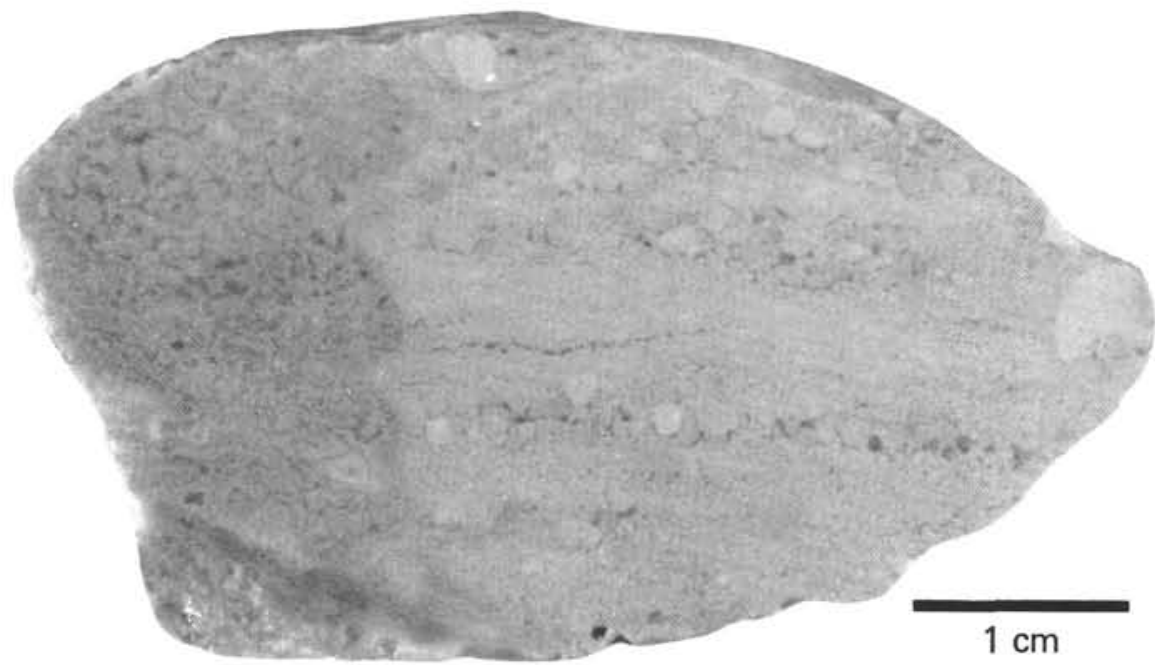

Figure 8. Margin of filled cavern (left) in layered algal-oolite lime grainstone. Note projections of some layers into the former cavern. Cavern contains ooids and fretted clasts of ooid grainstone and algal-pelletal packstone with early rim cement, a small-scale collapse breccia. Well-sorted carbonate silt, containing some ostracode shells (not seen elsewhere in sample), and coarse sparry cement complete the cavern fill. Sample 392A-24, CC. Sub-bottom depth 259.5 meters. Slab.
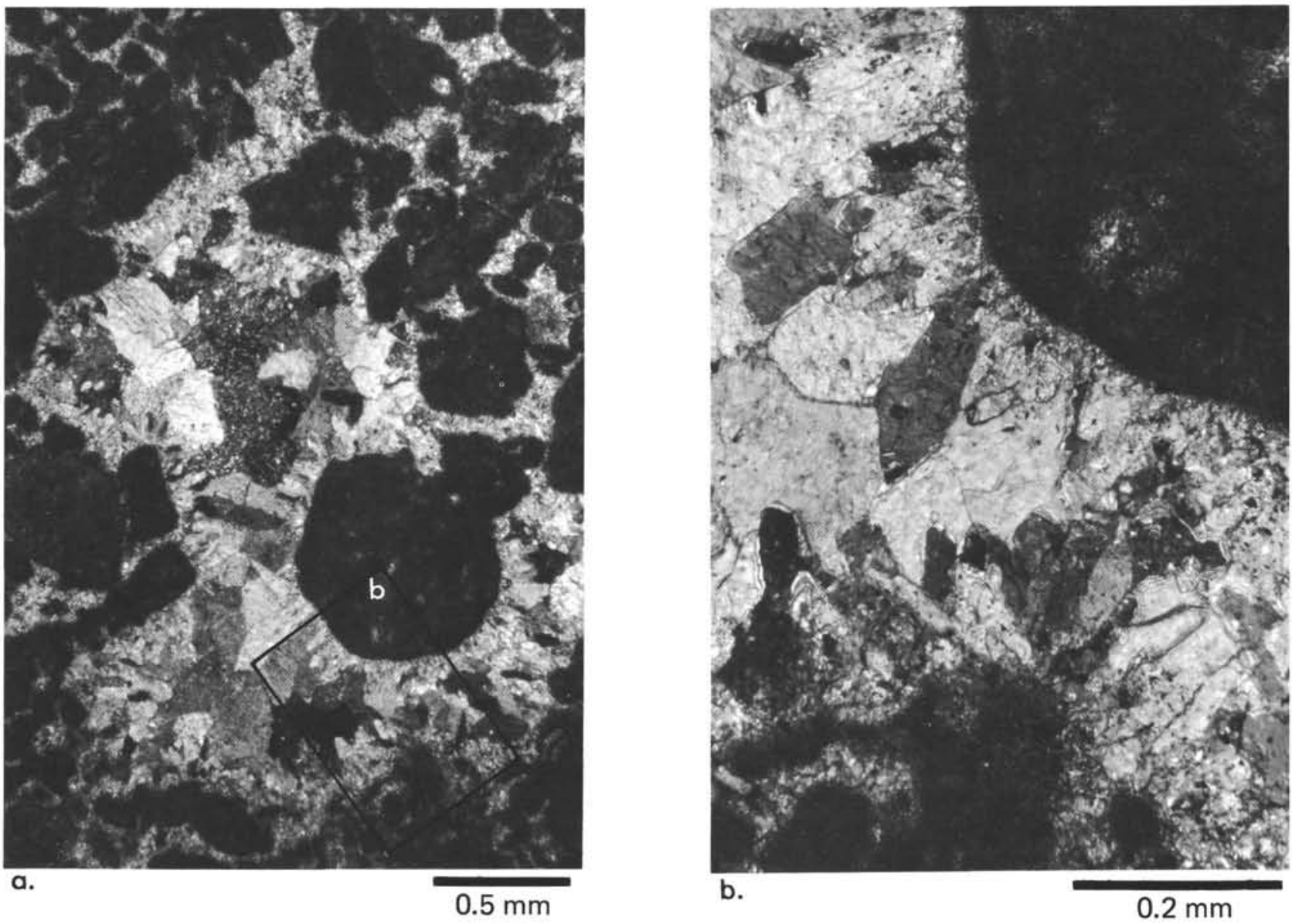

Figure 9. Cement morphology illustrated by sample from the fenestral limestone. (a) Cement-filled fenestral pore in pelletoidmiliolid lime packstone. Fine-grained equant calcite cement lines the pore walls, overlain by a medium-grained, euhedral, bladed cement, which grades into coarse-grained equant cement. (b) Detail from A, rotated $30^{\circ}$ clockwise. Sample $392 \mathrm{~A}-9$ 1, $104 \mathrm{~cm}$. Sub-bottom depth 137 meters. Thin section, cross-polarized light. 


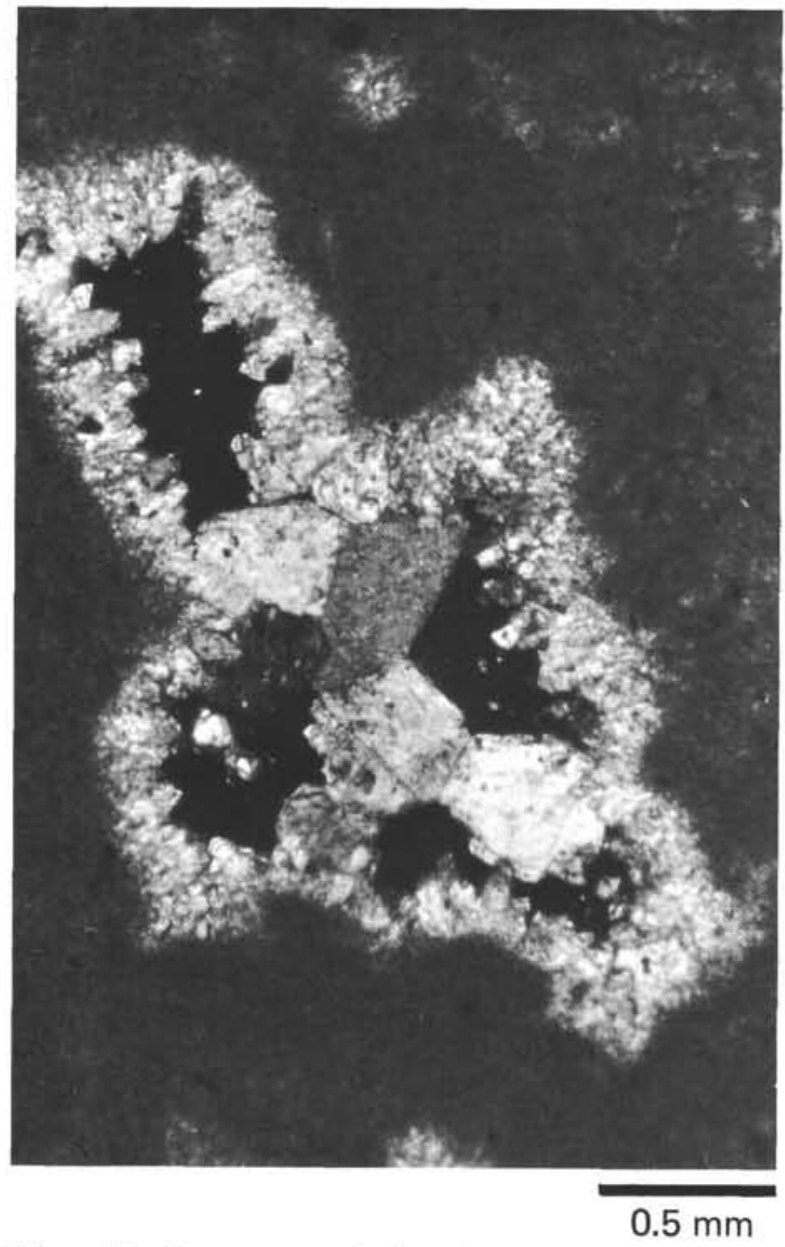

Figure 10. Cement morphology in primary interparticle pore, algal-intraclast lime packstone of skelmoldic limestone unit. Early (fine-grained) equant spar and well-developed bladed spar are overlain by a few coarse euhedral crystals growing into open pore. This obvious discontinuity between bladed and equant spar is unusual as is the incomplete filling by the equant spar, but this example probably illustrates a developmental stage which would be obscured with complete pore filling. Sample 392A-26-1, $136 \mathrm{~cm}$. Sub-bottom depth 270.4 meters. Thin section, crosspolarized light.

overlying units, the filling of this small cavern may have occurred during deposition of an overlying unit.

\section{OOLITIC LIMESTONE}

Pale brown oolitic, pelletoidal, and algal lime grainstones and packstones form a distinctive unit sandwiched between muddier Cretaceous limestones of the Blake Nose (Figure 2). This unit is 29 meters thick, and extends from 212.8 to 241.6 meters sub-bottom (Cores 392A-19 through 392A-22). Recovery in this interval was 9 percent. Some oolite is interbedded with the underlying skelmoldic limestone, but only two beds (each about $15 \mathrm{~cm}$ thick) of skelmoldic limestone interrupt the oolitic interval.

\section{Lithology}

This unit includes a variety of rock types with varying proportions of three principal constituents: ooids, pelletoids, and calcareous green algae. Intraclasts are locally abundant. Depositional textures are grainstone and packstone in roughly equal proportions, but even the muddiest packstones contained some intergranular pore space. The only exceptions within the recovered core are beds of microcrystalline, skelmoldic lime wackestone in samples $20-1,55-79 \mathrm{~cm}$ and $21-1,120-137 \mathrm{~cm}$.

\section{Sedimentary Structures}

Grainstone and packstone are interbedded on the scale of a few millimeters in many samples (Figure 13). We saw no inclined beds or cross laminations and poor recovery precluded detection of larger bedding features. Interlayering of coarse and fine beds is present in numerous samples (Figure 13a). The coarser layers are poorly sorted with grains ranging in size from $25 \mathrm{~mm}$ intraclasts (Figure 14) to pelletoids smaller than $20 \mu \mathrm{m}$. Micritic matrix is present locally.

A distinctive feature of this unit is the repetition of micritic layers less than a centimeter thick within the grainstone-packstone sequence (Figure 15). These layers may represent pauses in sedimentation accompanied by slight lithification to form an incipient hard ground. They are poorly developed, however, and lack definitive criteria for hard grounds such as boring and encrusting biota. Accordingly, we will refer to them by a non-genetic name, "muddy intervals." We noted 11 muddy intervals while describing the cores onboard ship (visual core descriptions), but we have since seen more than 20 muddy intervals in thin sections and up to four intervals in single samples a few centimeters thick (Figure 15).

At the top of a muddy interval the grains are closely packed and highly micritized to produce a very dense layer (Figure 16). Lower in a muddy interval, smoothly rounded constructional pores (fenestrae) give the matrix a spongy texture (Figure 17) which grades rapidly downward into the normal depositional texture, grainstone or packstone. The mud contains unidentified calcareous microfossils (Figure 18) and is indistinctly laminated (Figure 19) in a few examples. Grains are truncated at the top of two muddy intervals (Figure 16); elsewhere a few grains protrude through the dense mud (Figures 17, 18).

In several examples the interval is capped by a discontinuous laminated calcareous crust that is texturally indistinguishable from oolitic coatings (Figure 17). The upper surfaces are smooth to hummocky with up to $8 \mathrm{~mm}$ of relief. Several muddy intervals terminate laterally within the samples; the interval thins and close-grain packing grades into normal packing.

"Sheet cracks," horizontally elongate pores lined with spar (Fischer, 1964, p. 114), overlie many of the muddy intervals (Figures 17, 18, and 19). They are discontinuous and occur elsewhere in the absence of micritic intervals, so the apparent association is perhaps fortuitous. A thin discontinuous layer of sediment, including infiltrated silt, floors some sheet cracks and overlies the muddy intervals (Figure 17). 


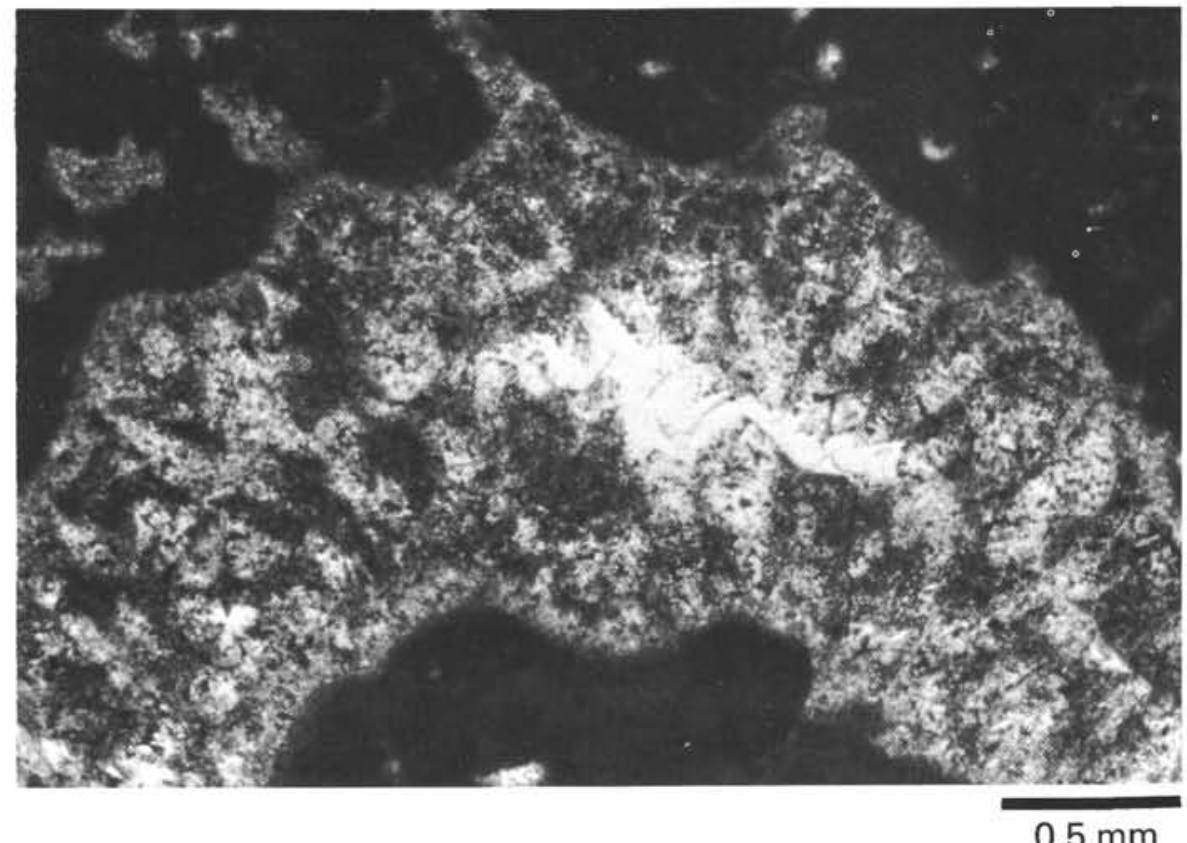

Figure 11. Cloudy and clear cement filling fenestral (?) pore in muddy skeletal-pelletoid lime packstone, skelmoldic limestone unit. Cloudy appearance, best seen in thick sections such as this, is produced by abundant mineral inclusions up to $35 \mu \mathrm{m}$ in diameter. Note narrow rim around edge of pore which contains inclusions, but is texturally distinct. This probably corresponds to an initial zone that is transparent in reflected light, overlain by a milky translucent zone, corresponding to the inclusion-rich zone, and an inner transparent zone. Sample 392A-23-1, $149 \mathrm{~cm}$. Sub-bottom depth 251.5 meters. Thin section, plane light.

\section{Constituents}

Ooids, the most persistent and characteristic constituent of this unit (Figure 20), occur in all but a few samples. Their abundance ranges from scattered ooids, commonly micritized, to practically 100 percent of the grains. Thickness of ooid coating varies within individual samples from a single lamina to thick coats, up to $0.4 \mathrm{~mm}$ thick, with 13 or more laminae (Figure 20). Laminae are concentric, but radial orientation of crystals within each lamina produces a faint pseudo-uniaxial cross in cross-polarized light. In a few instances, a strong radial fabric locally transects and obliterates the concentric layering. Ooid nucleii include all of the ambient particles pelletoids, fossils, intraclasts, and ooid fragments (Figure 20). Larger grains are uncoated or less thickly coated; presumably this is because they are less readily tumbled by traction currents, which is ordinarily necessary for coating. Ooid size differs among layers and ranges from about 100 $\mu \mathrm{m}$ to nearly a centimeter. Broken ooids are common in several layers.

Pelletoids also occur in practically every sample. Most appear to have been hard at time of deposition, on the basis of the criteria outlined above. Micritized ooids and intraclasts were clearly sources of pelletoids, along with possible fecal pellets and altered skeletal grains. Intraclasts occur in most samples. "Grapestone," lightly cemented composites with dense micritic borders and spongy interiors (Illing, 1954; Purdy, 1963a), are the most common intraclasts (Figure 14). Fragments of lime mud and cemented burrow linings (Figure 21) also form intraclasts. Lithoclasts are rare.

Green algae are the most abundant skeletal components. Codiaceans, especially Cayeuxia, are present in all samples (Figure 22a) and are abundant in some. Various dasyclad algae, including Acroporella cf. radoicicae, a Tethyan Lower Cretaceous form, are also volumetrically important (Figure 23). Other skeletal components are sparse; they include miliolids and a variety of other benthic foraminifers; gastropods (Nerinea sp. and other smaller forms), pelecypod fragments, a few ostracodes, and a possible branching coral.

The matrix of the packstone consists of closely packed, equant grains, $2-5 \mu \mathrm{m}$ in size. The distinction between primary lime mud, multiple generations of diagenetic mud, possible micritic cement, and micritic envelopes on grains is difficult, at best.

\section{Depositional Porosity}

Interparticle porosity initially ranged from less than 5 per cent in the muddier packstone to about 45 per cent in loosely packed coarse grainstone, judging from estimates of cement-filled porosity and from modern analogs (Enos, 1977). Intraparticle pores in the sparse skeletal grains (Figures 22, 23) and grapestone intraclasts (Figure 14) were too small, too few, and too isolated to contribute significantly to the pore network. Shelter pores beneath the 

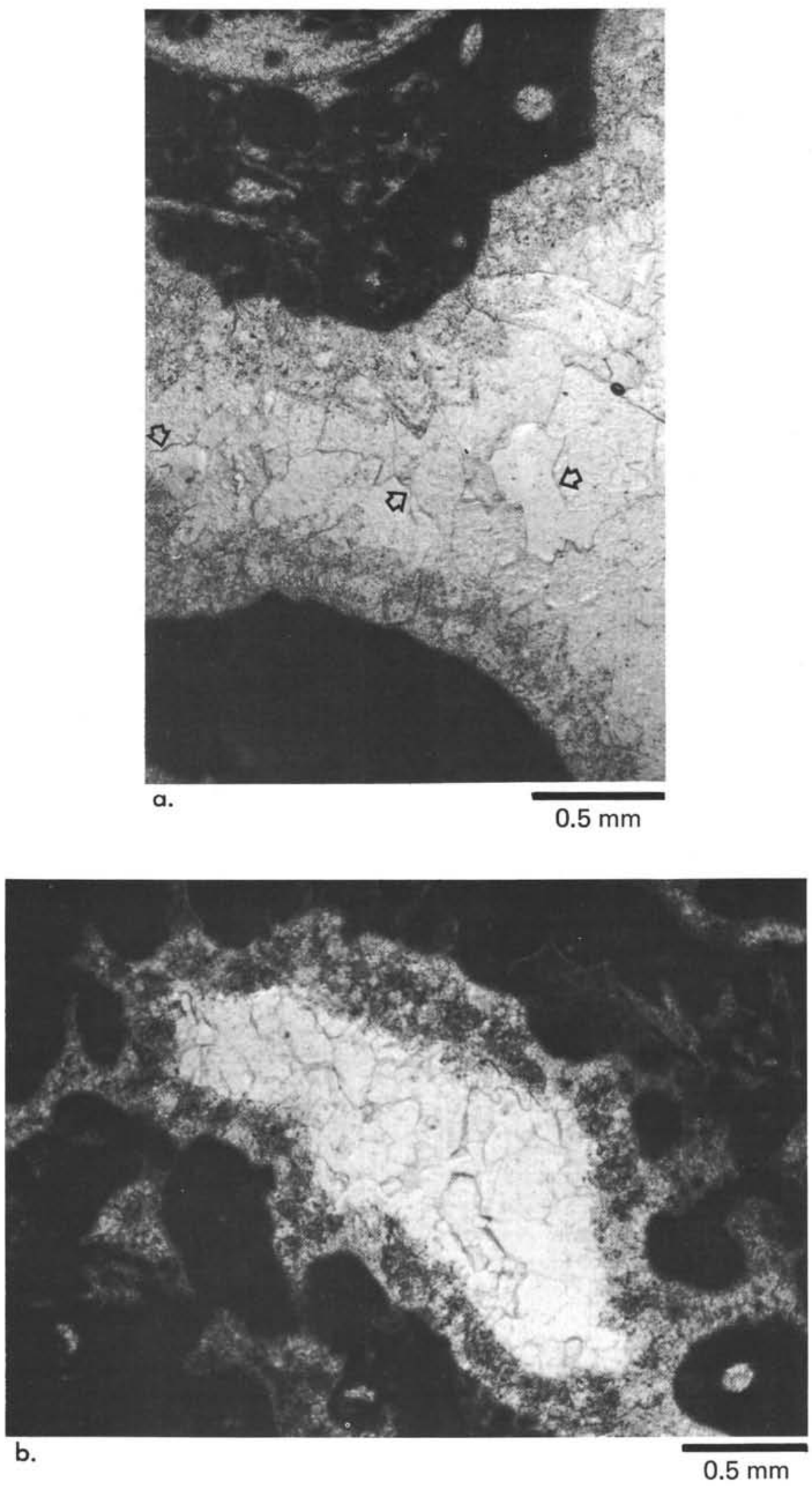

Figure 12. Examples of cloudy cement from other units. (a) Fenestral limestone, pelletoid and mollusk-mold lime packstone with some porosity retention (open arrows). Note that some bladed crystals extend beyond the inclusion-rich zone to terminate as clear crystals (solid arrow). Had the section been cut horizontally through the center of the pore, this bladed crystal would appear to be the clear, equant, final pore-filling stage. Sample 392A-9-1, $142 \mathrm{~cm}$. Depth $137.4 \mathrm{~meters}$. Thin section, plane light. (b) Oolitic limestone, pelletoid lime packstone. Note narrow bright rim at pore margin. Sample $392 A-$ 20-1, $137 \mathrm{~cm}$. Depth 222.9 meters. Thick section, plane light. 

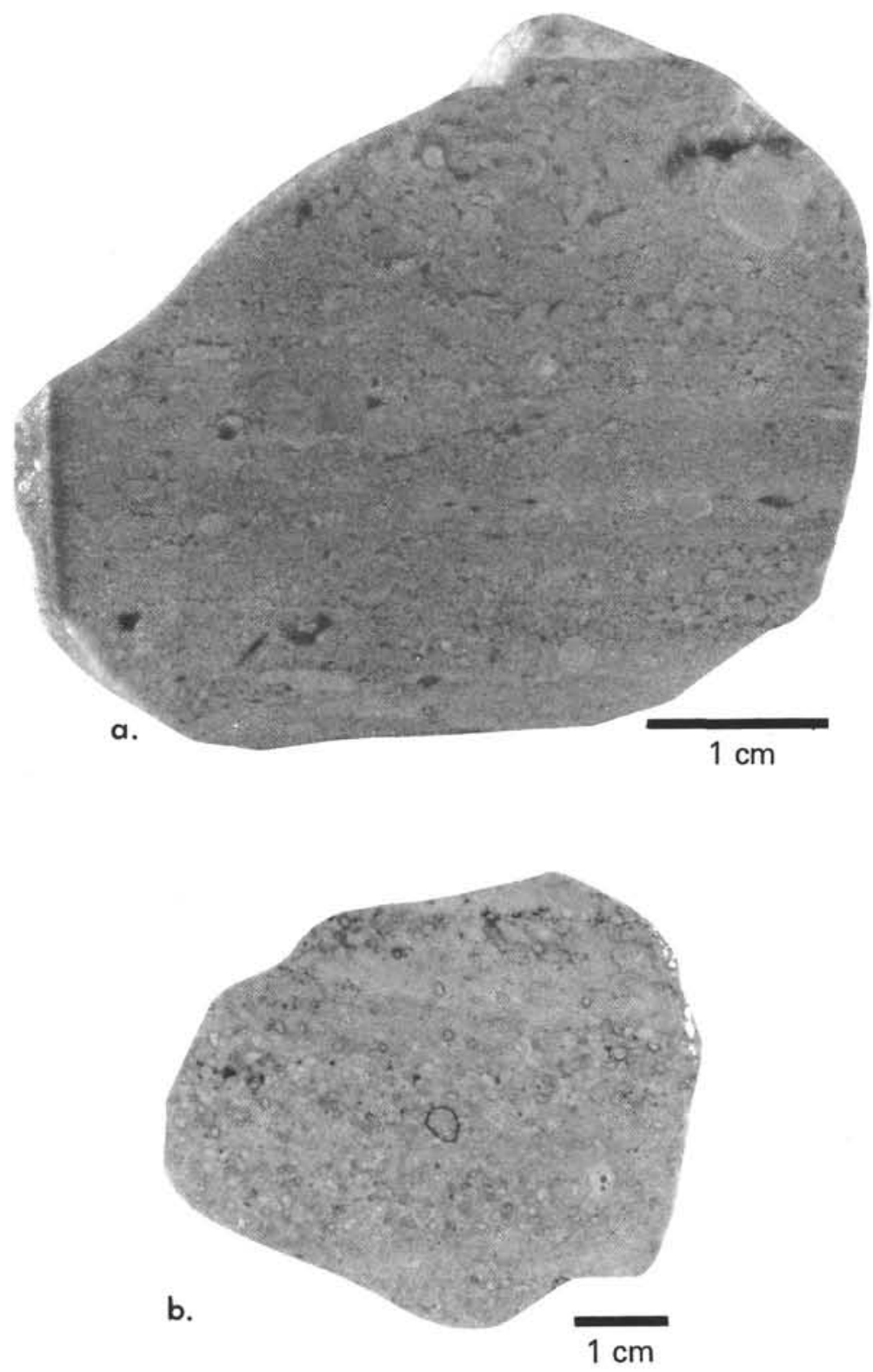

Figure 13. Layering in oolitic limestone. (a) Interlaminated algalpelletoid grainstone and packstone (ooids rare and micritized). Coarse-fine layering is superposed; size is essentially independent of depositional texture. Sample 329A-21-1, 103-106 cm. Depth 232 meters. Slab. (b) Interlayered oolitic packstone and grainstone. Sample 392A-22-1, 95-99 cm. Depth 241.5 meters. Slab.

larger grains were likewise volumetrically unimportant. Fenestral pores, including some vertical tubes similar to those in the overlying fenestral limestone, were confined to the muddier packstone interbeds and the muddy interfaces. Sheet cracks formed large and volumetrically significant pores locally (Figure 17).

\section{Depositional Environment}

Ooids with well-developed, concentric coatings occur today in a limited variety of settings, such as submarine bars, tidal channels, and beaches, which have in common shallow depths, high energy, and supersaturation with calcium carbonate. We can scarcely infer sand-body geometry from one or two cores, but sedimentary structures in these samples are most consistent with an origin in submarine tidal bar belts without well-developed spillover lobes, such as those in the Schooner Cays area of the Great Bahama Bank (Ball, 1967). The abundance of green algae and paucity of other skeletal constituents is consistent with deposition in this setting. Ooids typically comprise very unstable substrates that commonly are submarine deserts 


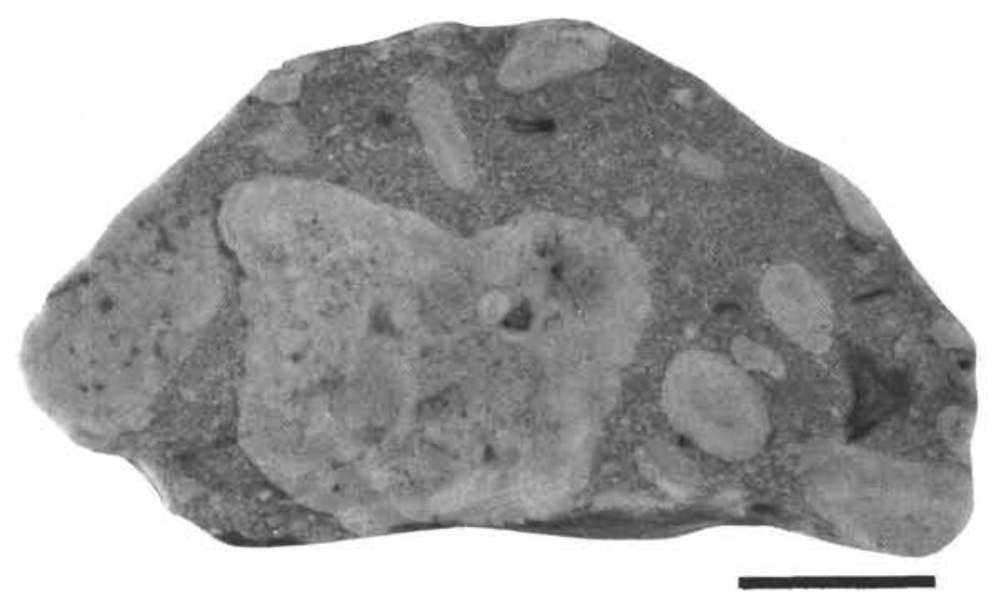

$1 \mathrm{~cm}$

Figure 14. Intraclast-skeletal lime grainstone. Larger intraclasts show dense rims and spongy centers typical of grapestone. Sample 392A-19-1, 105-107 cm. Depth 213 meters. Slab.

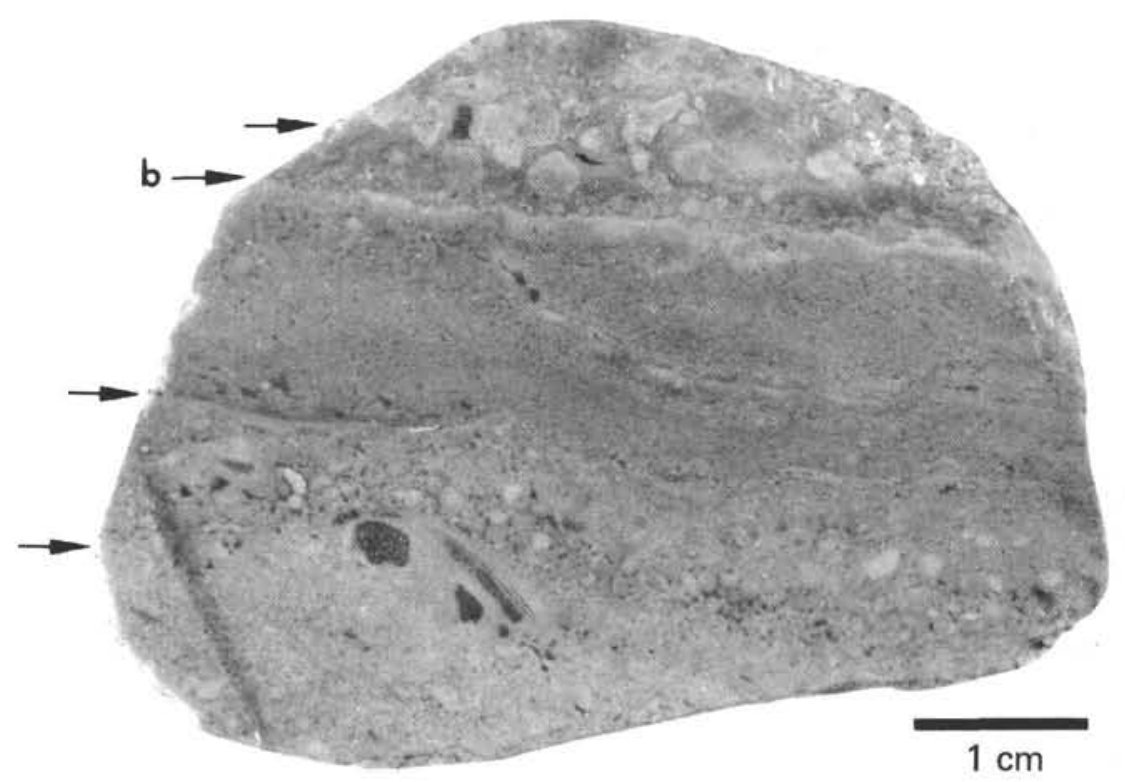

Figure 15. "Muddy intervals" (arrows) in oolitic limestone. Sample 392A-201, 112-116 cm. Depth 222.6 meters. Slab.

(Purdy, 1964), but calcareous green algae are pioneer colonizers of such substrates (Perkins and Enos, 1968; Enos, 1977). Pelletoids and intraclasts commonly occur in oolitic sediments (Purdy, 1963a; Ball, 1967).

The muddy intervals represent a temporary period of bottom stabilization which allowed mud accumulation, micritization, possibly cementation, and formation of laminated crusts. An exact modern analog is not known, although the laminated crusts suggest analogy with the smooth aragonite crusts ("pelagosite") formed on beachrock surfaces in the Persian Gulf (Purser and Loreau, 1973). More limited stabilization in a microenvironment such as troughs between migrating sand waves appears more consistent with the persistent deposition of oolite. However, inclined lamination, a predictable feature in either a beach-rock or sand-wave setting was not detected.

\section{Diagenetic History}

Secondary porosity development was minor in the oolitic limestone. It consisted of a few small vugs, fractures, and molds developed from the scarce mollusk shells but not from the calcareous algae or ooids. Total secondary porosity probably never exceeded 2 per cent. It was subsequently filled with cement and diagenetic sediment. Post-depositional processes also destroyed virtually all of 


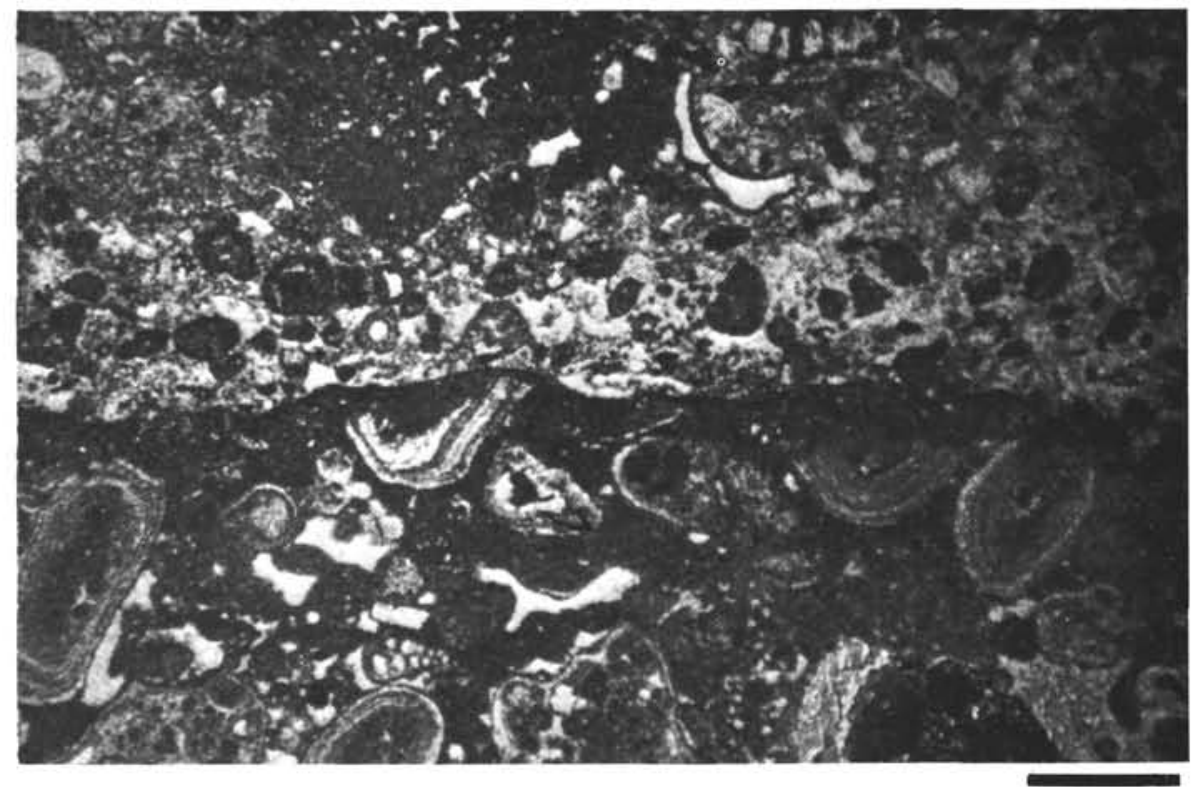

$1 \mathrm{~mm}$

Figure 16. Detail of "muddy interval", (b in Figure 15) showing micritization and truncation of grains. Thin section, plane light.

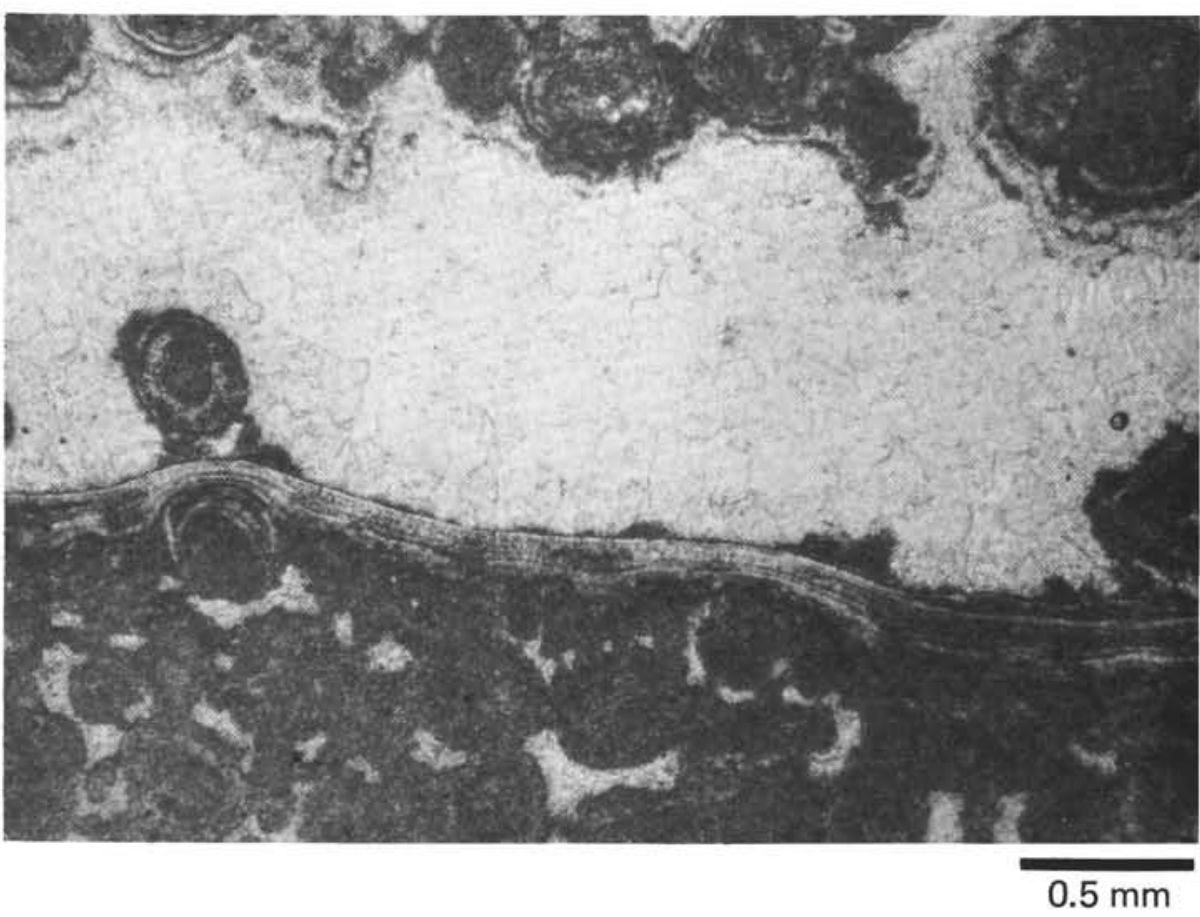

Figure 17. Laminated "oolitic" crust capping a muddy interval in intraclast-oolite lime grainstone. Micritization and/or mud infiltration produced a compact layer but rounded pores give a spongy appearance to lower part. Note protrusion of asymmetrically coated ooid (left) above muddy matrix into laminated crust. Overlying sheet crack patchily floored with mud and ooids. Pendant cement on roof. Sample 392A-20-1, $82 \mathrm{~cm}$. Sub-bottom depth 222.3 meters. Thin section, plane light. 


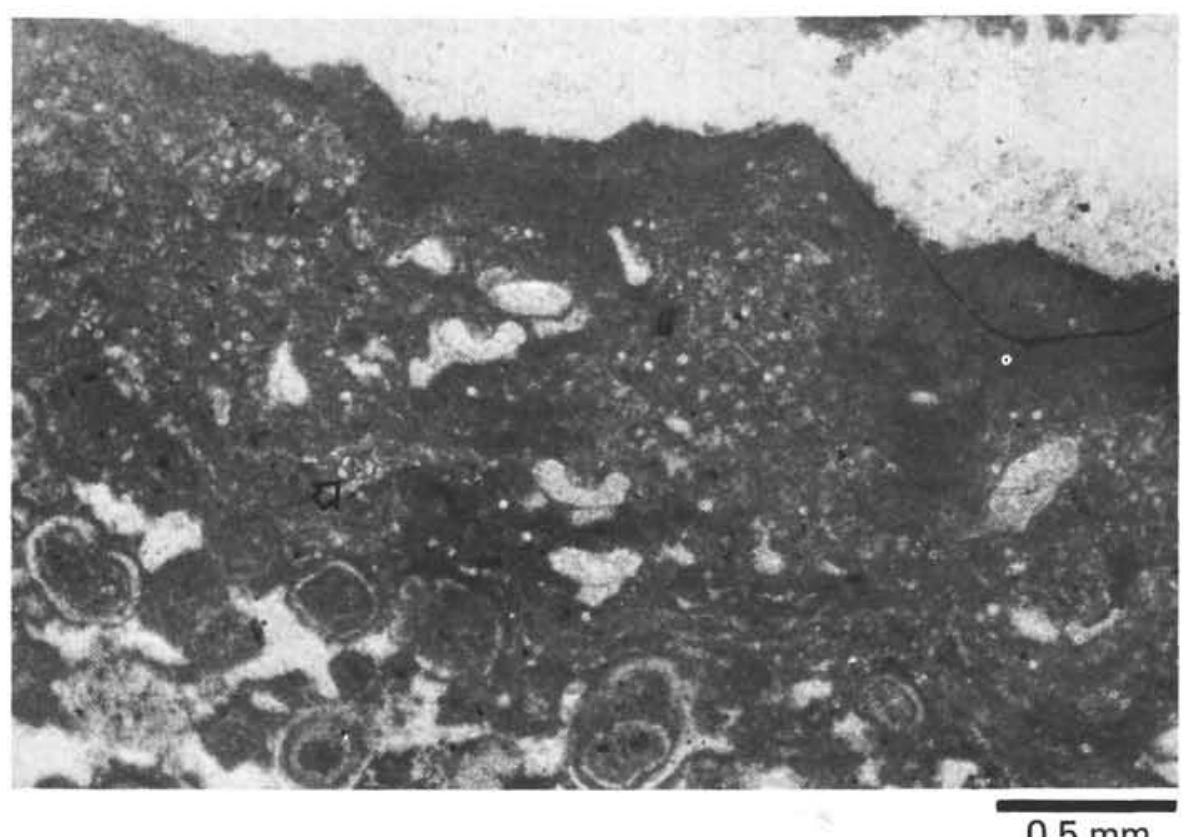

$0.5 \mathrm{~mm}$

Figure 18. Muddy interval with unidentified microfossils (small spheres and irregular micritic tubes) and foraminifers (arrow) in oolite grainstone. Sample $392 A-21-1,75 \mathrm{~cm}$. Sub-bottom depth 231.8 meters. Thin section, plane light.

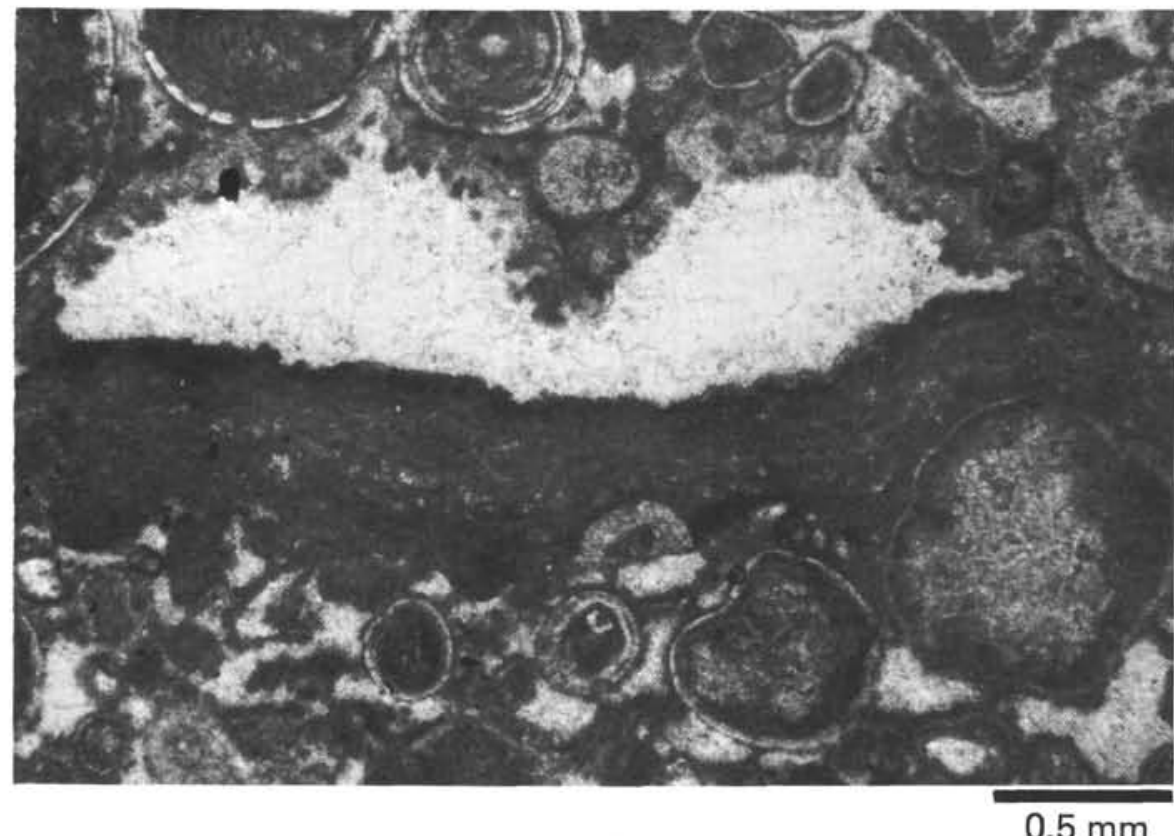

Figure 19. Vaguely laminated muddy interval in oolite grainstone, overlain by small sheet crack with pelleted sediment "suspended" from roof. Sample 392A21-1, $75 \mathrm{~cm}$. Sub-bottom depth 231.8 meters. Thin section, plane light.

the abundant primary porosity, and replaced the metastable carbonate phases with calcite.

All of the diagenetic events recorded by the oolitic limestone could be dovetailed into a coherent diagenetic sequence. This is an artificial procedure, however, because several events such as infiltration by marine sediment and early, probably submarine, cementation occurred at or near the depositional interface. Thus they did not occur simultaneously throughout the unit and are correlative only in terms of genesis, not in terms of time.

Events producing abrupt changes rather than a gradual evolution of diagenetic environment, such as an influx of fresh water to produce leaching, are more realistic bases for correlation of diagenetic events. In the oolitic limestone, however, leaching was on such a small scale and so intricately related to infiltration of marine sediment (see 


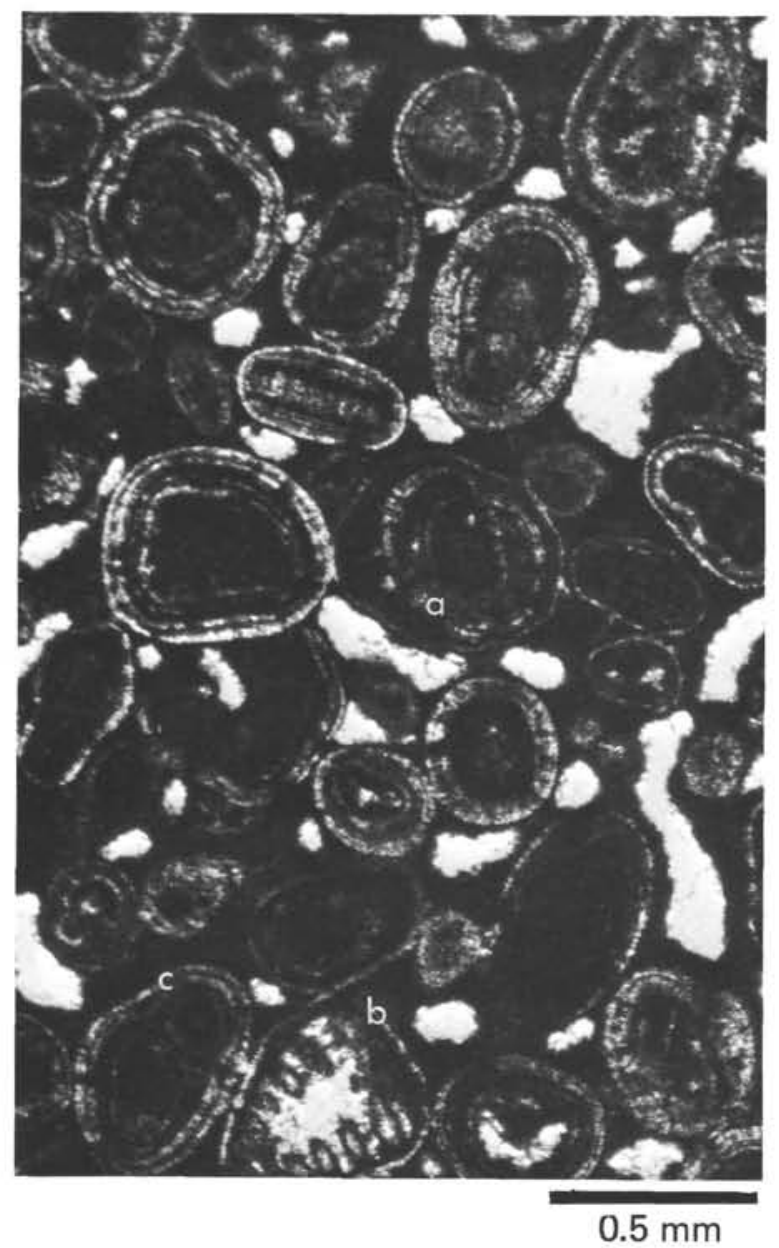

Figure 20. Oolite packstone. Thickness of coating varies greatly. Nucleii include pelletoids, altered ooids (a), skeletal grains (b), and composite grains (c). Matrix is dense micrite with smoothly curved boundaries. Sample 392A-21-1, 75-99 cm. Subbottom depth 222.3 meters. Thin section, plane light.

below) that it must have resulted from a series of brief exposures alternating with deposition rather than from a prolonged episode of subaerial exposure. A possible setting for the leaching is in fresh water lenses on small islands, built by local sediment accretion. Examples are islands of the Schooner Cays oolite belt of the Great Bahama Bank (Ball, 1967; Ball and Shinn, 1967). Molds could possibly form in seawater; however, modern examples come only from deeper water (Friedman, 1965) and mold formation is unlikely to occur in an active oolite shoal.

Perhaps the most complicating factor in deciphering the diagenetic history of the oolite limestones is the occurrence of several types of diagenetic sediment which reflects contrasting early diagenetic environments that recurred repeatedly as deposition proceeded. Some internal sediment is clearly marine as indicated by microfossils (Figure 24). This sediment consists of silt-size (5-10 $\mu \mathrm{m})$ equant crystals that are commonly clotted into small diffuse pelletoids that were probably soft when deposited. This sediment forms the floor of some sheet cracks and also occurs in some fossil molds, which indicates that it is diagenetic (Dunham,

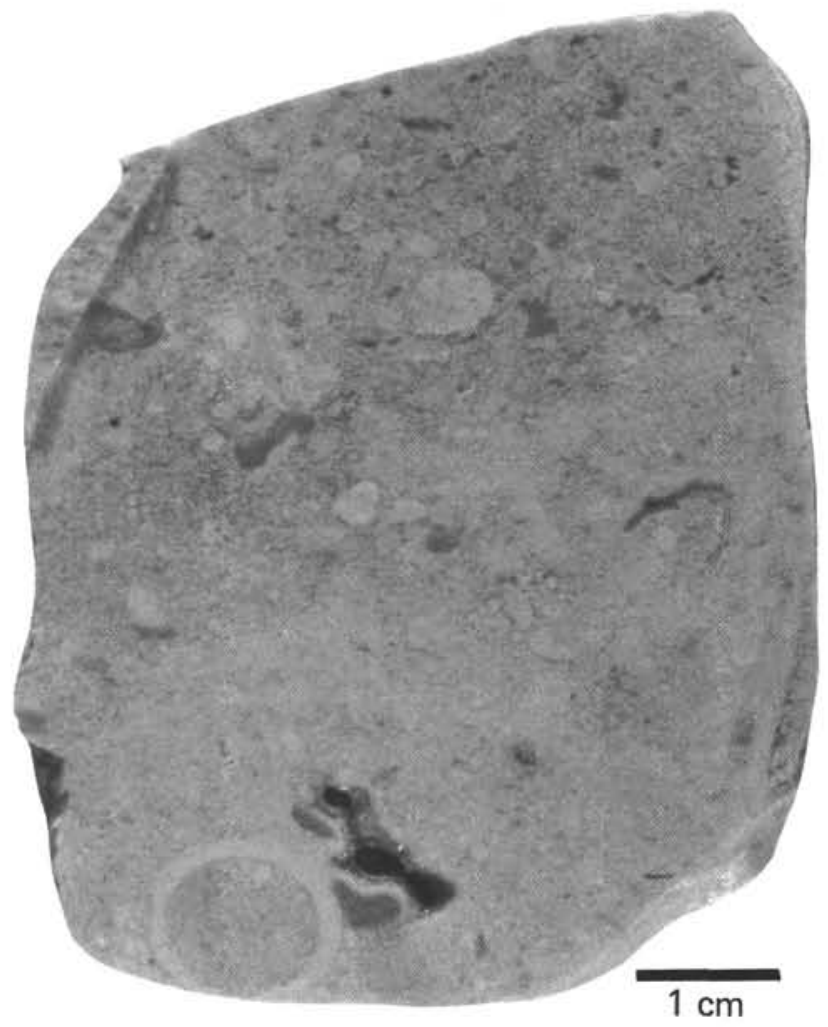

Figure 21. Pelletoidal lime packstone in oolite unit. Cemented burrows preserved intact (lower left) and as curved intraclasts. Some fenestral and vuggy porosity preserved. Sample 392A-20-1, 137-142 cm. Subbottom depth 222.9 meters. Slab.

1969a). Mode of occurrence and a distinctive texture distinguish diagenetic sediment from the normal matrix.

Two layers of diagenetic internal marine (?) sediment occur in several samples (Figure 25). A thin rim of clear cement locally separates the two layers. In one sample, the older sediment within molds was partially leached before the younger sediment was deposited (Figure 36). Internal marine sediment must filter through the interstices of grains filled with nearly motionless water. Consequently, it is not likely to accumulate far below the sediment surface except in unusual settings (Dunham, 1969a, p. 147). Thus deposits of diagenetic internal sediment that occur in widely separated samples can be correlated only in terms of genesis, not in terms of time. They do serve to show that cementation and leaching alternated with deposition very close to the sediment surface.

A more widespread and volumetrically significant diagenetic sediment is a dark microgranular crust that forms uniform (Figure 26) to fretted (Figures 27, 28) rims around nearly every grain in some samples. At grain contacts and intergranular pore constrictions this crust forms narrow necks or bridges with curved boundaries assuming a characteristic hour-glass shape (Figures 20, 27, 28). Small (10-30 $\mu \mathrm{m})$, indistinct pelletoids are common in this sediment, both in rims and in necks (Figure 28), but fossils are found at only one spot. The crust is distinguished from the diagenetic sediment discussed above by being darker and fine grained, by a different mode of occurrence, by the general lack of fossils, and by a distinct boundary 

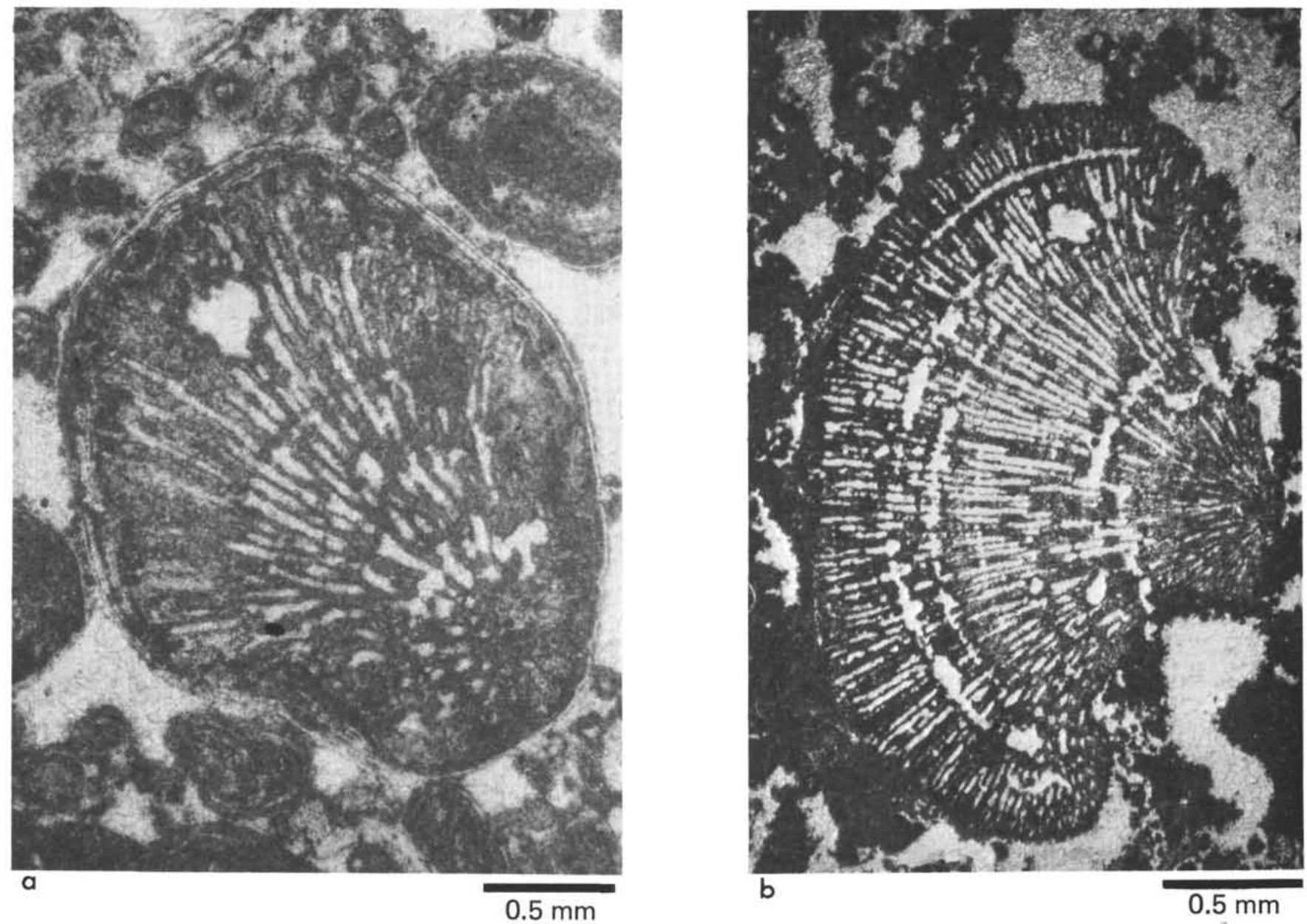

Figure 22. Calcareous algae. (a) Cayeuxia sp., oolitically coated and slightly leached, in intraclast-oolite lime grainstone. Sample 392A-20-1, $82 \mathrm{~cm}$. Sub-bottom depth 222.3 meters. Thin section, plane light. (b) Slightly leached Solenopora sp.(?), coralline red alga, from fenestral limestone. Sample 392A-10-2, $55 \mathrm{~cm}$. Sub-bottom depth 141 meters. Thin section, plane light.

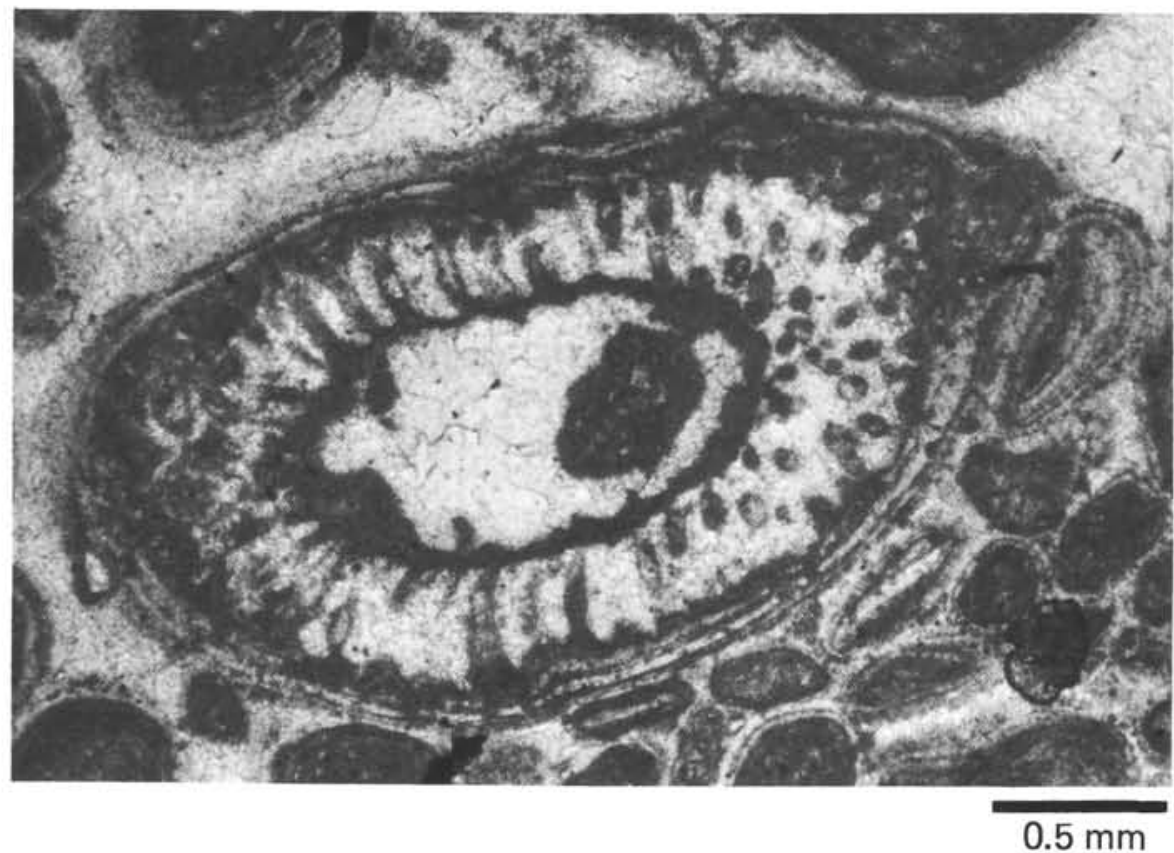

Figure 23. Dasyclad green alga, Acroporella $c f$. radoicicae, in oolite lime grainstone. Sample 392A-21-1, $75 \mathrm{~cm}$. Sub-bottom depth 231.8 meters. Thin section, plane light. 


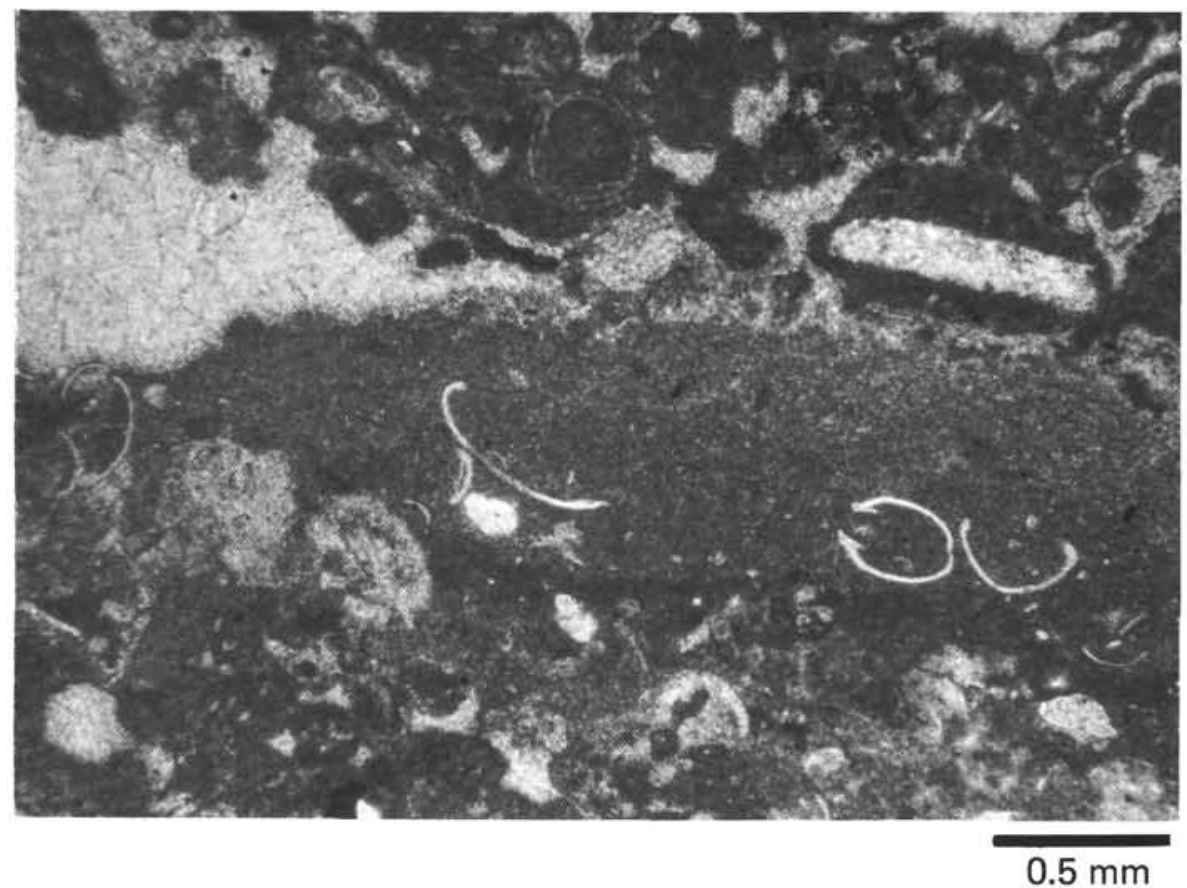

Figure 24. Internal sediment containing smooth-shelled ostracodes partially filling a sheet crack. Note vague pelleted texture visible at top and denser micrite layer at base. Sample 392A-20-1, 112 cm. Sub-bottom depth 222.6 meters. Thin section, plane light.

separating the two in the few cases where they occur together (Figure 24). This sediment is locally difficult to distinguish from micrite envelopes (Bathurst, 1966) which are particularly common on mollusks and ooids. The distinction is made by the nature of the contact between grain and micrite. Micrite envelopes fade into the unaltered grain along an irregular surface, where individual microborings may be present (Figure 29a). The outer surface corresponds to the grain boundary and is characteristically sharp and regular. In contrast, the microgranular crust has a smooth contact with the underlying grain but is typically irregular at the upper, free surface (Figure 29b). Relationships at points of grain contact may also be diagnostic (Figures 26, 30). The microgranular crust is typically pelleted, which not only distinguishes it from micrite envelopes but shows that it was sediment rather than micritic cement. Associated lithification by micritic cement may have contributed to formation of the microgranular crust, however.

The curious hour-glass shapes and curved contacts of the microgranular crust at grain contacts are reminiscent of the meniscus cement shown by Dunham (1971) to be diagnostic of precipitation in a two-fluid-phase system consisting of air and water, i.e., the vadose zone. Can the distribution of vadose sediment mimic that of vadose cement? Perkins (1977) presents examples of internal sediment with meniscus shapes from the Pleistocene of Florida which he carefully documents as originating in the vadose zone. Similar occurrences of "centrifugal micrite" noted by Purser (1975, p. 259) from the Middle Jurassic of France were interpreted as subaerial features but possibly from a marine vadose setting in the supratidal zone. The surface tension around air bubbles may be very effective at plastering muddy suspensions against the entire perimeter of the pore with an extra increment at points of maximum curvature.

In the oolite from the Blake Nose, the microgranular crust is the earliest diagenetic event recorded in most samples. In a few cases it rests on an earlier rim of cement. It predates the less dense marine diagenetic sediment where the two occur in the same sample. In all cases the crust is older than the cement that occludes the bulk of the pore space. The microgranular sediment is volumetrically significant as pore-space filling and may have drastically reduced primary permeability by its concentration at the pore throats.

The microgranular crust marks an important stage in the diagenetic history because it records a significant change in the diagenetic environment, the emergence, at least temporarily, from submarine conditions. The water in the two-fluid system may have been either fresh or marine. A marine vadose zone exists in beaches and tidal flats. In some cases, leaching of fossils was the next event following formation of the microgranular crust, so it might mark the development of a fresh water table. However, meniscus features also occur within the "muddy intervals," which appear to reflect slight pauses in sedimentation rather than complete emergence (Figures 17,31). This may be a result of air trapped in pores beneath surface mud during tidal cycles. The single instance of micritic diagenetic sediment that contains fossils is probably marine as well. The widespread microgranular crusts of diagenetic sediment should not be attributed to a single event. They document emergence sufficient to introduce air into the pores along with either fresh or salt water. 

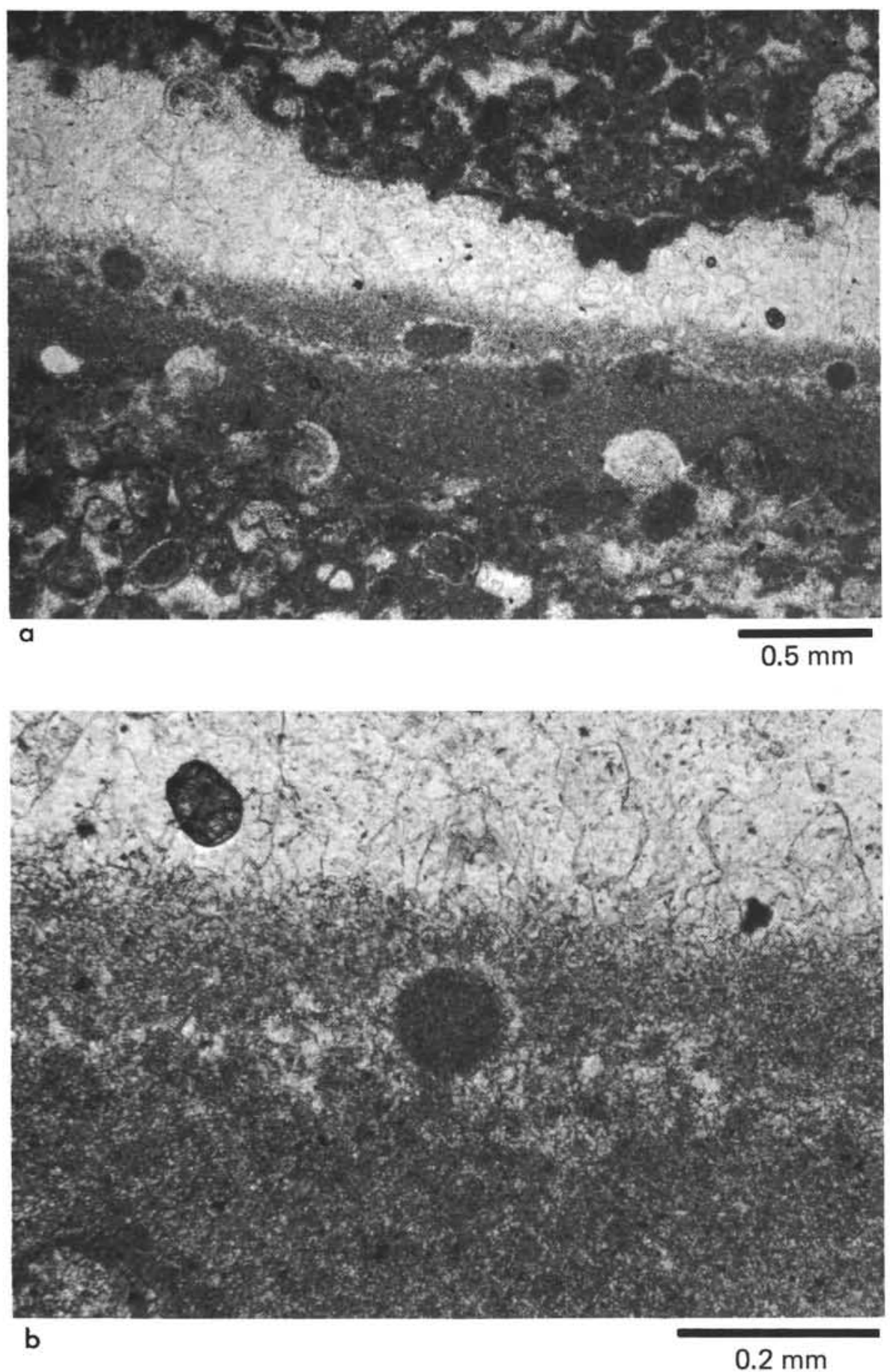

Figure 25. Internal sediment. (a) Internal sediment within sheet crack overlain by thin rim of cement and by a second layer of internal (diagenetic) sediment. Large pelletoids along boundary were deposited before the cement. Lower layer contains ostracodes elsewhere in this sample (see Figure 24, second sediment layer, pelletoids, and cement are barely discernible at right center of that figure). (b) Detail of contact and cement layer. Lower layer is indistinctly pelleted. Ovoids in overlying coarse spar are artifacts of slide preparation. Sample 392A-20-1, $112 \mathrm{~cm}$. Sub-bottom depth 222.6 meters. Thin section, plane light.

Another diagenetic feature that probably reflects a two-fluid-phase system is the bladed cement fringe that forms pendants hanging from individual grains (Figure 32) and from the roofs of sheet cracks (Figure 33). These microstalactites probably precipitated in a vadose zone by asymmetric nourishment of cement crystals (Purser, 1969; Freeman, 1971) from pendant films of water (pendant and funicular water, Smith, 1961). Pendant cement postdates 


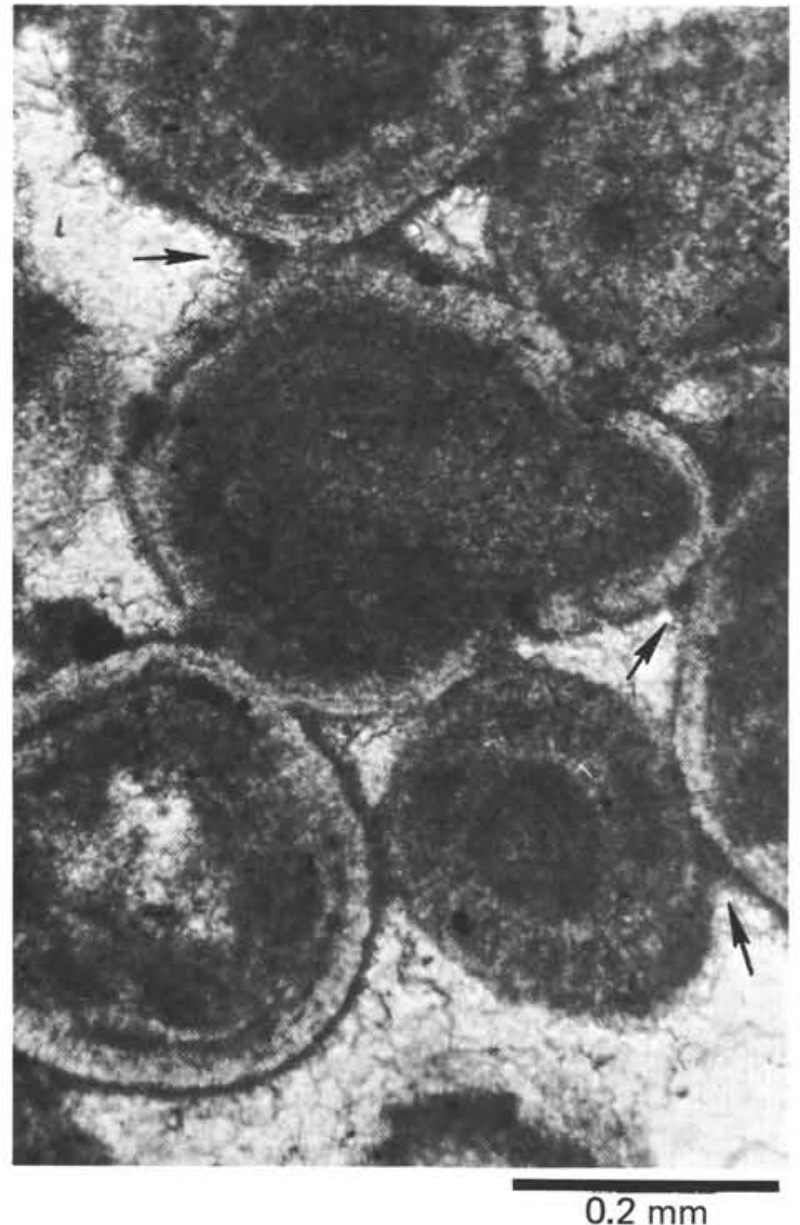

Figure 26. Micrite rims on ooids, oolite lime grainstone. Absence of the micrite at the points of contact and increased thickness adjacent to the contacts (arrows) shows that the micrite is not an alteration envelope but a post-depositional accumulation. Sample 392A-21-1, $75 \mathrm{~cm}$. Sub-bottom depth 231.8 meters. Thin section, plane light.

the microgranular crust in the several examples where they occur together (Figure 34), but preceded precipitation of the major pore-filling cements in all cases. It occurs in a few molds. As with the microgranular crust, the pendant cement could have been deposited in either a fresh-water or marine vadose zone. The fibrous habit of the crystals could suggest saline water (Folk, 1974), but similar crystal habits are found in cave dripstones.

This brings us to the final, major pore-filling cements. These are similar to those in the skelmoldic limestone in that there are three evolutionary stages in crystal morphology, (1) a finely crystalline equant crust, (2) a bladed fringe with crystals up to $250 \mu \mathrm{m}$, and (3) a relatively coarse mosaic of equant crystals (Figures 9, 31, 32). As in the skelmoldic limestone, the earlier cement contains numerous inclusions (but it is not radiaxial fibrous) and the later cement is clear (Figures 12b, 35). The change in clarity corresponds roughly to the boundary between the bladed and mosaic cements, but there are many local exceptions. These three cement types occur in all pore types, primary and secondary. Their distribution is generally uniform along pores throughout a sample, but instances of marked asymmetry which accentuate a pendant effect were noted.

We infer that these cements precipitated from fresh water inasmuch as they followed the development of exposure criteria such as molds, meniscus sediment, and pendant cement. We cannot exclude the possibility of some early submarine cementation, but criteria for submarine cement or replaced submarine cement are lacking. Despite the zoning, the major pore-filling cements are interpreted to represent a single episode of cementation, possibly prolonged and discontinuous. The large equant crystals suggest precipitation from low-salinity waters in a chemically stable environment (Folk, 1974). Stability implies the phreatic zone which would be consistent with the generally uniform cement distribution.

A single example serves to illustrate the complexities in diagenetic history within the oolite unit. Pelletoidal packstone from Core 20 was partially leached to form skeletal molds (Figures 36, 37). Some molds are lined with a thin, ragged crust of equant cement that is overlain by carbonate mud containing a few unidentified fossils and pelletoids (Figure 36). A second period of leaching is recorded by vugs formed within the diagenetic carbonate mud (Figure 37). Maintenance of the vug roofs without collapse suggests partial lithification prior to leaching. A second influx of internal sediment, pelleted but without visible fossils, formed geopetal fills in the vugs. Several short periods of emergence, to account for leaching and submergence with sedimentation and perhaps submarine lithification, occurred early in the history of this rock. The next event was massive cementation, beginning with inclusion-rich bladed cement in fan-shaped fringes and succeeded by clear, equant cement which sealed the pores. We infer that these cements were precipitated in the fresh-water phreatic zone.

\section{FENESTRAL LIMESTONE}

The youngest unit of the limestones encountered on the Blake Nose is the most diverse in terms of depositional texture, but a uniform syndeposition overprint of fenestral porosity has produced a readily recognizable unit. Very pale brown fenestral limestone comprises the top 114 meters of the limestones at Site 392. It was cored in Hole 392A from 99.3 to 212.8 meters sub-bottom (Core 5, Section 1 through Core 19, Section 1) with 9 per cent recovery. Fragments of fenestral limestone were recovered in both cores from Holes 392 below about 48 meters sub-bottom.

\section{Lithology}

Packstone and wackestone in roughly equal proportions comprise perhaps two-thirds of the fenestral limestone unit. The remaining third consists of subequal amounts of grainstone and mudstone. These rock types are interbedded on scales ranging from more than a meter down to a few millimeters. Depositional texture terms (Dunham, 1962) are difficult to apply to this rock because of in situ synsedimentary brecciation which accompanied the formation of fenestral porosity (Figure 38). If this texture, which is interpreted as a diagenetic overprint, were used in classification, most of the rock would be intraclastic packstone and grainstone. However, we regarded only 

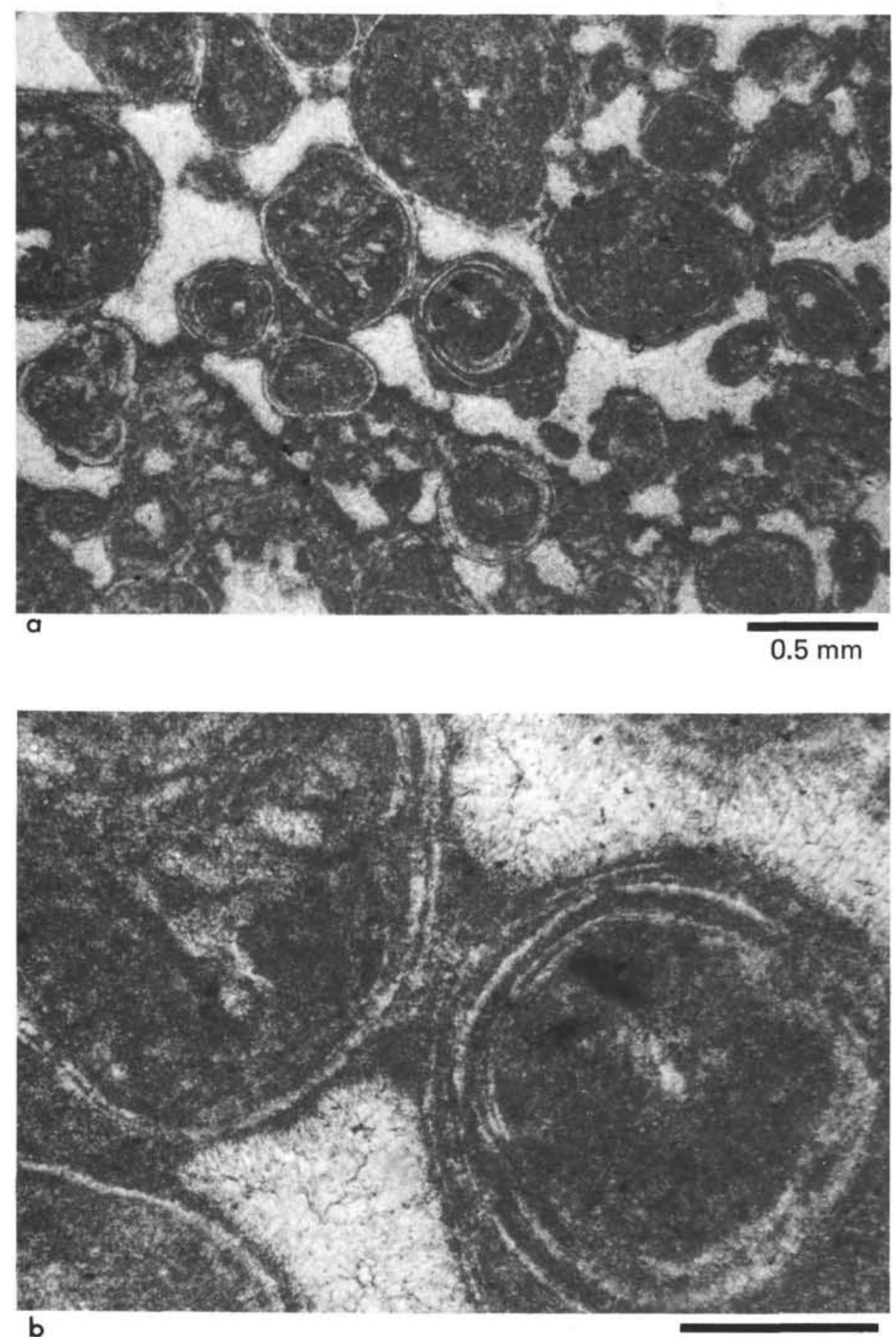

b

\section{$0.2 \mathrm{~mm}$}

Figure 27. Micrite rims on ooids showing necks and bridges with curved surfaces joining grains. (a) General view. (b) Detail from a; note curvature of micrite surface. Coarser texture at point of closest approach may reflect early cement or neomorphism of the micrite. Sample 392A-20-1, $82 \mathrm{~cm}$. Sub-bottom $222.3 \mathrm{me}$ ters, Thin section, plane light.

intraclasts that were apparently transported as representative of original depositional texture.

Pelletoids, skeletal components, and intraclasts are the principal allochems, in approximate order of abundance. Skeletons are more important in the mud-supported textures (wackestone and mudstone); pelletoids and interclasts are dominant in the grain-supported rocks (packstone and grainstone).
Short intervals of microcrystalline limestone with skeletal molds (Figure 39), somewhat similar to the skelmoldic limestone unit, were encountered in Hole 392A, Cores 5, 6, 15,16 , and 17 .

\section{Sedimentary Structures}

The thickest lithologically homogeneous interval recovered is slightly more than a meter. Thicker intervals 

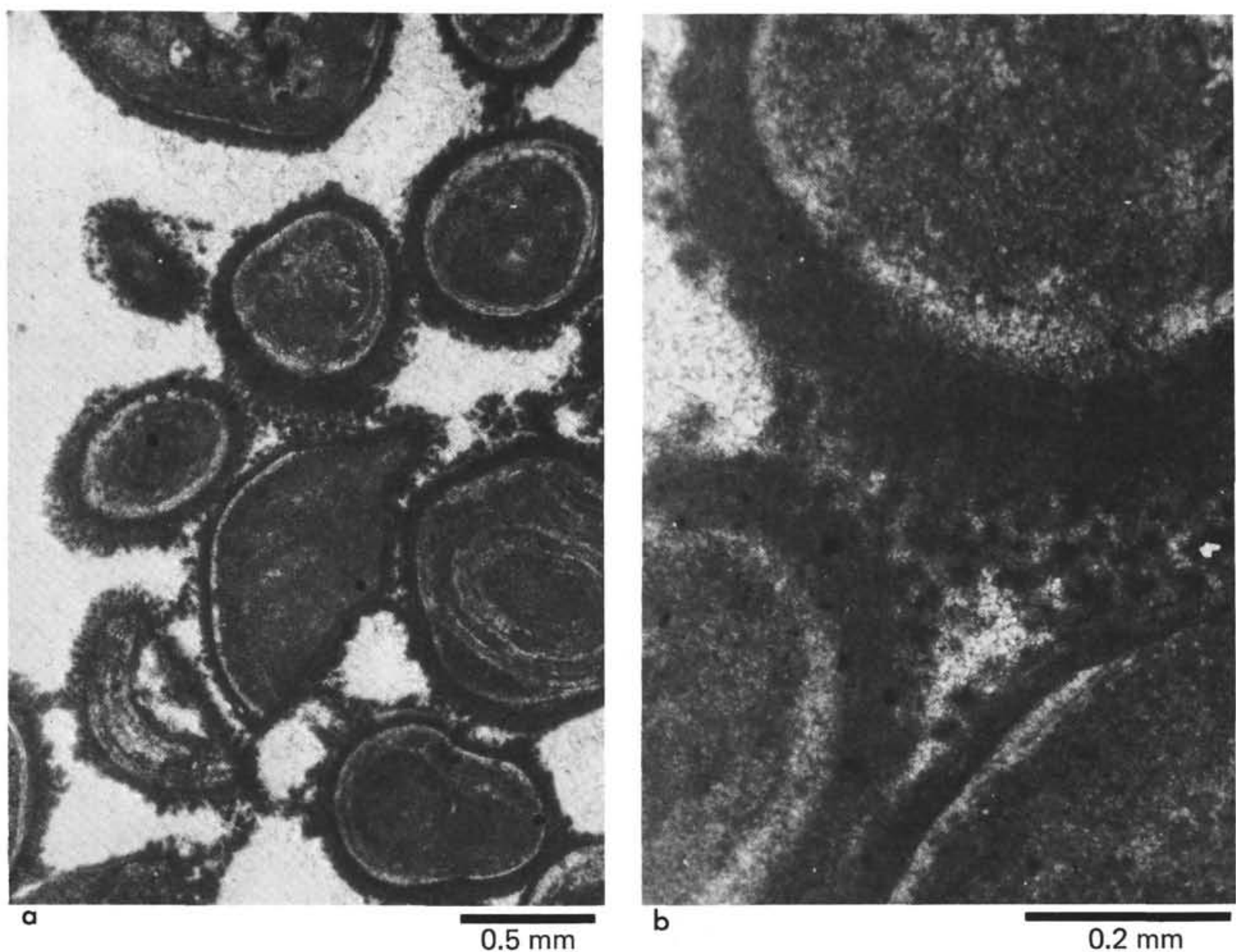

Figure 28. Pelleted texture of diagenetic sediment. (a) Pelletoids visible only in outer portion of micrite; pelleted sediment here forms bridges (lower right) and necks with curved surfaces. Dark micrite is alteration envelope on at least the grains at upper right and center; outer edge of grain is locally visible as faint bright rim. Depositional texture was oolite grainstone; "matrix" is diagenetic sediment, $(b)$ detail of pelletoids; here they merge with dark micrite. Sample 392A-22-1, $109 \mathrm{~cm}$. Sub-bottom depth 241.6 meters. Thin section, plane light.

Orientation unknown.

may have been obscured by incomplete recovery. Stratification ranging from vague layering to distinct millimeter lamination (Figure 40 ) is present in more than a third of the thin sections studied. A few thin beds are graded. Broken or warped laminae are common (Figure 40). Polygonal cracks, presumably desiccation cracks, occur on several bedding surfaces (Figure 41).

\section{Constituents}

Skeletal remains occur throughout but are not abundant except in a few layers dominated by a single organism. The fossil assemblage in general is less varied than in the two underlying units. Miliolid foraminifers are the most common fossil, followed by gastropods (particularly high-spired forms), and ostracodes (Figure 42). Fragments of thin-shelled bivalves and benthic foraminifers other than miliolids are rare. Dasyclad green algae (Salingoporella annulata group) occur in several samples but are common in only one. A few fragments of codiacian green algae, a coralline red alga (Solenopora sp., Figure 22b), and colonial corals were found. Probable molds of blue-green algal filaments occur in small clots and intraclasts in nearly a third of the thin sections (Figure 43).
Pelletoids are the dominant particle type in most samples. In samples of mud-supported limestone they merge into a clotted or matted matrix (Figure 43a), except around the edges of larger fenestral pores, which suggests that the original pelletoids were soft. This probably accounts for the lack of pelletoids in a few muddy samples. Hard pelletoids are common in grain-supported limestones (Figures 38b, 42).

Intraclasts of the muddier interbedded intervals are fairly common. A distinctive type of intraclast is shard- or crumb-like bits of mud that could not have been transported very far (Figure 38b). More common than these intraclasts are broken laminae that can mentally be fitted back together (Figures 38b, 44) and clasts with angular corners despite plastic deformation (Figure 40) indicating that they were formed essentially in situ.

The matrix consists of equant calcite crystals ranging from 1 to $6 \mu \mathrm{m}$ in many samples and from $1 / 2$ to $12 \mu \mathrm{m}$ in some poorly sorted wackestones. The finer crystals are rounded; the coarser ones irregular. No dolomite was detected by X-ray diffraction or by thin-section examination. 

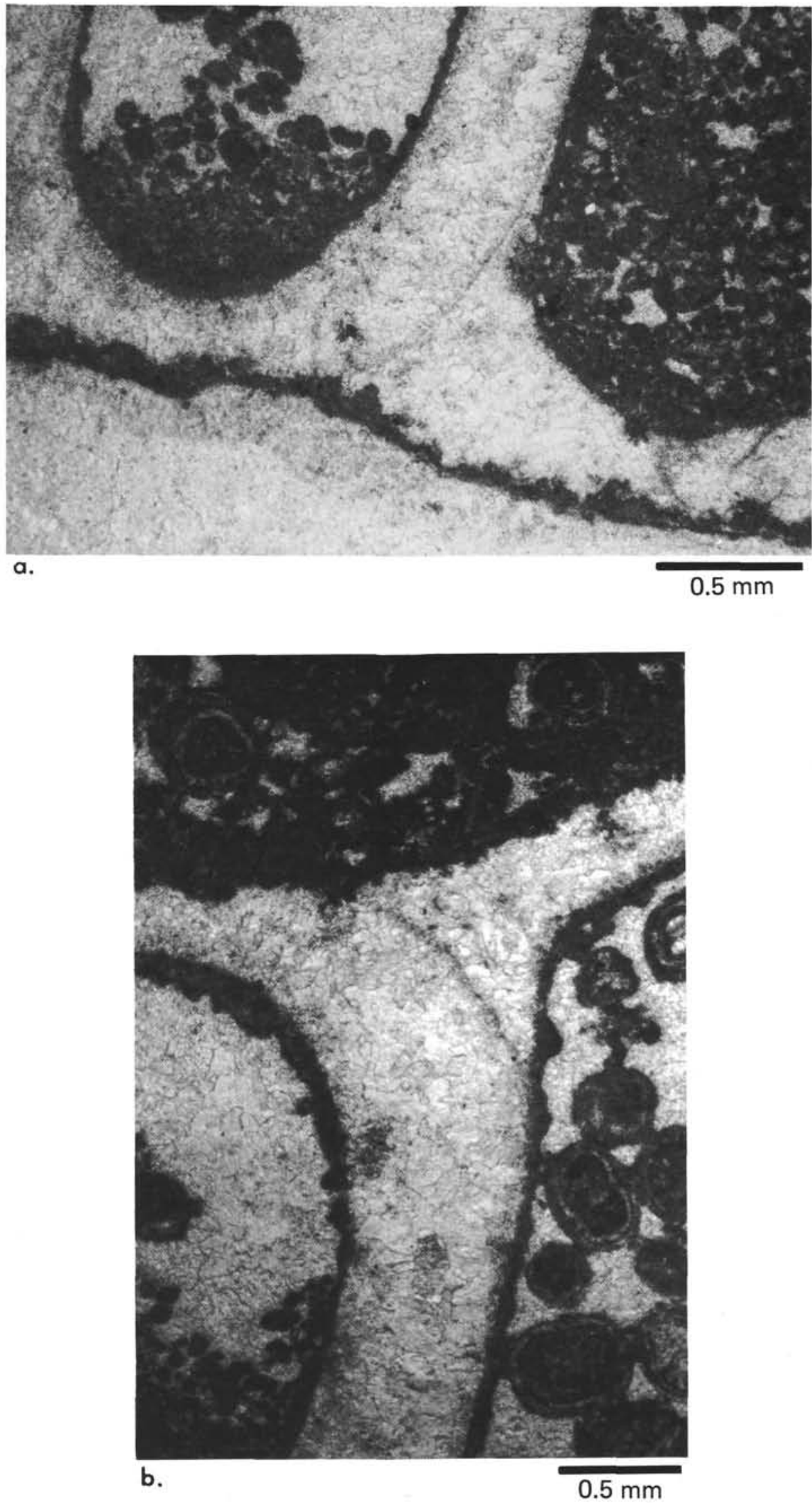

Figure 29. Micrite rims on gastropod mold. (a) Exterior micrite rim (bottom) was alteration envelope; its inner surface (toward shell) is very irregular and includes a few discrete borings. (b) Micrite rims bordering interior cavities (bottom) has smooth inner surface but shows pelletoids and lumps toward interior cavity. This was muddy sediment. $a$ and $b$ are different parts of same fossil; contrast interior and exterior rims in each photo. Sample 392A-20-1, $82 \mathrm{~cm}$. Sub-bottom depth 222.3 meters. Thin section, plane light. 
A

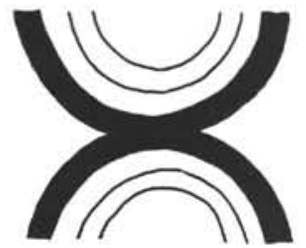

C

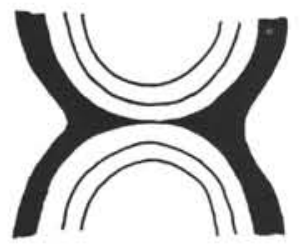

B

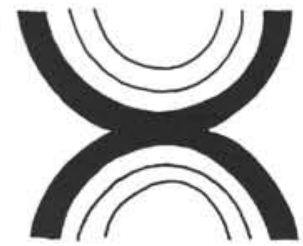

D

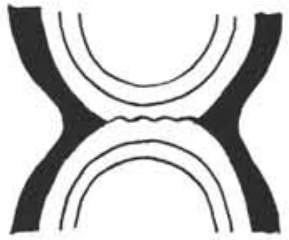

Figure 30. Sketches of grain contacts with micrite rims to illustrate diagnosis of micrite alteration envelopes vs. infiltrated muddy sediment. (a) Indicates alteration envelope in the absence of $B$ - or $C$ - type contacts in same specimen. (b) Overly close approach, suggestive of infiltrated sediment. (c) Point contact of grains beneath micrite and curved micrite surface; diagnostic of infiltrated sediment. (d) Stylolitic contact, no criterion is infallible in the face of the perversity of nature.

\section{Depositional Porosity}

Interparticle porosity, which ranged up to 40 per cent in the grainstones and some of the packstones, has been almost totally occluded by internal sediment (Fischer, 1964; Dunham, 1969a) and by cement. Shelter porosity which occurred beneath some of the larger clasts has also been

filled. Intraparticle porosity was confined to only a few samples in which skeletal grains are volumetrically significant (Figure 43).

We infer that the fenestral porosity, which initially occurred in nearly all samples in volumes up to 30 per cent (Figures 38, 40, 44), formed at the depositional interface. Fenestrae are large, elongate, rounded or irregularly shaped pores that do not truncate individual grains (Figure 45). Elongation is usually horizontal, but vertical elongation is also common. Some fenestrae were formed by disruption of muddy laminae which collapsed forming very loose packing (Figures 38,44$)$. Disruption is normally confined to a few layers, primarily the muddier ones. Underlying and overlying layers may also be disrupted, but disruption is independent of neighboring fenestrae. In grain-supported rocks, fenestral pores are usually lined with closely packed grains that apparently held the pore open (Figure 46), a fabric termed "keystone vugs" by Dunham (1972). A striking variant of fenestrae is subsphaerical pores joined by vertical or arcuate tubes and cracks of smaller width which look like a string of beads (Figure 47). Some fractures join fenestral pores, but pass around rather than through grains. This indicates that the fractures formed before extensive lithification and were probably genetically related to the fenestral pores (Figure 6).

Many fenestrae are floored by internal sediment (Figure 48 ), which shows normal grading in some cases. Internal sediment has infiltrated extensively into the intergranular pore space, particularly into those below fenestral pores (Figure 48). Locally, intergranular space was totally filled by sediment to produce a muddy packstone texture from an original depositional texture of clean packstone or

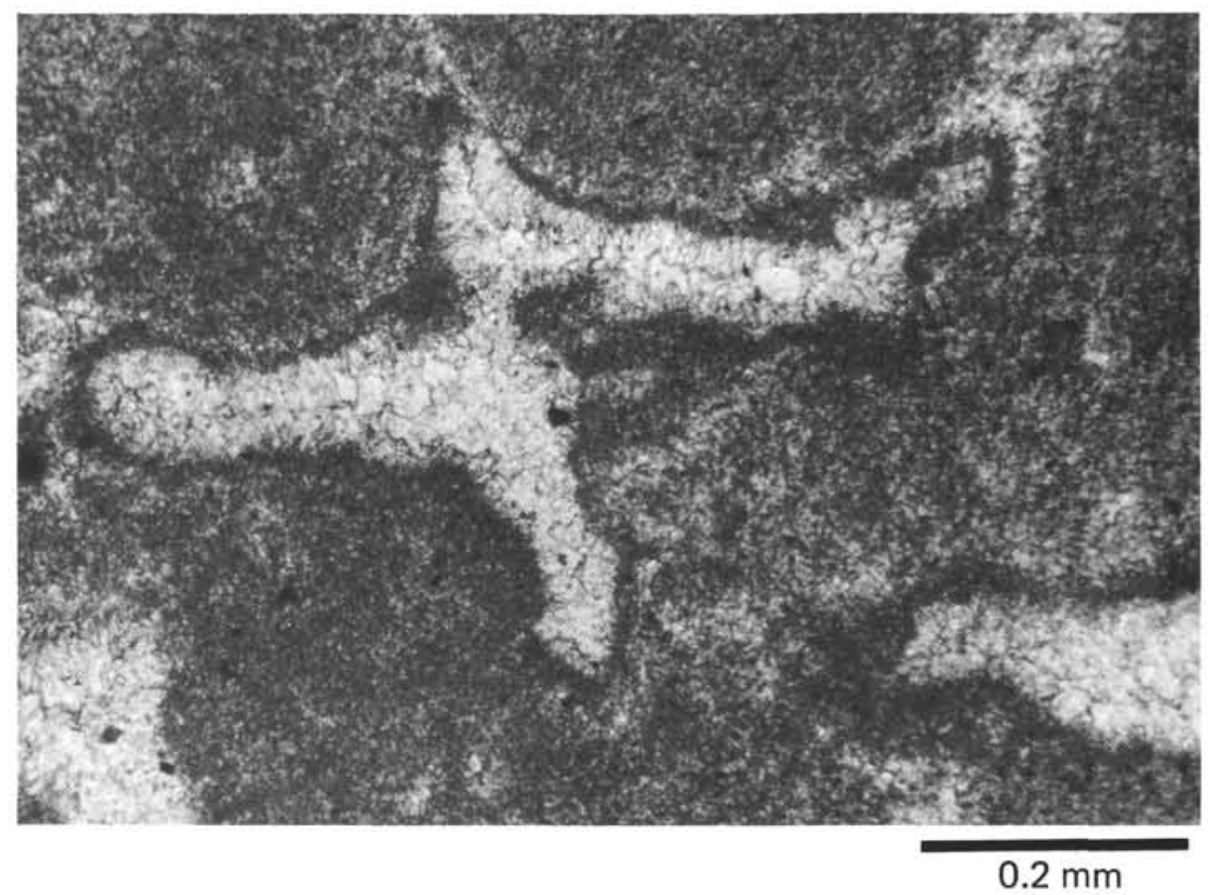

Figure 31. Micrite-rimmed pore with curved surfaces within a muddy interval (detail of same interval illustrated in Figure 17). Sample 392A-20-1, $82 \mathrm{~cm}$. Subbottom depth 222.3 meters. Thin section, plane light. 

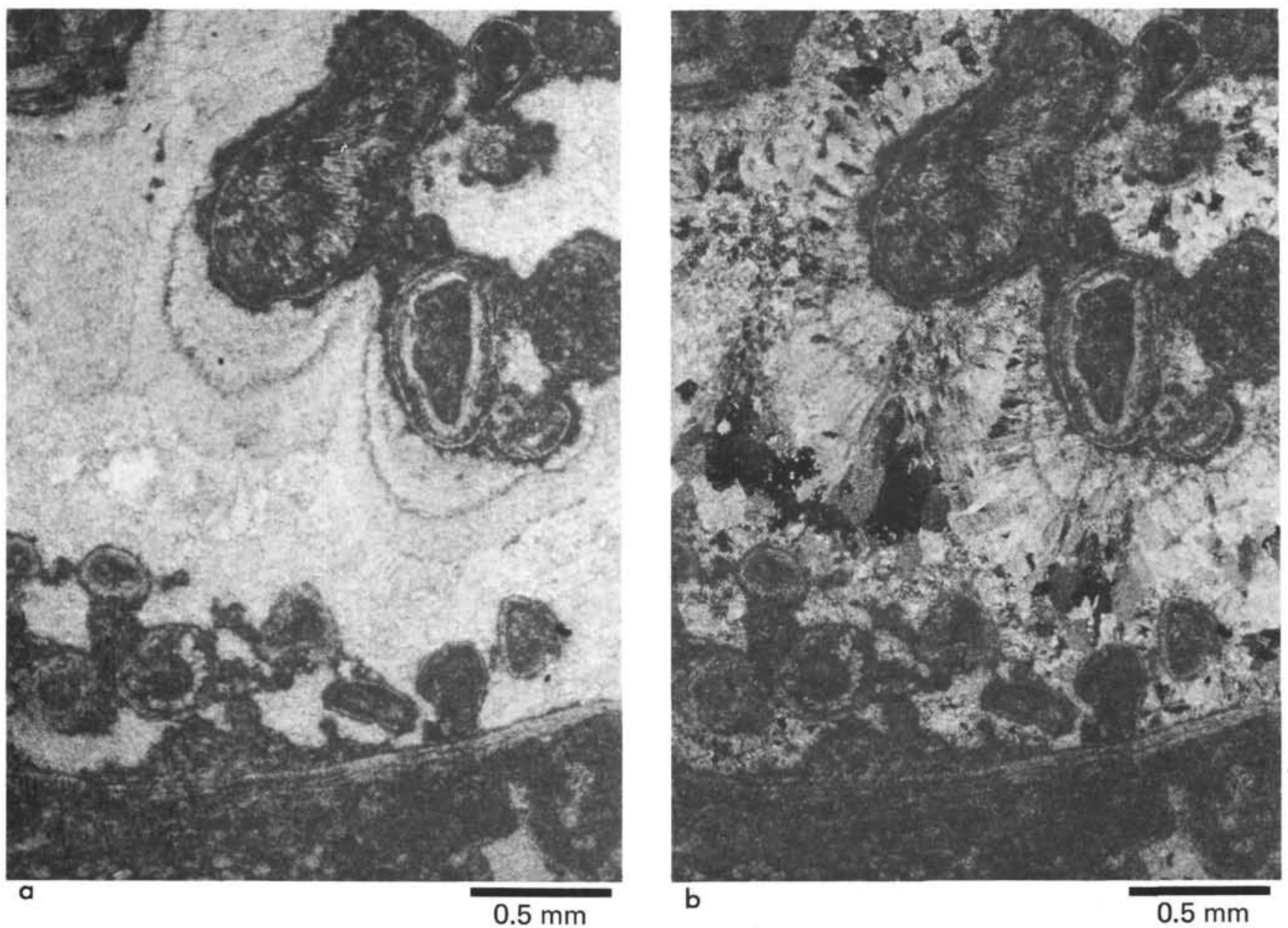

Figure 32. Pendant cement. (a) Multiple asymmetric (pendant) crusts of bladed spar extending downward into a sheet crack overlying a laminar-coated muddy interval in intraclast-oolite grainstone. Thin section, plane light. (b) Same in cross-polarized light. Sample 392A-20-1, $82 \mathrm{~cm}$. Sub-bottom depth 222.3 meters.

grainstone (Figure 49; also Figure 50). The internal sediment is a more uniform light-gray color than is the sedimentary matrix (Figures 48, 49). The lighter color probably reflects looser packing of the internal sediment. Grain size is variable, ranging from 1-2 $\mu \mathrm{m}$ in some pores and up to 5-25 $\mu \mathrm{m}$ in others. It forms perched cones on tops of grains (Figure 49) and steeply inclined "cascade surfaces" as well as sub-horizontal geopetal structures. No fossils were found in the internal sediment.

\section{Depositional Environment}

We interpret the fenestral limestone as a tidal flat deposit because of the presence of desiccation polygons, ruptured laminae, abundant intraclasts, laminated and micrograded beds, and a low-diversity fossil assemblage that includes blue-green algae (Roehl, 1967; Shinn et al., 1969; Logan et al., 1970; Purser, 1973; Enos and Perkins, in press). Crumb-like texture is produced by alternate wetting and drying (Enos and Perkins, in press) and fenestral porosity is commonly associated with tidal-flat deposits (Shinn, 1968). Although the fenstral limestone is lithologically diverse, the fenestral texture persists throughout an interval of 114 meters.

Fenestral porosity is inferred to result from the escape of fluids (water, air, or other gases) from the sediment. The vertical orientation of many of the fenestrae (Figures 46, 51) and the bubble-like form with vertical connecting tubes (Figure 47) particularly suggest fluid escape. Horizontal elongation of fenestrae beneath muddy layers and disruption of muddy layers indicate entrapment of upward-migrating fluids beneath layers of low permeability (Figure 40). "Keystone"' packing of grains (Figure 46) is characteristic of two-fluid-phase systems with air or other gas trapped by surface tension of the water (Dunham, 1972).

Internal sediment may be deposited by migrating fluids, particularly where the fluid lifts and eventually deforms or ruptures a confining layer. Graded internal sediment is a common result. These phenomena have been observed in artificially layered sand and mud in shaking-table experiments in which water was expelled by liquefaction of the sand layers (Karcz and Enos, 1975). The internal sediment differs from the mud matrix in that it lacks fossils, is more loosely packed, and is more variable in grain size.

Fenestrae were formed at or near the depositional surface as indicated by the independent disruption of adjacent sediment layers, by loose packing of ruptured layers and by reworking of the resultant intraclasts. In this near-surface setting, there probably would not have been sufficient compactive pressure to expel water from the sediment at the rate indicated by the degree of deformation. A gas such as 

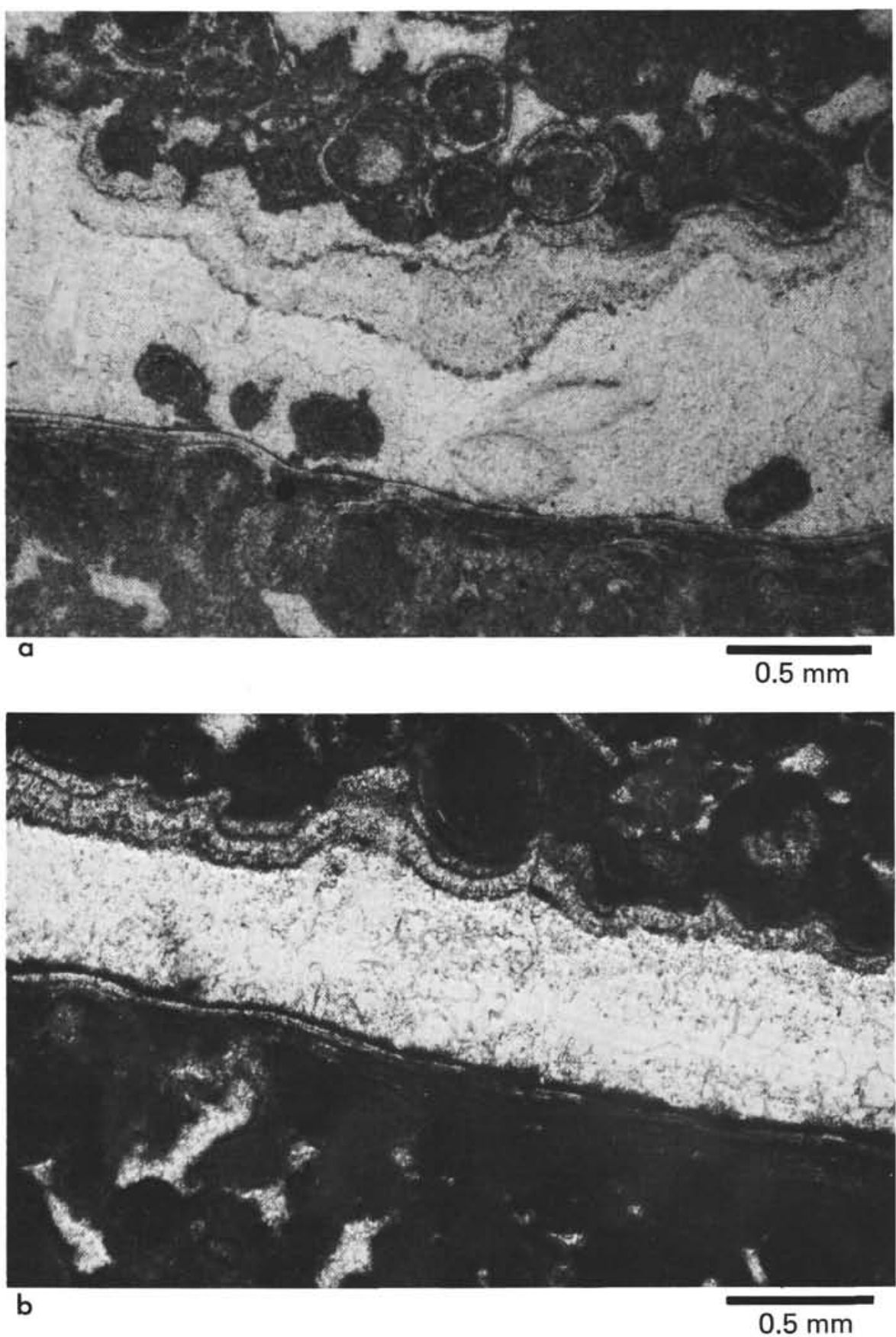

Figure 33. Pendant cement crusts in sheet cracks overlying laminar-coated muddy intervals. (a) A few pelletoids and traces of ostracodes(?) overlie the interface. Spar surrounding the ostracodes has passive-filling, cement, textures. (b) Multiple pendant cement crusts, each terminated by a micritic band (diagenetic sediment? micritization of cement?) which led to nucleation of new crystals. Both examples from Sample 392A-20-1, $82 \mathrm{~cm}$. Sub-bottom depth 222.3 meters. Thin section, plane light.

air would rise and expand through the nearly water-saturated sediment under hydrostatic pressure alone. Air, however, would not have the capacity nor competence to transport internal sediment in the quantity and size present. Probably gas and water both played a role in sediment deformation and internal sedimentation.
The source of the considerable volume of gas necessary to produce these structures is a mystery. Both life processes and decay of algae produce some gas within the sediment (Shinn, 1968). Air may be trapped during the alternating flooding and exposure of a tidal flat. Air trapped during subaerial exposure of the underlying oolite may have been 

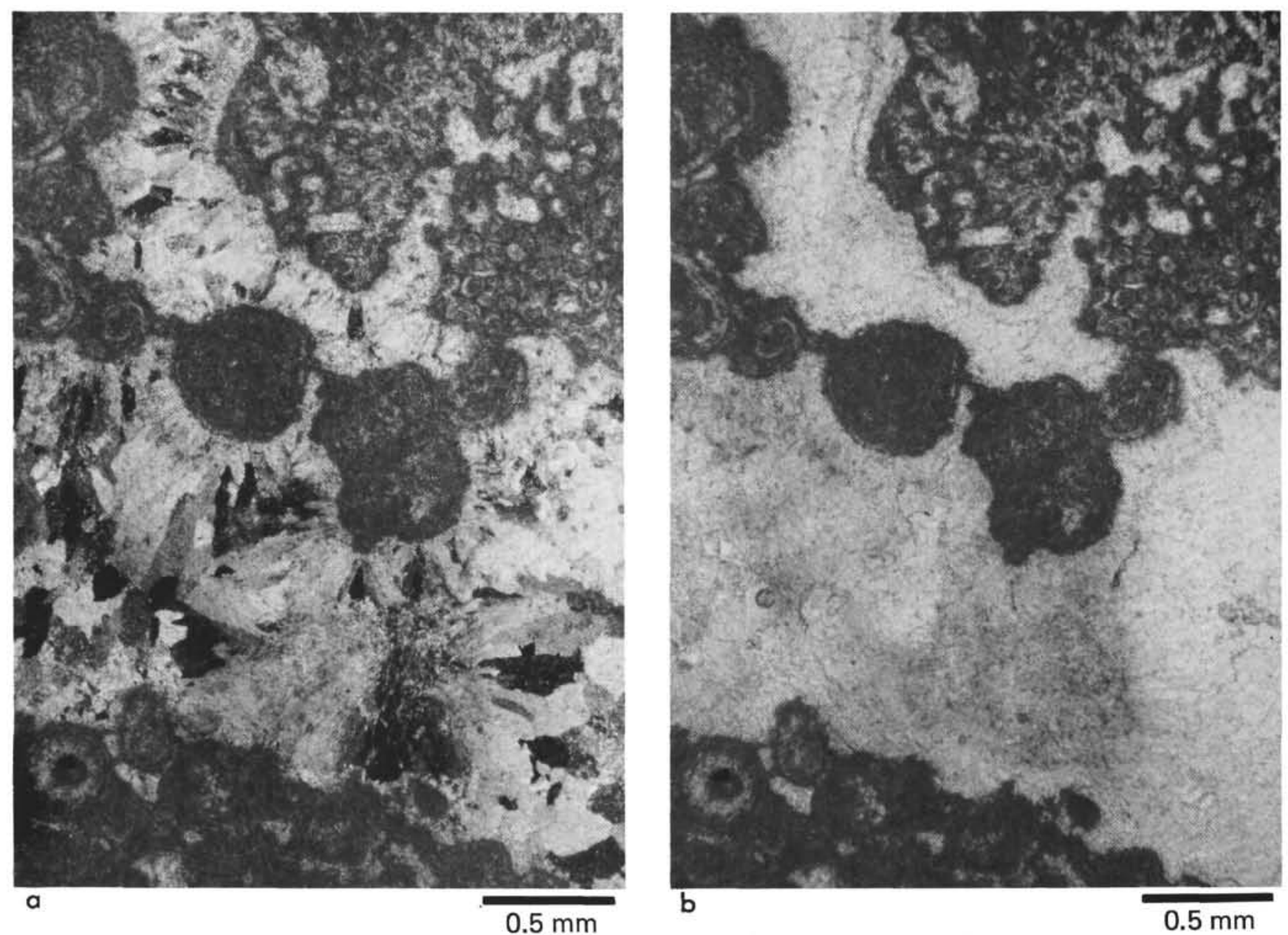

Figure 34. Pendant cement overlying micritic bridges between grains and filling solution cavity in green algal grain (upper right). Note large "stalactite" extending nearly to the floor of the sheet crack. (a) Plane light. (b) Cross-polarized light. Sample 392A-20-1, $82 \mathrm{~cm}$. Sub-bottom depth 222.3 meters. Thin section.

slowly expelled by increasing hydrostatic pressure. Extensive vertical migration seems unlikely, however, because there are numerous low-permeability muddy layers and only a few laminae were disrupted at a time.

\section{Diagenetic History}

The history of pore development in the fenestral limestone virtually ended with the massive fluid exodus outlined above. Some moldic porosity was perhaps developed during intermittent exposure to rainfall and runoff on tidal flats. The common occurrence of diagenetic sediment within the molds (Figure 50) suggests early mold formation. Some of the unfilled molds may have been produced later by circulating groundwater. Total moldic porosity exceeded 5 percent in only one sample. Vugs occur in only a few samples with less than 2 percent porosity.

The diagenetic events which followed destroyed the extensive fenestral porosity, local intergranular porosity, and solution porosity. Present porosity, which is less than 3 per cent, occurs as incompletely filled fenestrae. Internal sediment, which was probably deposited at the same time as development of fenestral porosity, locally filled some of the fenestrae and virtually all of the intergranular pores (Figure 49). The principal pore destruction, however, resulted from cementation.
Cement morphologies are very similar to those of the two underlying units (Figures 9, 10, 52). Finely crystalline, equant cement lines the pore walls and is overlain by a fringe of medium- to coarsely crystalline bladed cement which in turn is overlain by coarse, equant spar (Figure 9). Inclusions (Figure 12a) are less uniformly developed than in the underlying units. In a few samples, all of the cement is clouded with numerous inclusions; in most the late cement of equant calcite is clear. There are no inclusions in cements near the top of the unit.

The cement morphologies indicate that the pores were saturated with water; the equant habit and large size of the crystals suggest that the waters were meteoric. Inasmuch as solution porosity is minor within this unit, most of the cement must have been introduced from elsewhere. The cement probably came from solution of the upper part of the unit and downward redistribution of calcium carbonate. Cementation was probably completed before the Blake Nose was submerged, the limestone surface was encrusted by iron, and pelagic deposition began. Salt water is a possible source of cement, but it is not known to be effective in precipitation of coarsely crystalline cement more than a few centimeters below the sediment surface. Moreover, marine cements are normally fibrous aragonite or microcrystalline magnesium calcite rather than equant or 

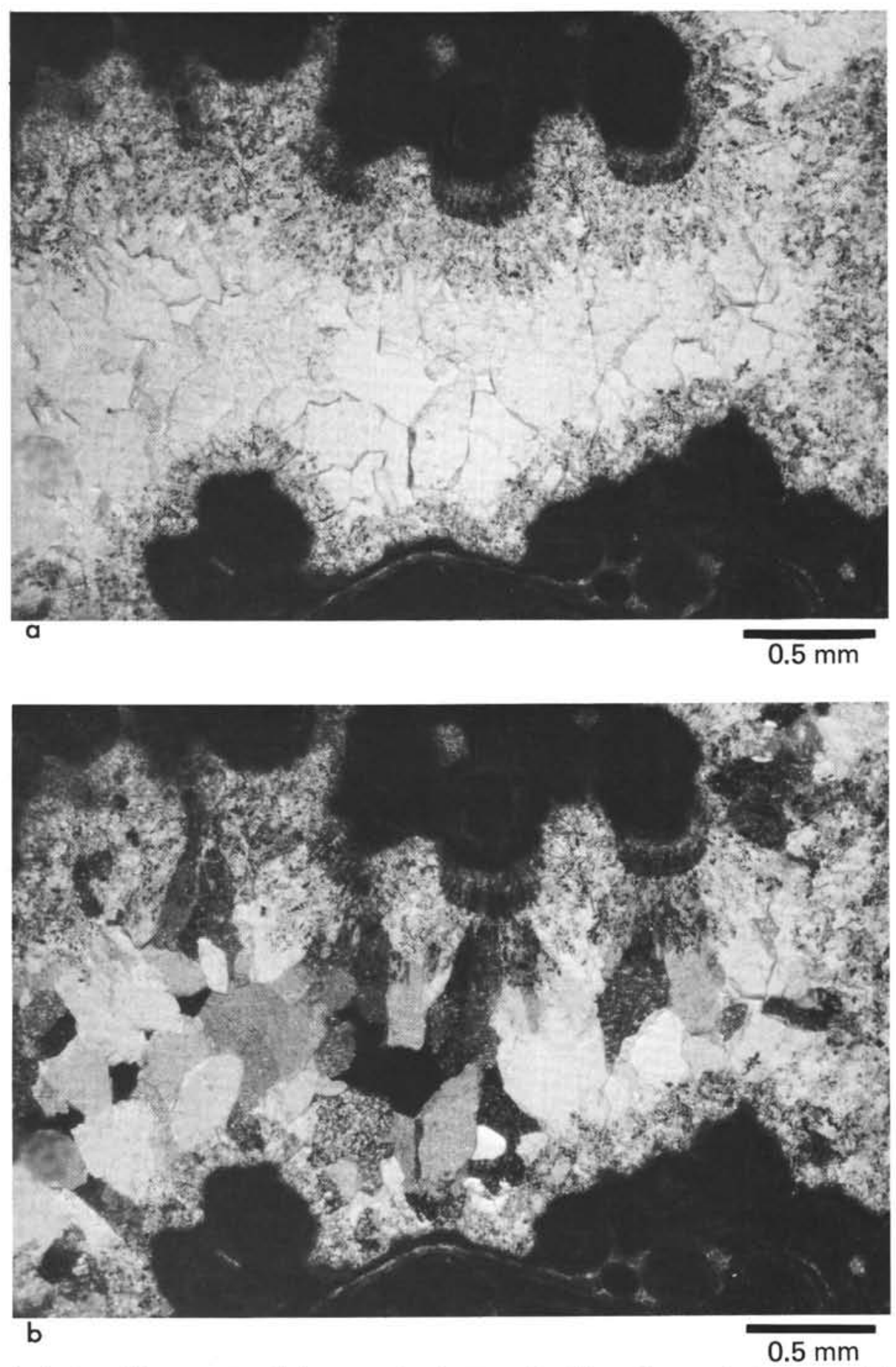

Figure 35. Cloudy, inclusion-rich cement and clear spar in sheet crack with earlier pendant cement. (a) Plane light. Cloudy layer is also asymmetric. (b) Cross-polarized light, showing that bladed crystals generally extend somewhat beyond the cloudy portion. Porosity remains in pore center (dark patches). Sample 392A-20-1, $82 \mathrm{~cm}$. Sub-bottom depth 222.3 meters. Thin section.

bladed calcite. Fabric evidence for replacement of marine cements, such as radiaxial fibrous calcite (Kendall and Tucker, 1973) is lacking.

\section{RED-STAINED LIMESTONE}

The uppermost well-indurated rock at Holes 392 and 392A is an interval of limestone containing reddish-brown ooids ${ }^{1}$,

\footnotetext{
'T.F. objects to the use of the term "ooid" for the diagenetic structures described here. To be consistent with the AGI
}

red-coated lithoclasts, and coarse skeletal debris, laced by laminated reddish-brown crusts (Figure 53). Only two disoriented fragments of this rock were recovered at Hole 392 ; about $13 \mathrm{~cm}$ of fragments were recovered from adjacent parts of two cores with 13 percent total recovery at Hole 392A. At Site 390, this interval is represented by red ooids,

Glossary we have nonetheless employed "ooid" for these spheroidal laminated structures that are normally less than $2 \mathrm{~mm}$ in diameter. 


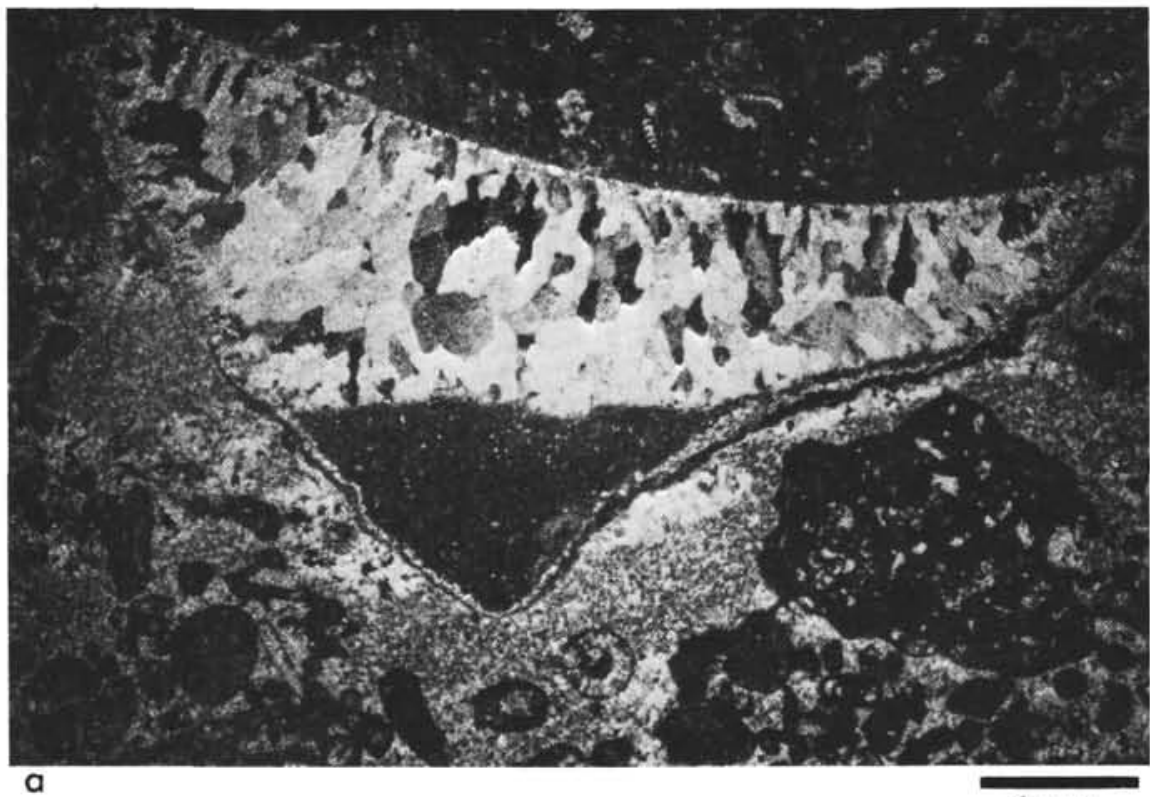

$1 \mathrm{~mm}$

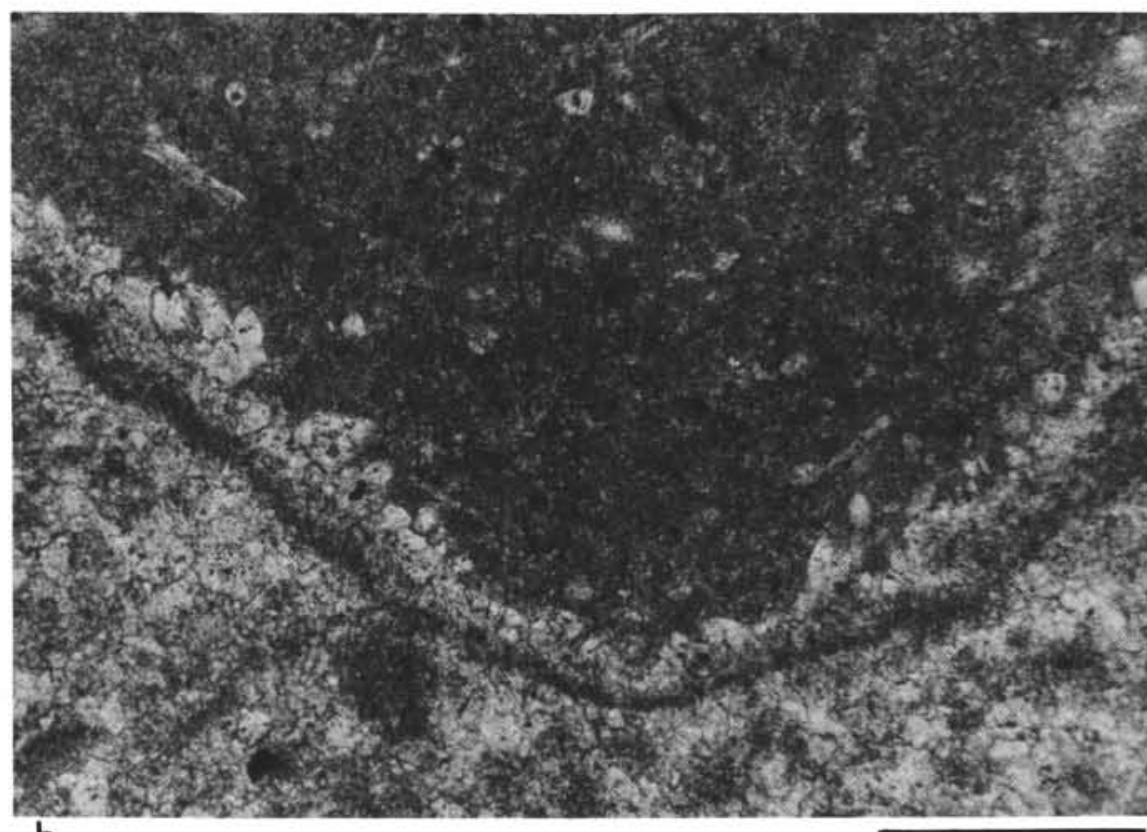

b

$0.2 \mathrm{~mm}$

Figure 36. Mold-filling events in oolitic limestone unit. (a) Large skeletal(?) mold preserved by micritic rim. A thin crust of cement coats the interior of the rim and is overlain by vaguely pelleted diagenetic sediment containing unidentified microfossils. Pelleted sediment in the shelter beneath the mold is also diagenetic and overlies the more compact diagenetic sediment elsewhere in the thin section. Pore-filling cement within the mold is texturally indistinguishable from that outside. Sample 392A-20-1, $137 \mathrm{~cm}$. Sub-bottom depth 222.9 meters. Thin section, cross-polarized light. (b) Detail of base of mold showing cement rim, fossils and vague clotting in overlying sediment, and loose pelletoids in later sediment (bottom). Plane light.

glauconite pelletoids, limonite staining, and pore-filling "red clay."

\section{Description}

The rock samples are motley and heterogeneous in appearance (Figure 53). The matrix consists of micritic carbonate and poorly preserved coccoliths. The skeletal debris includes head corals and possible ahermatypic branching corals, a sclerosponge (stromatoporid?), codiacian green algae, bryozoans, several belemnites, and a few mollusk fragments (Figure 53). One lithoclast contains a probable rudistid fragment. Microscopic skeletal remains 


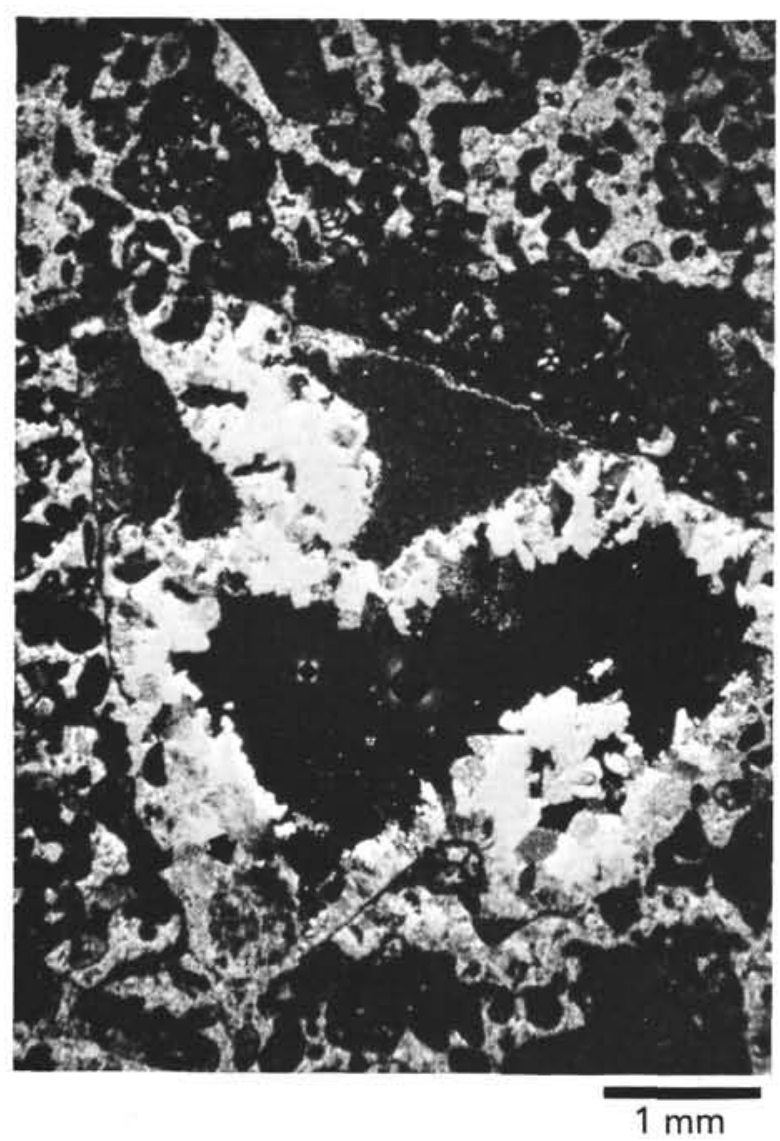

Figure 37. Diagenetic sediment within a gastropod(?) mold in pelletoidal packstone rests against a thin cement crust (top of mold). Diagenetic sediment fill was later leached and the resultant vug partially filled by spar. Diagenetic sediment projecting into the vug must have been somewhat lithified prior to vug formation. The few pelletoids at the base of the vug (arrow) rest on the initial cloudy phase of the spar which eventually partially filled the vug leaving a large pore. These pelletoids are a second episode of diagenetic sediment and are correlated with the loosely packed pelletoids in Figure 36 and in other vugs in this sample. Sample 392A20-1, $137 \mathrm{~cm}$. Sub-bottom depth 222.9 meters. Thin section, cross-polarized light.

include benthic foraminifers, echinoderm fragments, ostracodes, unidentified spicules, calcitized radiolarians, and numerous coccoliths (Figure 54).

The lithoclasts are angular fragments of coccolith wackestone, skeletal packstone, and muddier rocks containing ostracodes (?), globular and thick-shelled foraminifers, and a few calcareous ooids. Virtually all are coated and highly impregnated with an earthy reddish-brown stain containing about 20 per cent $\mathrm{Fe}_{2} \mathrm{O}_{3}$ (Table 1). Goethite was identified by X-ray diffraction along with traces of siderite and dolomite. Apophyses of the goethitic coating extend into the matrix (Figure 55).

The red ooids are well-formed oblate spheroids up to $3 \mathrm{~mm}$ in diameter. They have multiple concentric or asymmetric laminae of reddish-brown material and contain about 25 per cent $\mathrm{Fe}_{2} \mathrm{O}_{3}$ (Table 1), identified as goethite (Figure 56). Most ooids lack a well-defined nucleus. Some nucleii were leached or were lost in slide preparation (Figure 56). Those nucleii remaining consist either of red-stained mud containing coccoliths or fragments of composite grains and broken ooids (Figure 57). Well-preserved coccoliths occur sandwiched between the concentric bands of most ooids (Figures 58, 59). A few broken ooids occur in the matrix and some oolitic laminae are truncated (Figure 60). The ooids are irregularly distributed in clusters and wavy bands that transect some lithoclasts (Figure 53). In a few cases the clusters are obviously burrow fillings. A few ooids are slightly polygonal and appear to be fitted with their neighbors. Some individual ooids appear to transect the boundaries of burrows, suggesting that they post-date burrowing. Others are truncated at the burrow (boring) margins and some project slightly into the burrows as resistant peninsulas.

Irregular iron-stained laminae pervade this rock. They cut across some clasts, bridge the matrix between others, weave through ooid concentrations, and line solution-etched surfaces (Figure 53). Most of the laminae consist of reddish-brown goethite. Oriented carbonate crystals also produce a few light-gray laminae with pearly luster. Black "dendrite" stains on surface crusts and within cavities may be manganese oxides. The $\mathrm{MnO}$ content in a bulk sample of the red crust is less than 0.4 per cent (Table 1).

\section{Interpretation}

The lithoclasts and abraded skeletal fragments that are an important component of this rock clearly originated as detrital particles. The laminated crusts cross-cut detrital particles which shows that they were formed in situ by diagenetic alteration. The laminated crusts on the lithoclasts are similar in appearance and composition and have wispy apophyses which extend into the matrix, indicating their in situ origin.

Most ooids in modern environments are formed by direct precipitation of calcium carbonate in highly agitated, shallow-water environments. Analogous conditions have been inferred for most ooids in the geologic record. However, there are several cases of carbonate ooids or pisolites formed under very different conditions: in low-energy marine lagoons (Freeman, 1962); in deeper water with low sedimentation rates (Jenkyns, 1972; Purser, 1975, p. 230); on hypersaline supratidal flats (Lucia, 1968; Scholle and Kinsman, 1974; Asserto and Folk, 1976); or through subaerial diagenesis in situ (Swineford et al., 1958; Dunham, 1969b, 1972; James, 1972). The origin of non-carbonate ooids is poorly understood.

Formation of the pisolites at Site 392 by repeated movement in an agitated environment is suggested by the broken ooids and truncated laminae. Sorting, which is consistent with this interpretation, but less diagnostic, is also suggested by the presence of smoothly concentric laminations, some well-defined nucleii, and the uniform size of the ooids.

This evidence is contradicted by cross-cutting relationships of the ooids which suggests post-depositional 

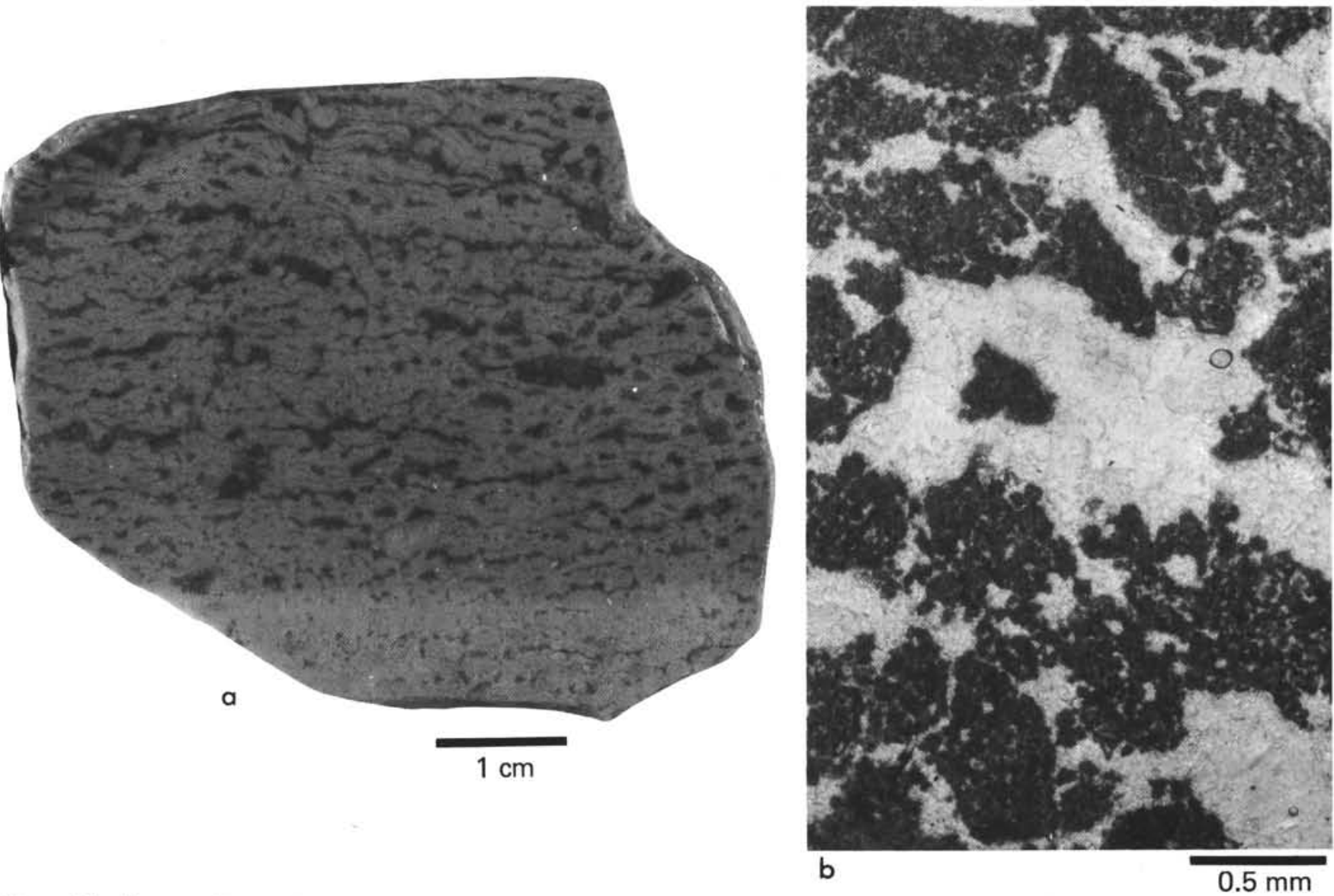

Figure 38. Fenestral limestone. (a) Extensive fenestral pores (cement filled) resulting in brecciated appearance of the sediment. Sample 392-2-2, 135-139 cm. Sub-bottom depth 59.9 meters. Slab. (b) Thin section of a showing fenestral pores, pelleted texture of sediment, and crumb-like muddy intraclasts. Plane light.

origin. Individual ooids cross the boundaries of burrows or borings. Carbonate mud of the matrix is visible between laminae (Figures 58, 59), and clusters of ooids transect lithoclasts (Figure 53). The consistent oblate spheroidal shape further suggests in situ origin. The close similarity in appearance and composition between the laminated reddish-brown ooids and the laminated crusts suggests a close genetic relationship between the two.

The apparent contradictions can be resolved in favor of predominately in situ origin by supposing that the broken ooids were truncated by burrowing and boring organisms. Some occur as truncated grains at the edges of borings. Ordinarily the other half would be chewed into tiny particles or dissolved. However, either half may have survived in a few cases to be reworked by further burrowing or coated by continued oolitic growth. Clusters of burrow-filling attest to organic reworking of the ooids. This reinforces the inference that ooids and crusts originated near the sediment surface as suggested by their distribution as a thin crust.

Identifying the environment of diagenetic alteration to form the red-stained, oolitic limestone is more difficult. The rocks immediately beneath the crust comprise a shoaling-upward sequence culminating in tidal-flat deposits.
Subaerial diagenetic alteration products are evident. The overlying deposits are all of pelagic origin, predominantly calcareous nannofossil oozes. Particles within the thin red-stained limestone interval include clasts from the underlying limestone and marine fossils ranging from shallow-water photosynthesizing green algae to possible deeper water (ahermatypic?) corals and nektonic belemnites.

The striking similarity of the laminated and red-stained crusts to those forming by subaerial weathering of limestones in many subtropical areas (Multer and Hoffmeister, 1966; James, 1972; Perkins, 1977) prompted us onboard ship to tentatively conclude that the crust resulted from subaerial weathering soon after deposition of the tidal-flat limestone. We considered the ooides analogous to caliche pisolites, although many of the diagnostic criteria are either lacking or poorly developed.

The most compelling evidence for the environment of diagenetic alteration is the common occurrence of calcareous nannoplankton within the laminated crusts and between concentric laminae of the ooides as well as within the micritic matrix, lithoclasts, and ooid nucleii. This links the crusts and ooids to the overlying pelagic deposits rather than the underlying shallow-water limestones. The crust and 


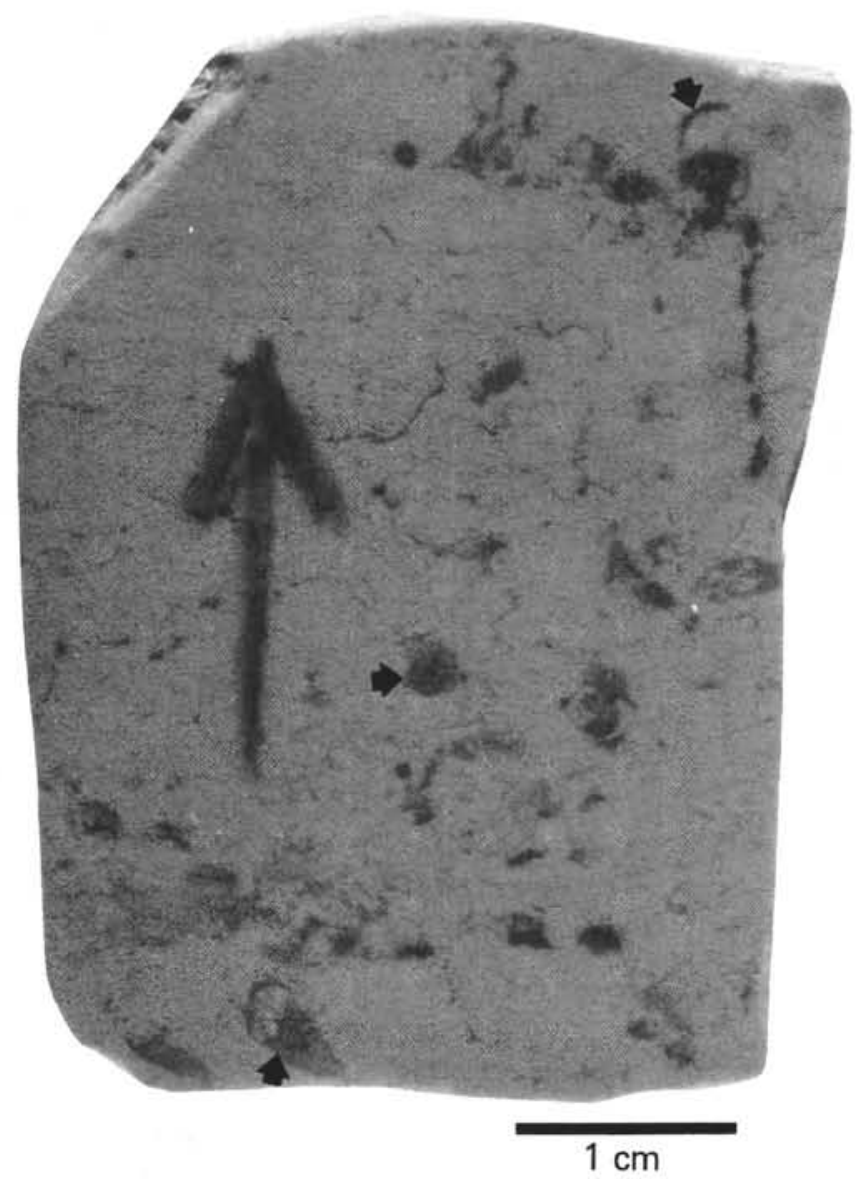

Figure 39. Spar-filled skeletal moldic porosity in slightly crystalline clotted, foraminifer-lime wackestone. Small arrows indicate gastropod molds. Fenestral porosity was well developed, especially near lower left and upper right; a few percent remains. Sample 392A-6-1, 69-74 cm. Sub-bottom depth 108.2 meters. Slab.

ooids probably formed during initial rapid submergence under conditions of very slow sedimentation. A submarine-weathering origin is more consistent with association of marine megafossils and the evidence of penecontemporaneous reworking by burrowing and boring organisms. The lithoclasts were associated with debris from rock outcrops on the sea floor rather than with a soil rubble. Many were coated as they were incorporated into the weathering rind. Some of the ooids may also have formed or grown by reworking on the sea floor rather than exclusively by in situ development. This would further resolve some of the conflicting evidence.

Comparable iron ooids containing goethite, hematite, and, rarely, chamosite from the Jurassic of Sicily have been ascribed to pelagic deposition within the photic zone by Jenkyns (1970). Ample evidence of submarine vulcanism associated with the Sicilian pisolites suggests a ready source of iron as well as manganese and other heavy metals concentrated in the pisolites. The Blake Nose ooids occur in a geologically similar setting-pelagic carbonates overlying shallow-platform carbonates-but were formed far from any

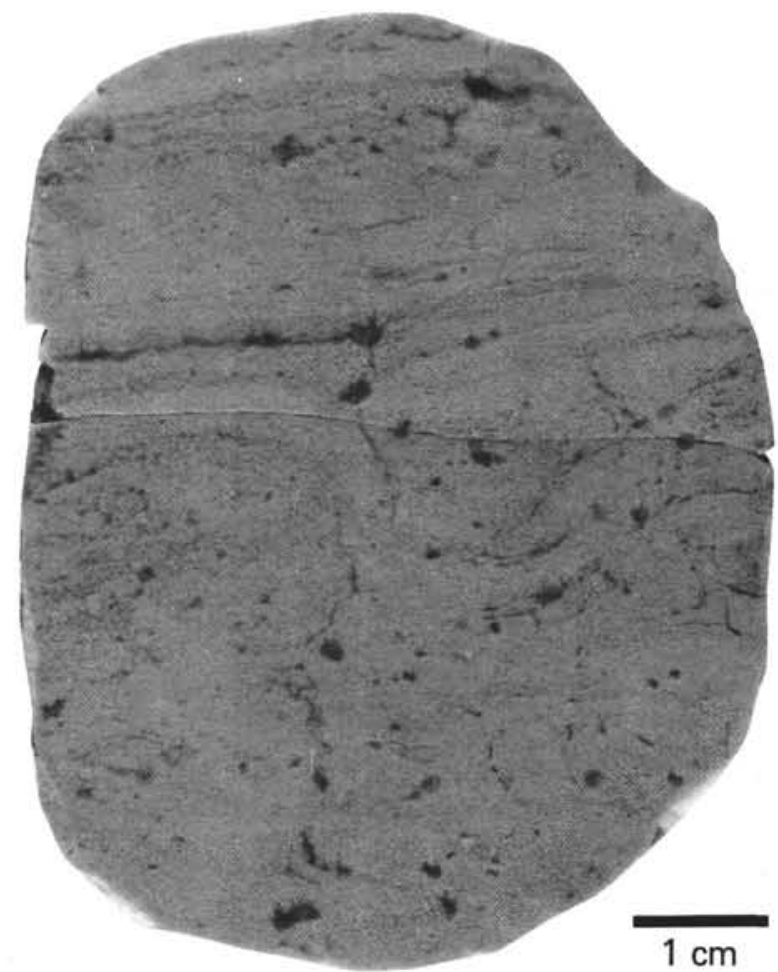

Figure 40. Laminated fenestral skeletal lime mudstone with ruptured and distorted laminae. Sample 392A-9-1, 66-73 cm. Sub-bottom depth 136.7 meters. Slab.

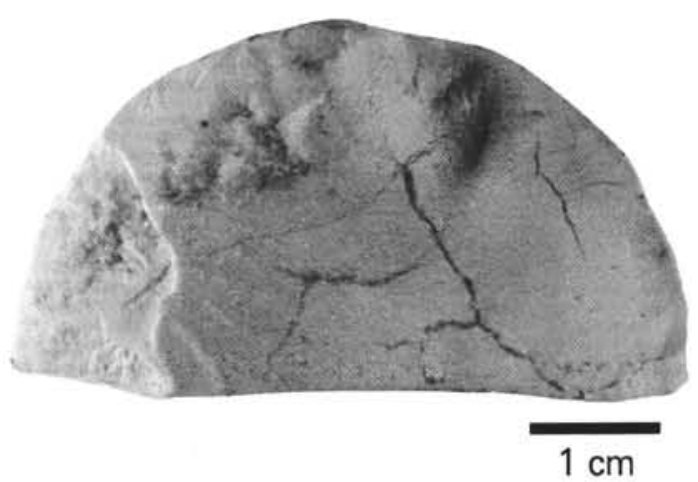

Figure 41. Polygonal cracks on horizontal surface of pelletoid lime packstone and mudstone. Sample 392A-17-1, 129-132 cm. Subbottom depth 194.3 meters. Core fragment.

known volcanic activity, do not contain appreciable concentrations of heavy metals (Table 1), are concentrated in a single thin layer, and contain no evidence that would restrict deposition to the photic zone.

Goethite, the exclusive mineral form of the iron that colors most of the crusts and the ooids, is a common subaerial weathering product. However, goethite is known from the deep sea in the Late Cretaceous "colorful clays" of the western North Atlantic (Lancelot et al., 1972; p. 928) and is common in deep-sea hydrothermal exhalates (Dymond and others, 1973; Zemmels and Cook, 1976), and iron-rich manganese nodules (Buser and Grütter, 1956; H.C. Jenkyns, 


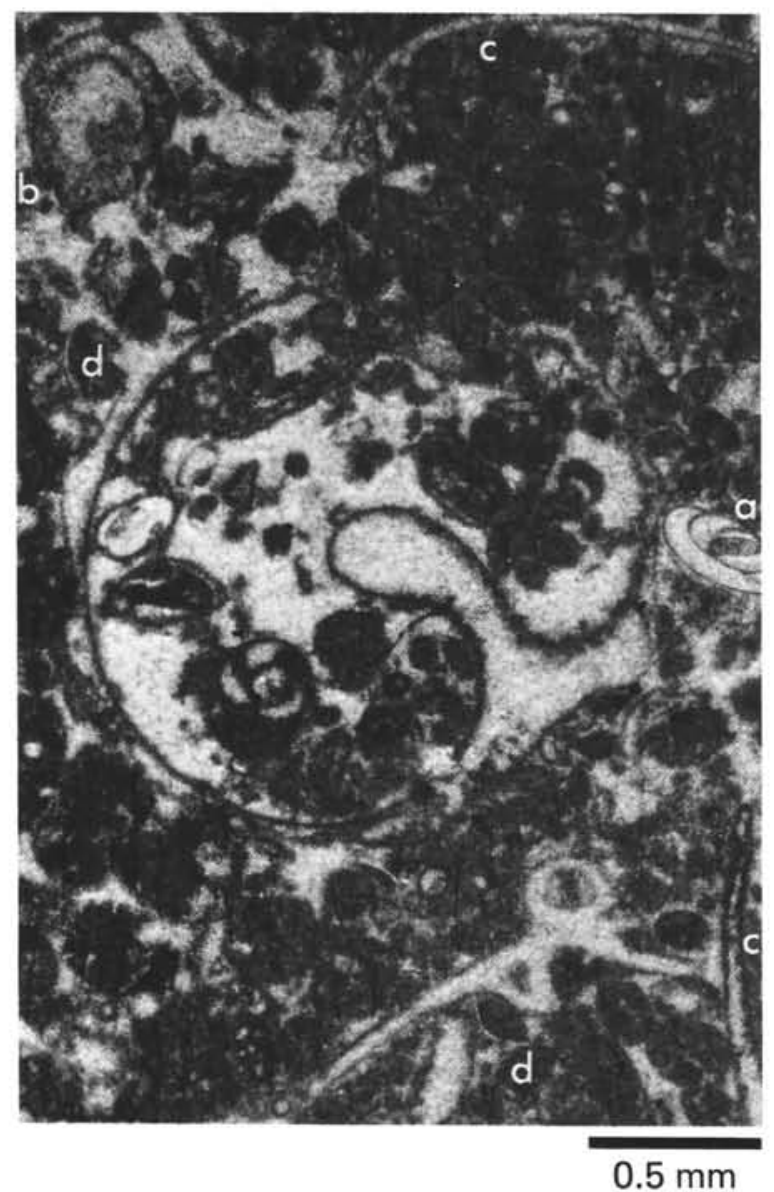

Figure 42. Unusually fossiliferous interval of fenestral limestone; skeletal lime wackestone (locally pelletoid-skeletal packstone). Large fossil is gastropod mold preserved by partially collapsed interior micrite envelope; scraps of exterior micrite envelope visible at upper left and lower right. Other fossils are miliolids (a) dasyclad algae? (b) bivalves? (c) and ostracodes (d). Sample 392A-9-1, $142 \mathrm{~cm}$, Sub-bottom depth 137.4 meters. Thin section, plane light.

letter of 21 December 1976). The presence of associated black stains, presumed to be manganese oxides, is also nondiagnostic, as they are known from both subaerial-weathering dendrites and from deep-sea nodules.

\section{SUMMARY AND CONCLUSIONS}

The sequence from skelmoldic limestone upward through oolite to fenestral limestone records shoaling upward from level-bottom carbon-shelf sedimentation in a few meters or few tens of meters of water, through oolite shoals in extremely shallow water, to tidal-flat deposits. Because more than 250 meters of shallow-water carbonate sediment accumulated, the shelf edge must have been subsiding or sea level rising during its deposition, but carbonate production and accumulation rates were greater than the rate of relative sea-level rise. Thus the sequence is regressive. After the sediment surface had accreted to sea level, 114 meters of tidal-flat limestone were deposited. Some interlayering of lithologies typical of the three units, in particular the oolitic and skelmoldic limestone, suggests that the environments that produced the three units probably coexisted on the sea floor. Vertical accretion of the oolite above the relatively level sea floor could have produced some degree of restriction. When oolite accretion reached sea level, tidal flats developed to the leeward of oolite shoals, and, with periodic drops in sea level, of oolite islands. Diagenetic evidence for periodic subaerial exposure of the oolite is abundant. As the sediment surface approached sea level, through vertical accretion, lateral accretion became dominant and produced the particular sequence encountered at Site 392 by some geographic configuration such as that outlined in the Site 392 Report.

Some relief during deposition at the shelf edge in the vicinity of the Blake Nose is suggested by the present configuration (Figure 1; Site 392 Report, Figure 3, this volume), although it was also probably sculptured by post-depositional solution and erosion. We infer that the initial deposits, now altered to skelmoldic limestone, were level-bottom deposits closely analogous to those now accumulating at the margins of the Great Bahama Bank in areas lacking shelf-edge shoals. Relief and subsequent restriction developed with the accretion of oolite shoals.

There is little evidence to support the existence of a continuous barrier reef at the edge of the Blake Plateau. Reefs, of course, represent an extremely narrow target to find with limited drilling, thus we cannot rule out the existence of a reef. However, debris of the typical Lower Cretaceous reef-building organisms is virtually lacking in the rocks recovered. Very few fragments of colonial corals and no positively identified rudists or sponges were found. Corals are most abundant, along with possible sclerosponges associated with the laminated red crusts. These are interpreted as deposits formed during submergence at times of extremely slow rates of deposition. The organisms which were abundant throughout deposition of the three units are those typical of level-bottom submarine "meadows" green algae, miliolid foraminifers, and gastropods. Consequently, on the basis of our present knowledge, the Blake Nose profile is a carbonate shelf edge rather than a reef.

Development of porosity has been outlined individually for each unit. The skelmoldic limestone with largely secondary porosity and appreciable porosity retention contrasts markedly with the overlying two units in which porosity was predominately primary and later almost totally occluded. This suggests that the skelmoldic porosity underwent an extensive period of subaerial leaching, possibly before deposition of the younger units. Cover by the overlying units could have helped preserve the porosity by limiting circulation of cement-depositing waters. This, however, is inconsistent with the above model of coexistence of the three depositional environments at the shelf margin, although it could be accommodated with only minor changes in the model. Interbeds of skelmoldic limestone within the oolite and the fenestral limestone suggest that rock susceptibility, controlled by the original sediment properties, may have been a major control of diagenetic configuration. We found no positive evidence of an exposure surface subjected to subaerial erosion (cf. Perkins, 1977) between the skelmoldic and oolitic limestones. Although recovery 

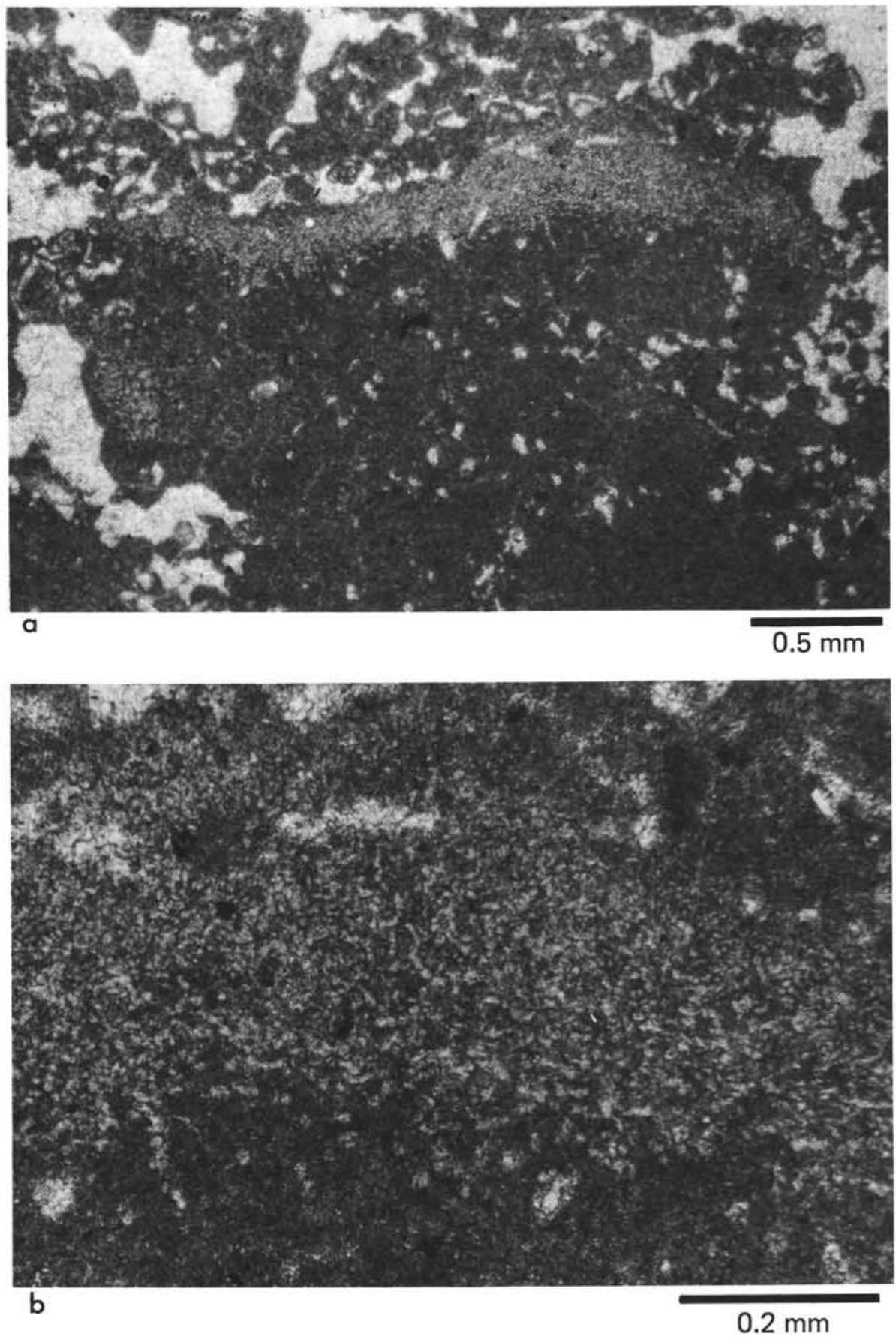

Figure 43. Blue-green algal filaments in pelletoid-skeletal lime wackestone. (a) Algal stromatolite in incipient intraclast; small projection at right center was probably a tuft of algal growth. Clot at lower left is also algal. (b) Detail of tuft; individual filaments visible. Sample $392 A-11-1,129 \mathrm{~cm}$. Sub-bottom depth 146.8 meters. Thin section, plane light.

was very poor in general, the actual contact was recovered (Core 19, Section 1).

The cement morphology in all three units is strikingly similar. The earlier cement is characterized by numerous inclusions except at the top of the fenestral limestone. This could indicate simultaneous cementation throughout the three units. It could equally well reflect early cementation (pre-burial) near the depositional interface but forming in response to recurrence of similar conditions, probably subaerial exposure with development of a fresh-water lens. The sediments most susceptible to solution formed skelmoldic limestone and the dissolved ions were transported to form cement in the rocks with higher initial porosity, the oolite and fenestral limestone.

Selected samples from all units were examined under cathode luminescence in an attempt to refine correlations of 


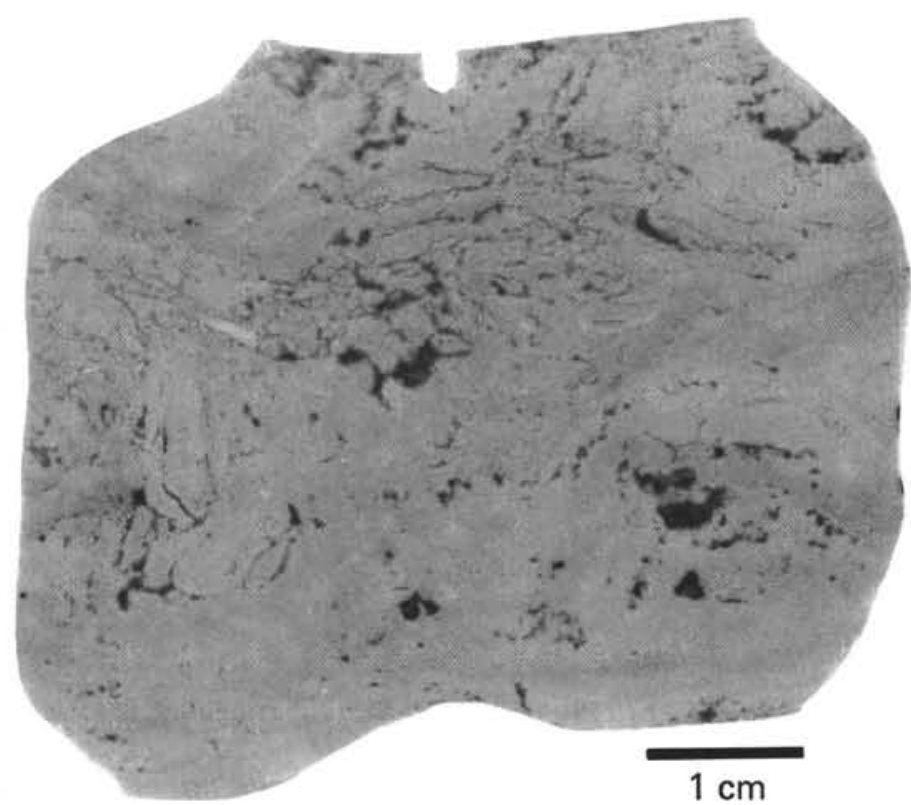

Figure 44. Fenestral porosity (spar filled) and in situ intraclasts in ostracode lime wackestone. Note deformed intraclasts (left center) and strings of ovoid fenestrae (lower right). Sample 392A-9-1, 99-103 cm. Sub-bottom depth 137 meters. Slab.

the cements (Meyers, 1974). Nearly all of the cements were totally dead to luminescence. A few luminescent cements were encountered in the late (but not the latest) stages of pore filling (Figures 61, 62), but these were in different units, and the luminescing cements did not persist even within a single thin section.

We favor the view of intermittent cementation in similar recurring environments over simultaneous cementation because it is more consistent with the inferred depositional and diagenetic history of individual units, but the evidence is inconclusive.

All of the observed diagenetic effects, with the exception of formation of the red crusts immediately above the Lower Cretaceous shallow-water sequence, probably occurred soon after the deposition of the units, before submergence with the onset of pelagic deposition in the Early Cretaceous (Barremian).

\section{ACKNOWLEDGMENTS}

We wish to thank Drs. Graham F. Elliott of the British Museum (Natural History) and Paul Brenckle of Amoco Production Company for identifications of the algae and William J. Meyers of State University of New York, Stony Brook, for making available his cathode luminoscope. Photography of core slabs was done by David Tuttle, chemical analyses by Max Budd, thin section preparation by Frank Sedlak, and X-ray diffraction analyses by Thomas Fernalld and Salvatore Corbo, all of State University of New York, Binghamton. We are grateful to Drs. Robin G.C. Bathurst, University of Liverpool, and Hugh C. Jenkyns, University of Durham, for critical review of the report.

\section{REFERENCES}

Assereto, R. and Folk, R.L., 1976. Brick-like texture and radial rays in Triassic pisolites of Lombardy, Italy: a clue to distinguish ancient aragonite pisolites: Sediment. Geol., v. 16, p. 205-222.
Ball, M.M., 1967. Carbonate sand bodies of Florida and the Bahamas: J. Sediment. Petrol., v. 37, p. 556-591.

Ball, M.M. and Shinn, E.A., 1967. Bahamian carbonate sands: Shell Film Library, Indianapolis, Indiana, $16 \mathrm{~mm}$ film, $45 \mathrm{~min}$.

Bathurst, R.G.C., 1966. Boring algae, micrite envelopes and lithification of molluscan biosparites: Geol. J., v. 5, p. 15-32. , 1971. Radiaxial fibrous mosaic. In Bricker, O.P.(Ed.), Carbonate cements: Baltimore (Johns Hopkins Press), p. 292-293.

Buser, W., and Grütter, A., 1956. Über die Natur der Manganknollen: Schweiz. Mineral. Petrog. Mitt., v. 36, p. 49-62.

Choquette, P.W. and Pray, L.C., 1970. Geologic nomenclature and classification of porosity in sedimentary carbonates: Am. Assoc. Petrol. Geol. Bull., v. 54, p. 207-250.

Cloud, P.E., Jr., 1962. Environment of calcium carbonate deposition west of Andros Island, Bahamas: U.S. Geol. Surv., Prof. Paper 350, p. 138.

Dunham, R.J., 1962. Classification of carbonate rocks according to depositional texture. In Ham, W.E. (Ed.), Classification of carbonate rocks-a symposium: Am. Assoc. Petrol. Geol. Mem. 1 , p. $108-121$.

1969a. Early vadose silt in Townsend Mound (reef), New Mexico. In Friedman, G.M. (Ed.), Depositional environments in carbonate rocks: Soc. Econ. Paleontol. Mineral. Spec. Pub. 14, p. 139-181.

, 1969b. Vadose pisolite in the Capital Reef (Permian), New Mexico and Texas. In Friedman G.M. (Ed.), Depositional environments in carbonate rocks: Soc. Econ. Paleontol. Mineral. Spec. Pub. 14, p. 182-191. ,1971. Meniscus cement. In Bricker, O.P. (Ed), Carbonate cements: Baltimore (Johns Hopkins Press), p. 297-300.

,1972. Capital Reef, New Mexico and Texas: Facts and questions to aid interpretation and group discussion: Permian Basin: 2Soc. Econ. Paleontol. Mineral. Pub. 72-14, 270 p. 


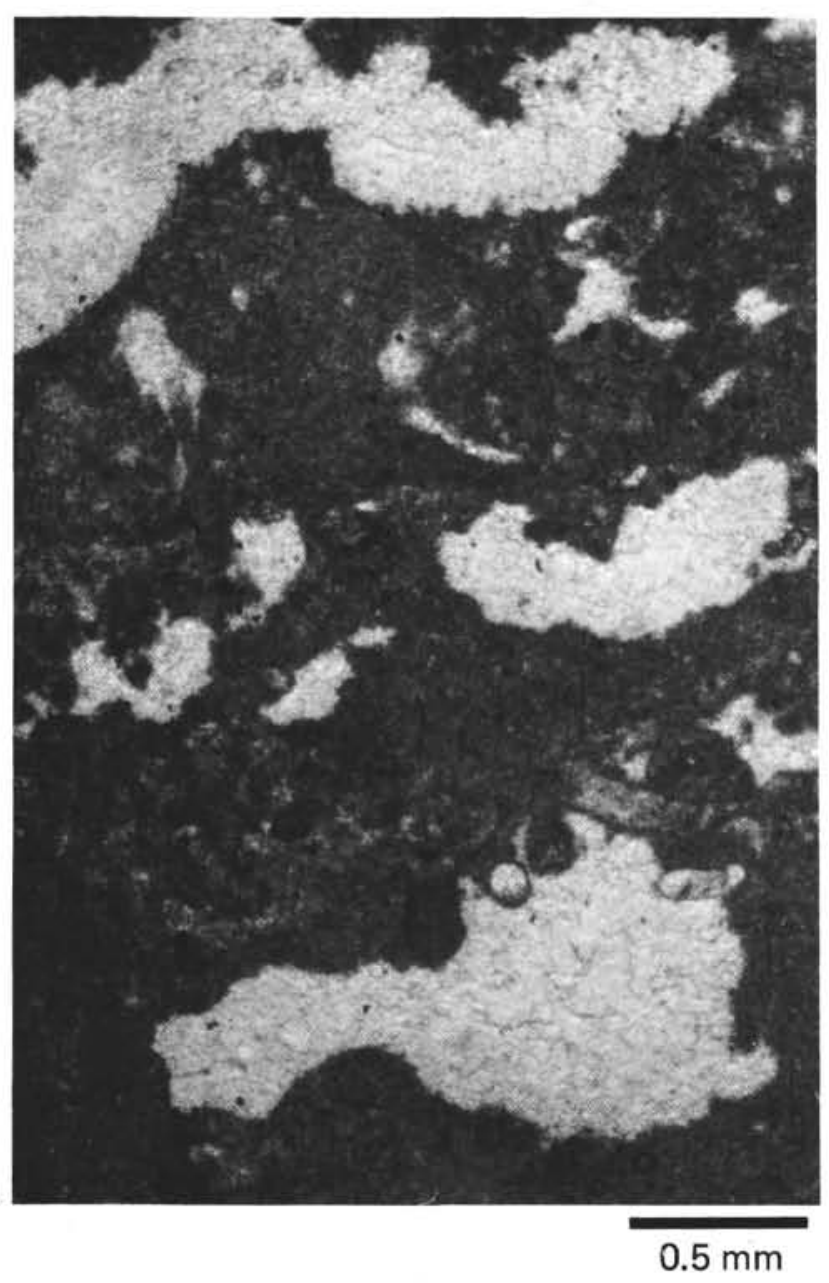

Figure 45. Layered, spar-filled fenestral structures in pelletoid-intraclast lime wackestone. Sample $392 A$ 10-2, $64 \mathrm{~cm}$. Sub-bottom depth 141.2 meters. Thin section, plane light.

Dymond, J., Corliss, J.B., Heath, G.R., Field, C.W., Dasch, E.J., and Veeh, H.H., 1973. Origin of metalliferous sediments from the Pacific Ocean: Geol. Soc. Am. Bull., v. 84, p. 3355-3372.

Enos, P., 1974. Map of surface sediment facies of the Florida-Bahama Plateau: Geol. Soc. Am. Map MC-5.

1977. Holocene carbonate sediments of the south Florida shelf margin. In Enos, P. and Perkins, R.D. Quaternary sedimentation in south Florida: Geol. Soc. Am. Mem. 147, p. 1-130.

Enos, P. and Perkins, R.D., in press. Evolution of Florida Bay from island stratigraphy: Geol. Soc. Am. Bull.

Fischer, A.G., 1964. The Lofer cyclothems of the Alpine Triassic. In Merriam, D.F. (Ed.), Symposium on cyclic sedimentation: Kansas Geol. Surv. Bull. 169, v. 1, p. 107-149.

Folk, R.L., 1959. Practical petrographic classification of limestones: Am. Assoc. Petrol. Geol. Bull., v. 43, p. 1-38. , 1965. Some aspects of recrystallisation in ancient limestones. In Pray, L.C. and Murray, R.C. (Eds), Dolomitization and limestone diagenesis-a symposium: Soc. Econ. Paleontol. Mineral. Spec. Pub. 13, p. 14-48.

, 1974. The natural history of crystalline calcium carbonate: effect of magnesium content and salinity: $J$. Sediment. Petrol., v. 44, p. 40-53.

Freeman, T., 1962. Quiet water oolites from Laguna Madre, Texas: J. Sediment. Petrol., v. 32, p. 475-483.

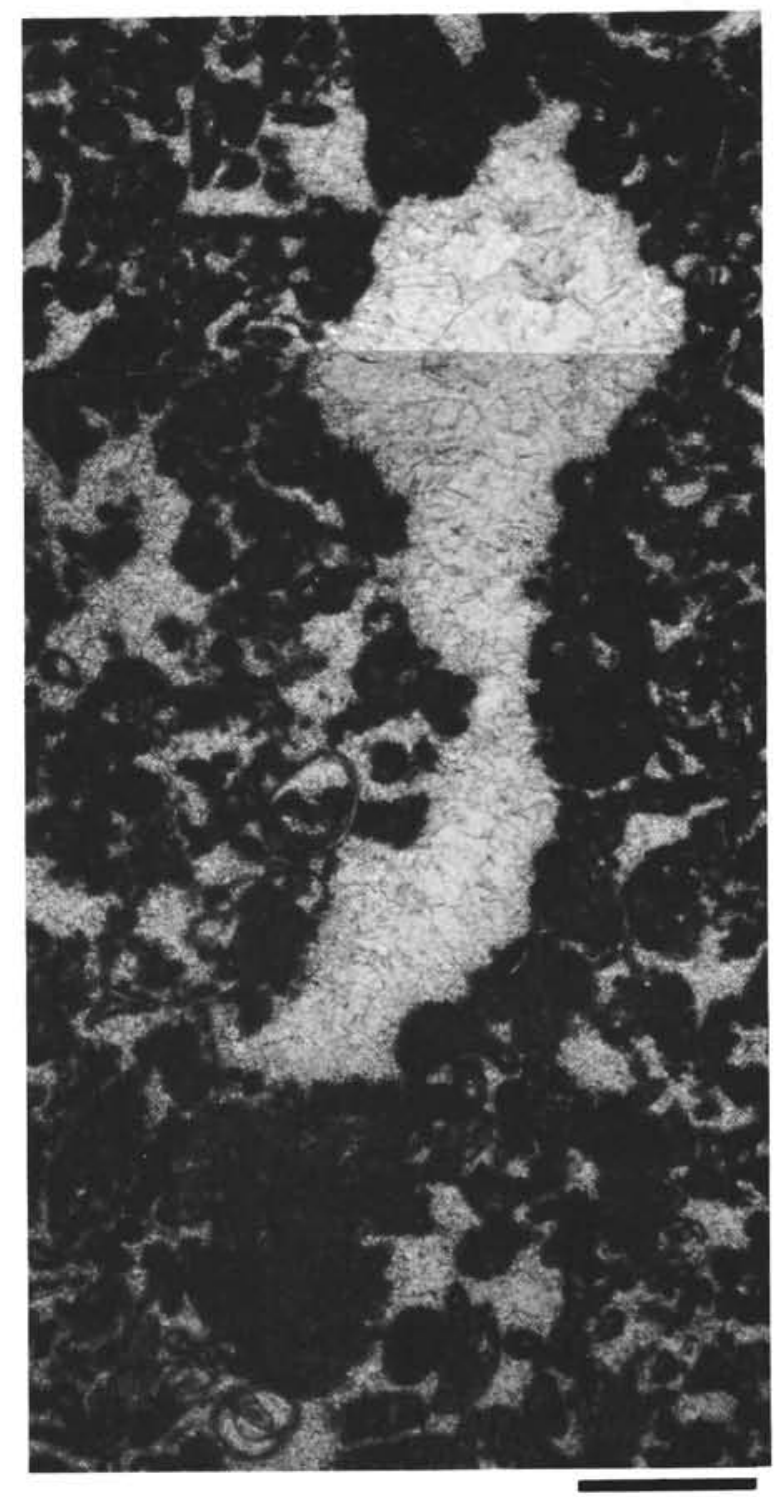

$0.5 \mathrm{~mm}$

Figure 46. Vertically elongate fenestral pore (spar filled) with closely packed margins; a "keystone vug." Geopetal accumulation of debris at base of fenestra. Miliolid-pelletoid lime packstone. Sample 392A-9-1, $102 \mathrm{~cm}$. Sub-bottom depth 137 meters. Thin section, plane light.

, 1971. Morphology and composition of Ordovician vadose cement: Nature, v. 233, p. 133-134.

Friedman, G.M., 1965. Occurrence and stability relations of aragonite, high-magnesium calcite, and low-magnesium calcite under deep-sea conditions: Geol. Soc. Am. Bull., v. 76, p. 1191-1196.

Heezen, B.C. and Sheridan, R.E., 1966. Lower Cretaceous rocks (Neocomian-Albian) dredged from Blake escarpment: Science, v. 154 , p. $1644-1647$.

Illing, L.V., 1954. Bahaman calcareous sands: Am. Assoc. Petrol Geol. Bull., v. 38, p. 1-95.

James, N.P., 1972. Holocene and Pleistocene calcareous crust (caliche) profiles: criteria for subaerial exposure: J. Sediment. Petrol., v. 42, p. 817-836. 

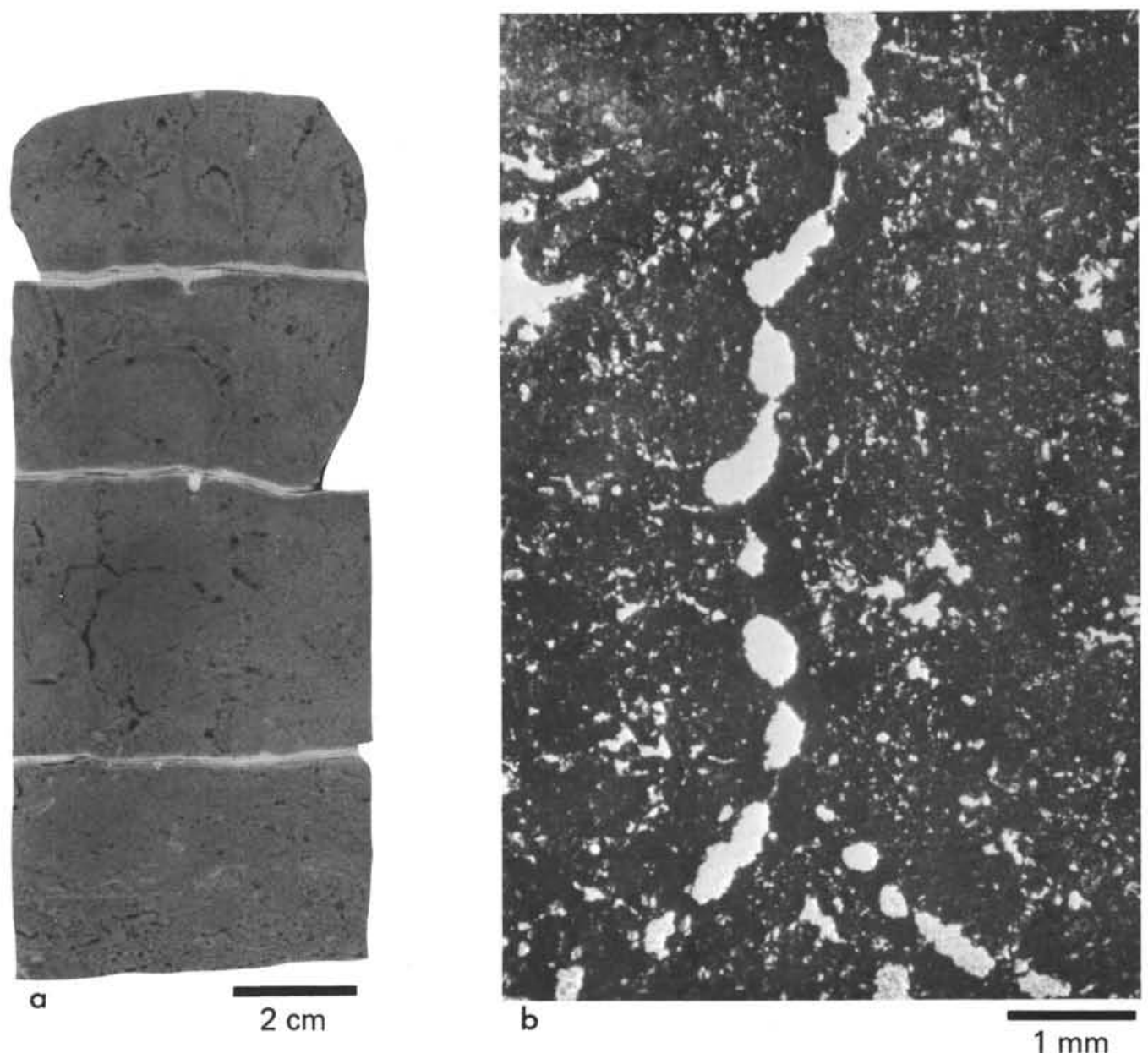

Figure 47. Fenestral bead strings. (a) Vertical and arcuate strings of ovoid fenestrae linked by tubes or cracks in skeletal lime wackestone. Sample 392A-11-1, 72-85 cm. Sub-bottom depth 146 meters. Slab. (b) Partially linked fenestrae in thin section. Sample 392A-17-1, $88 \mathrm{~cm}$. Sub-bottom depth 193.9 meters. Plane light.

Jenkyns, H.C., 1970. Submarine volcanism and the Toarcian iron pisolites of western Sicily: Ecolog. Geol. Helv., v. 63, p. 549-572.

, 1972. Pelagic “'oolites" from the Tethyan Jurassic: $J$. Geol., v. 80 , p. 21-33.

Karcz,I., and Enos, P., 1975. Soft sediment deformation.In Coates, D. (Ed.), Identification of late Quaternary sediment deformation and its relation to seismicity: (Report to New York Atomic and Space Authority), p. 13-38.

Kendall, A.C. and Tucker, M.E., 1973. Radiaxial fibrous calcite: a replacement after acicular carbonate: Sedimentology, v. 20, p. 365-389.

Lancelot, Y., Hathaway, J.C., and Hollister, C.D., 1972. Lithology of sediments from the western North Atlantic, Leg 11 Deep Sea Drilling Project. In Hollister, C.D., Ewing, J.I., et al., Initial Reports of the Deep Sea Drilling Project, V. 11: Washington (U.S. Government Printing Office), p. 901-949.

Logan, B.W., Read, J.F., and Davies, G.R., 1970. History of carbonate sedimentation, Quaternary Epoch, Shark Bay, Western Australia. In Carbonate sedimentation and environments, Shark Bay, Western Australia: Am. Assoc. Petrol. Geol. Mem. 13, p. 38-84.

Lucia, F.J., 1968. Recent sediments and diagenesis in south Bonaire, Netherlands Antilles: J. Sediment. Petrol., v. 38, p. 845-858.
Meyerhoff, A.A. and Hatten, C.W., 1974. Bahamas salient of North America. In Burk, C.A., and Drake, C.L. (Eds.), The geology of continental margins: New York (Springer-Verlag), p. 429-446.

Meyers, W.J., 1974. Carbonate cement stratigraphy of the Lake Valley Formation (Mississippian) Sacramento Mountains, New Mexico: J. Sediment. Petrol., v. 44, p. 837-861.

Multer, H.G. and Hoffmeister, J.E., 1968. Subaerial laminated crusts of the Florida Keys: Geol. Soc. Am. Bull., v. 79, p. 183-192.

Paulus, F.J., 1972. The geology of Site 98 and the Bahama Platform. In Hollister, C.D., Ewing, J.I., et al., Initial Reports of the Deep Sea Drilling Project, V. 11: Washington (U.S. Government Printing Office), p. 877-897.

Perkins, R.D., 1977. Pleistocene depositional framework of south Florida. In Enos, P. and Perkins, R.D. Quaternary sedimentation in south Florida: Geol. Soc. Am. Mem. 147, p. 131-198.

Perkins, R.D. and Enos, P., 1968. Hurricane Betsy in the Florida-Bahama area-geologic effects and comparison with Hurricane Donna: J. Geol., v. 76, p. 710-719.

Purdy, E.G., 1963a. Recent calcium carbonate facies of the Great Bahama Bank. 1. Petrography and reaction groups: J. Geol. v. 71, p. 334-355. 


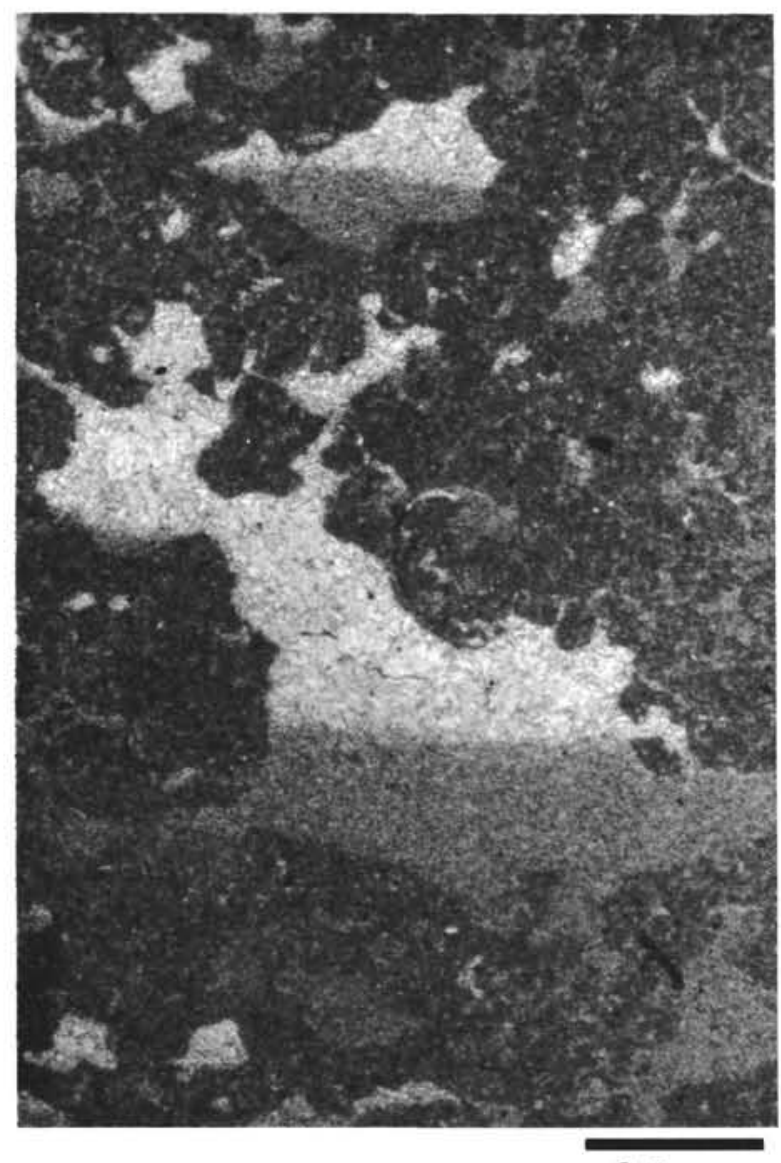

$0.5 \mathrm{~mm}$

Figure 48. Internal sediment flooring fenestral pores and totally filling many smaller fenestral and intraparticle pores. Pelletoid lime wackestone. Sample $392 A-6-1,105 \mathrm{~cm}$. Sub-bottom depth 108.6 meters. Thin section, plane light.

1963b. Recent calcium carbonate facies of the Great Bahama Bank 2. Sedimentary facies: J. Geol., v. 71, p. 472-497.

1964. Sediments as substrates. In Imbrie, J. and Newell, N. (Eds.), Approaches to paleoecology: New York (Wiley and Sons), p. 238-271,

Purser, B.H., 1969. Syn-sedimentary marine lithification of Middle Jurassic limestones in the Paris Basin: Sedimentology, v. 12, p. 205-230.
(Ed.), 1973. The Persian Gulf: Berlin (Springer-Verlag), p. 471.

, 1975. Sédimentation et diagénóse précoce des séries carbonatées du Jurassique moyen de Bourgogne. Unpublished D. Sc. Thesis, l'Université de Paris-sud "Centre d'Orsay," Orsay, France, p. 383.

Purser, B.H. and Loreau, J.-P., 1973. Aragonitic supratidal encrustations on the Trucial Coast, Persian Gulf. In Purser, B.H. (Ed.), The Persian Gulf: Berlin (Springer-Verlag), p. 343-376.

Roehl, P.O., 1967. Stony Mountain (Ordovician) and Interlake (Silurian) facies analyses of Recent low energy marine and subaerial carbonates, Bahamas: Am. Assoc. Petrol. Geol. Bull., v. 51 , p. $1979-2032$.

Scholle, P.A. and Kingman, D.J.J., 1974. Aragonite and high-Mg calcite caliche from the Persian Gulf-a modern analog for the Permian of Texas and New Mexico: J. Sediment. Petrol., v. 44, p. 904-916.

Sheridan, R.E., 1974. Atlantic continental margin of North America. In Burk, C.A. and Drake, C.L. (Eds.), The geology of continental margins: New York (Springer-Verlag), p. 391-407.

Sheridan, R.E., Berman, R.M., and Corman, D.B., 1971. Faulted limestone block dredged from Blake escarpment: Geol. Soc. Am. Bull., v. 82, p. 199-206.

Shinn, E.A., 1968. Practical significance of birdseye structures in carbonate rocks: J. Sediment. Petrol., v. 38, p. 215-223.

Shinn, E.A., Lloyd, R.M., and Ginsburg, R.N., 1969. Anatomy of a modern carbonattate tidal-flat, Andros Island, Bahamas: $J$. Sediment. Petrol., v. 39, p. 1201-1228.

Seisser, W.G., 1973. Diagenetically formed ooids and intraclasts in South African calcretes: Sedimentology, v. 20, p. 539-551.

Smith, W.O., 1961. Mechanism of gravity drainage and its relation to specific yield of uniform sands: U.S. Geol. Survey Prof. Paper 402-A, $12 \mathrm{p}$.

Swineford, A., Leonard, A.B., and Frye, J.C., 1958. Petrology of the Pliocene pisolitic limestone in the Great Plains: Kansas Geol. Survey Bull. 130, pt. 2, p. 97-116.

Traverse, A. and Ginsburg, R.N., 1966. Palynology of the surface sediments of Great Bahama Bank as related to water movement and sedimentation: Marine Geol., v. 4, p. 417-459.

U.S. Geological Survey, 1975a. Sediments, structural framework, petroleum potential, environmental conditions, and operational considerations of the United States Mid-Atlantic Outer Continental Shelf: Open File Report no. 75-61, p. 143. , 1975b. Sediments, structural framework, petroleum potential, environmmnmental conditions, and operational considerations of the United States South Atlantic Outer Continental Shelf: Open File Report no. 75-411, p. 262.

Zemmels, I. and Cook, H.E., 1976. X-ray mineralogy data from the Nazca Plate - Leg 34 Deep Sea Drilling Project. In Yeats, R.S., Hart, S.R., et al., Initial Reports of the Deep Sea Drilling Project, V. 34: Washington(U.S. Government Printing Office), p. $589-600$. 


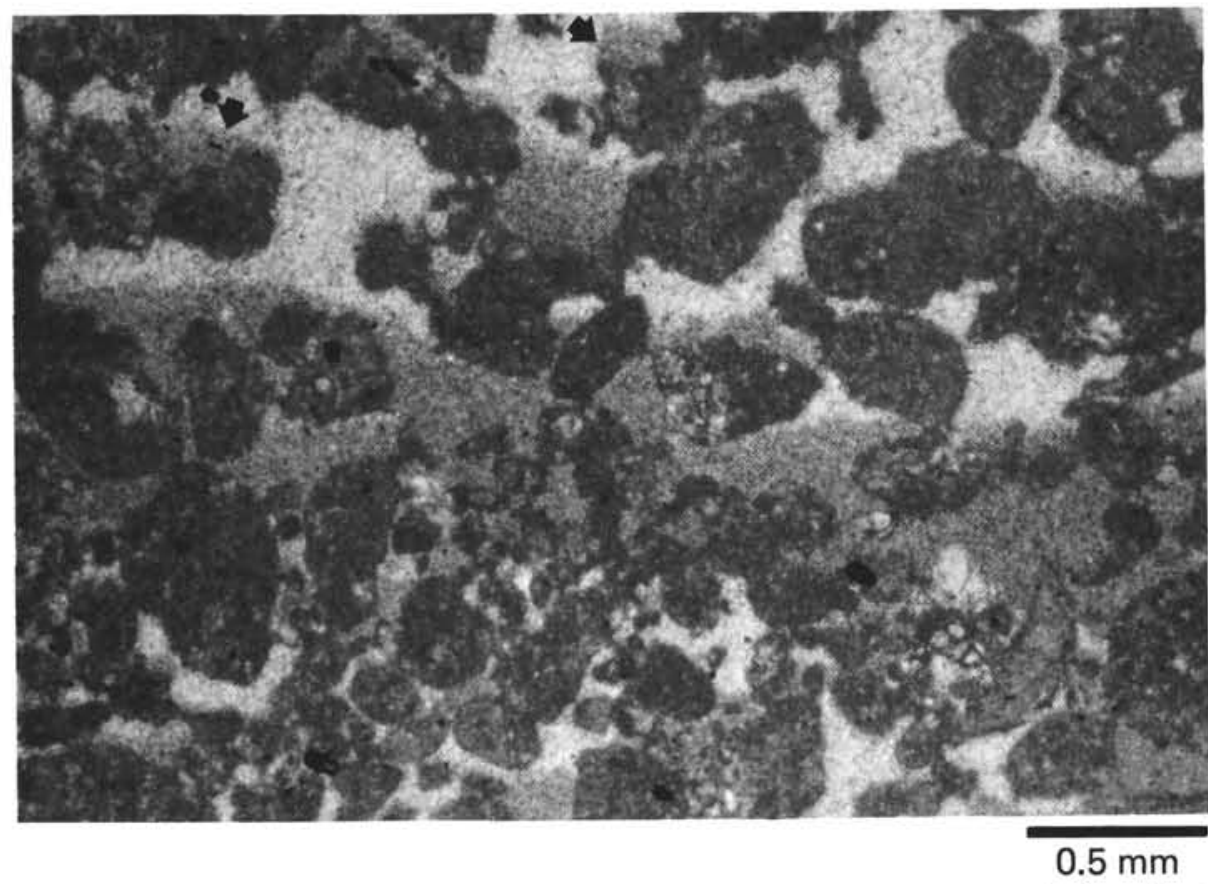

Figure 49. Internal sediment partially to totally occluding pore space in intraclastpelletoid lime grainstone to give appearance of packstone. Note perched sediment (arrows). Sample 392A-11-1, $85 \mathrm{~cm}$. Sub-bottom depth 146.3 meters. Thin section, plane light. 


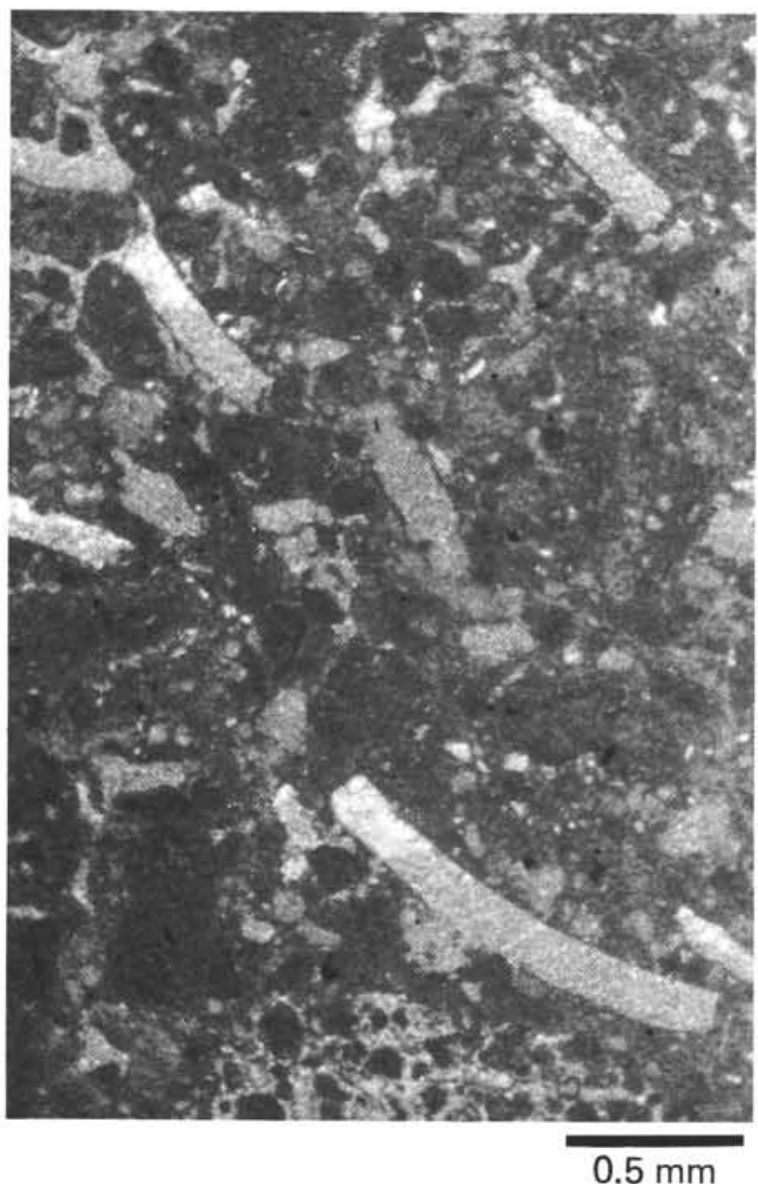

Figure 50. Skeletal (bivalve?) molds, partially filled with diagenetic sediment. Internal (diagenetic?) sediment fills much of primary interparticle porosity, too. Pelletoid lime packstone. Sample 392A5-2, $41 \mathrm{~cm}$. Sub-bottom depth 99.9 meters. Thin section, plane light.

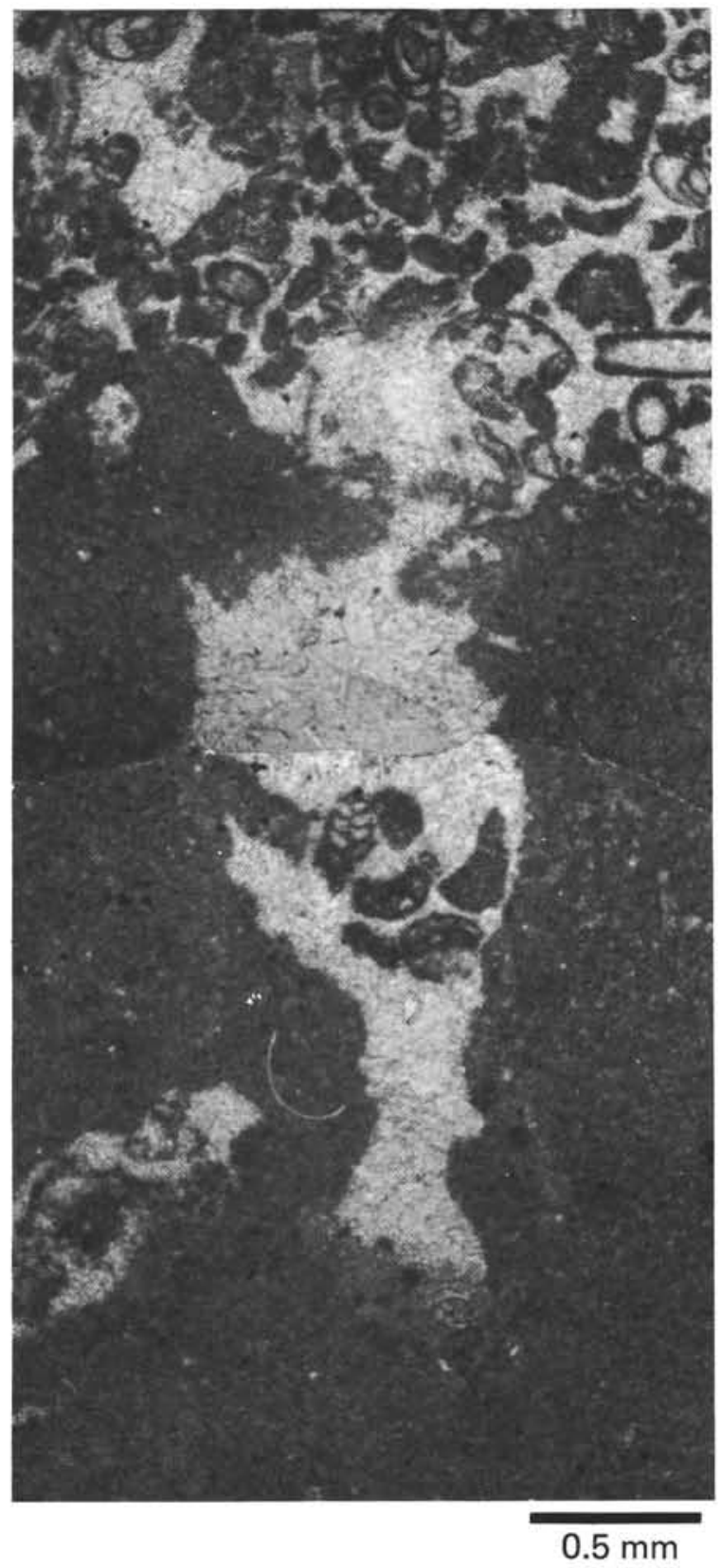

Figure 51. Vertical fenestra suggesting fluid escape from the skeletal lime mudstone layer erupting into the overlying pelletoid-foraminifer lime grainstone, with the collapse of particles back into the void. Geopetal fill of fine sediment floors the fenestra. Sample 392A-6-1, $91 \mathrm{~cm}$. Sub-bottom depth 108.5 meters. Thin section, plane light. 

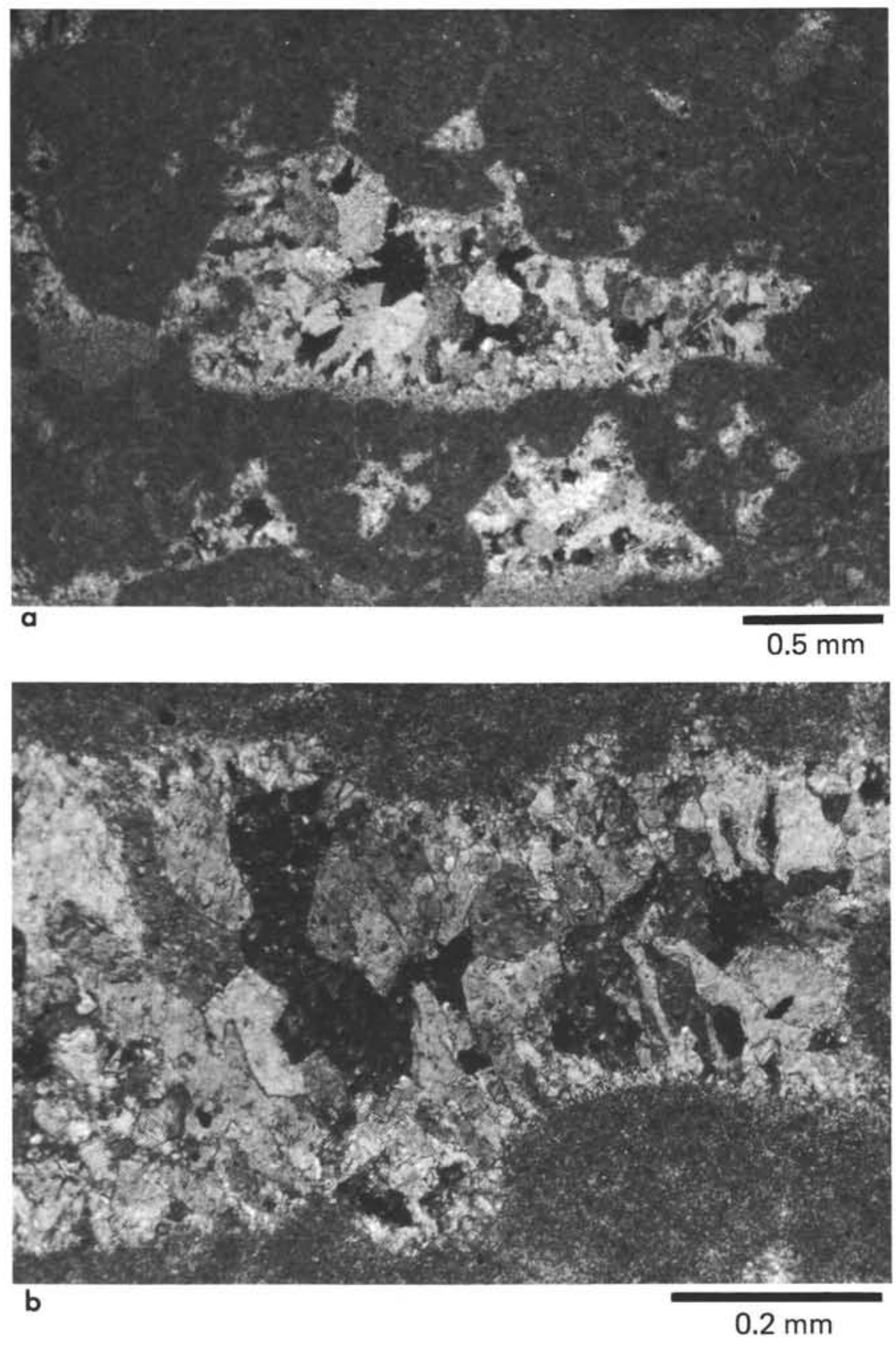

Figure 52. Cement morphology in fenestral pelletoid lime wackestone. Sequence is described in text. (a) Internal sediment is absent in large fenestra but underlies cement in left-adjacent and subjacent fenestrae showing that it was not occluded by cement. (b) Detail at right end of large fenestra. Final coarse equant spar is not developed in this narrower part of the pore. Sample 392A-6-1, $105 \mathrm{~cm}$. Sub-bottom depth 108.6 meters. Thin section, cross-polarized light. 


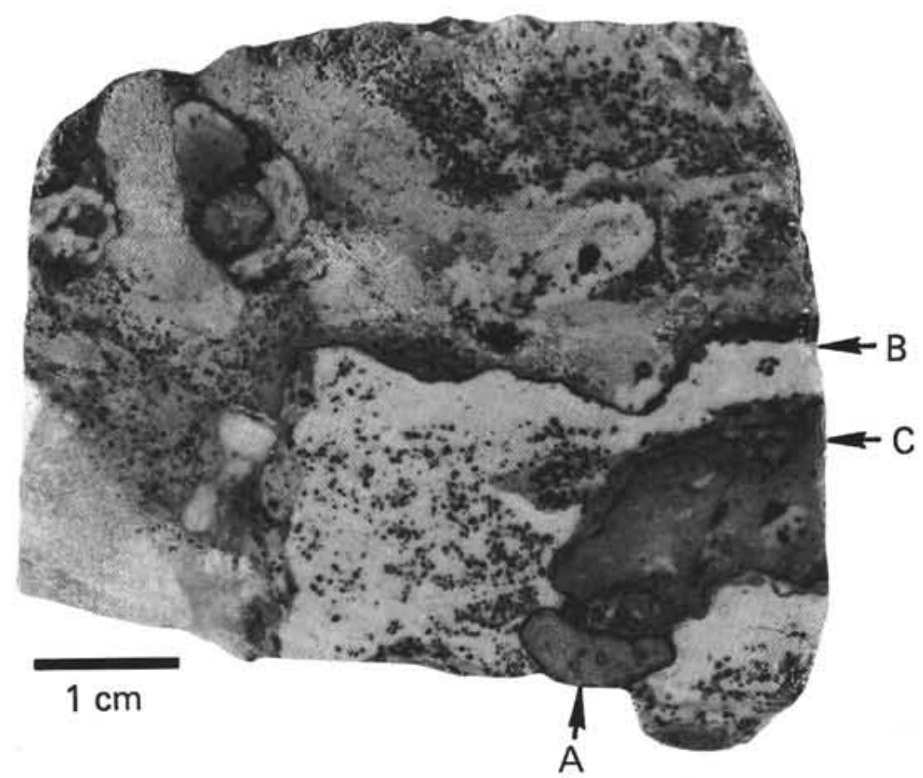

Figure 53. Red-stained limestones. Laminated reddish-brown crusts coat (a) and bridge lithoclasts and transect matrix of light-colored coccolith mudstone (b). Reddish, iron-rich ooids are developed within lithoclasts (a), matrix, and crusts (c). Sclerosponge(?) (Stromatoporid?) is at lower left. Sample 392A-4, CC (9-14 cm). Sub-bottom depth 90.1 meters. Slab. 


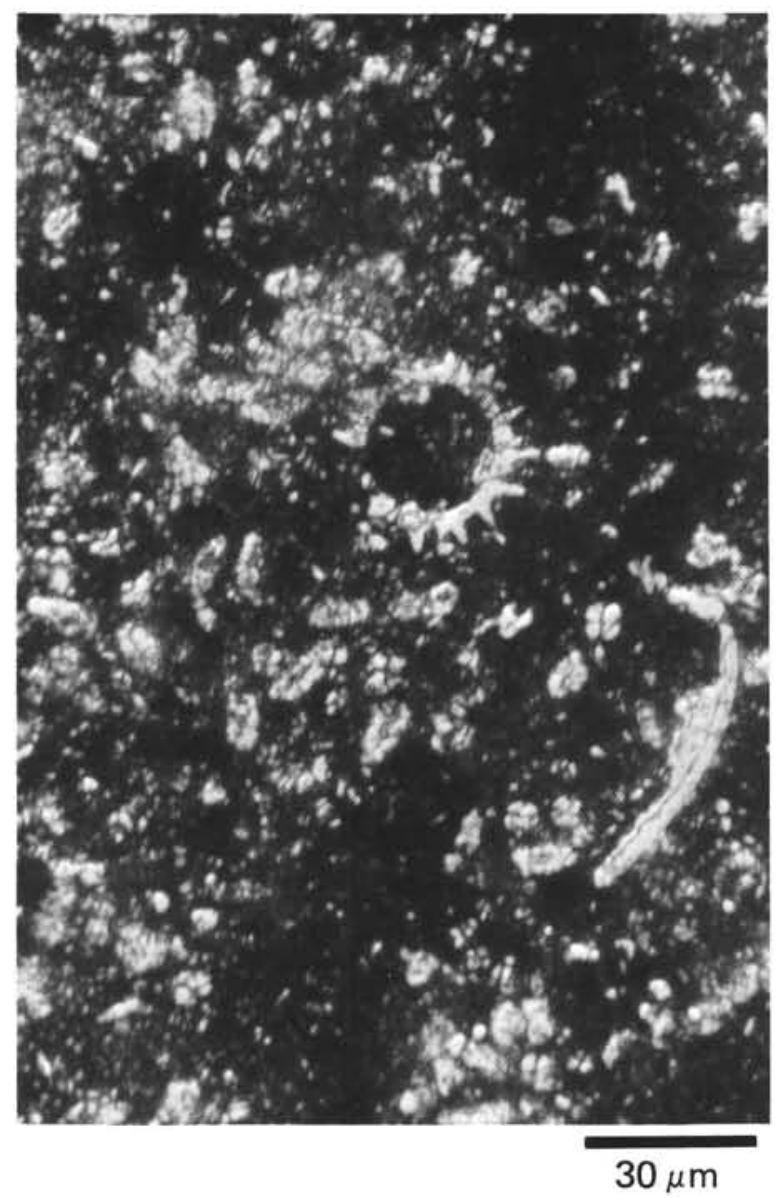

Figure 54. Numerous coccoliths and calcitized radiolarian (?) (center) in red-stained matrix adjacent to laminated red crust (lower open arrow in Figure 53). Thin section, cross-polarized light. Opaque red stain and plucking of carbonate in slide preparation account for large areas of total extinction. 


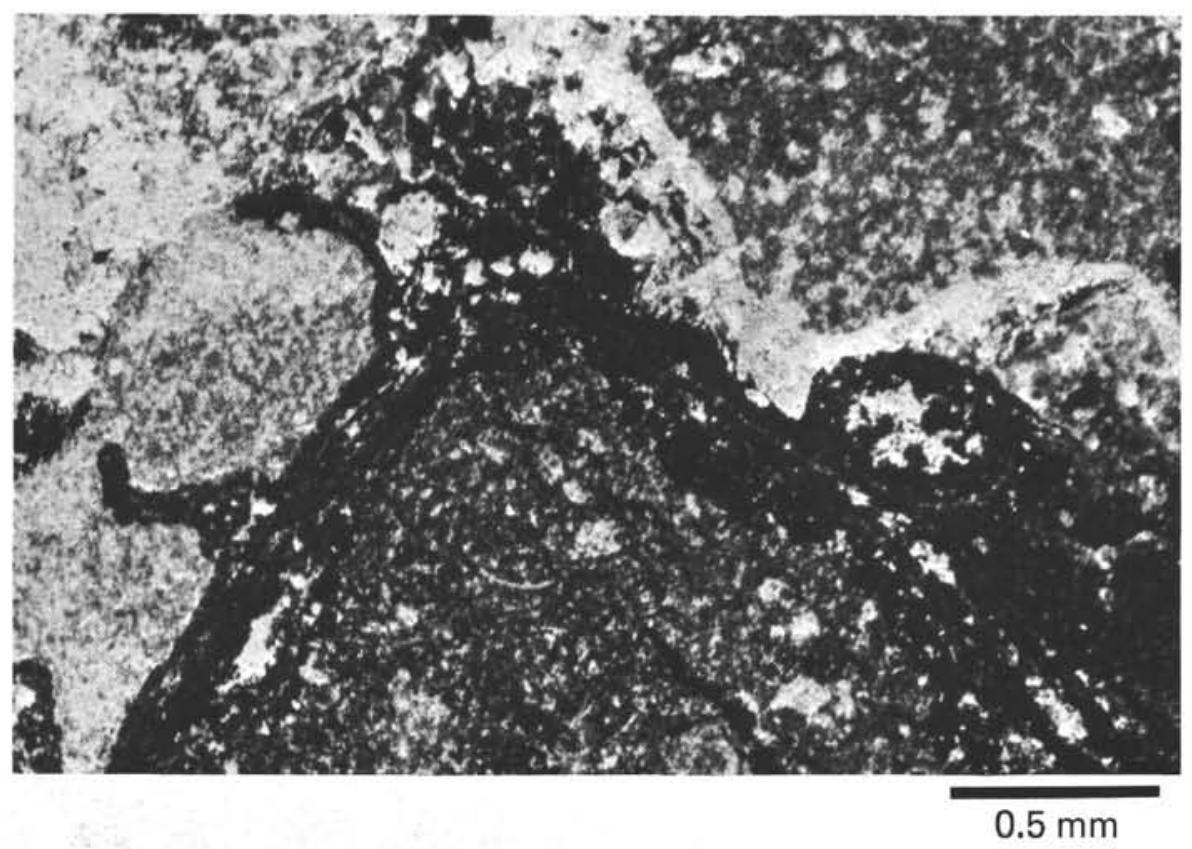

Figure 55. Encrusted coccolith mudstone lithoclast with apophyses of crust extending into adjacent matrix. Ooids occur within the crust (right). Sample $392 A-4, C C(9-14 \mathrm{~cm})$. Sub-bottom depth 90.1 meters. Thin section, plane light.

TABLE 1

Metal Concentrations in Red-Stained Limestone ${ }^{\mathrm{a}}$

\begin{tabular}{|c|c|c|c|}
\hline Sample & $\begin{array}{l}\mathrm{Fe}_{2} \mathrm{O}_{3} \\
\text { (Total Fe) }\end{array}$ & $\mathrm{MnO}$ & $\mathrm{TiO}_{2}$ \\
\hline $\begin{array}{l}\text { Red laminated crust } \\
392-1-1,143 \mathrm{~cm}\end{array}$ & 20.3 & 0.37 & 0.04 \\
\hline $\begin{array}{l}\text { Red-stained matrix } \\
392 \mathrm{~A}-4, \mathrm{CC}\end{array}$ & 20.2 & 0.04 & 0.00 \\
\hline $\begin{array}{l}\text { Red ooids } \\
392 \mathrm{~A}-4-1,125 \mathrm{~cm}\end{array}$ & 24.7 & 0.05 & 0.19 \\
\hline
\end{tabular}

\footnotetext{
a Analyst: M. Budd, SUNY Binghamton.
} 


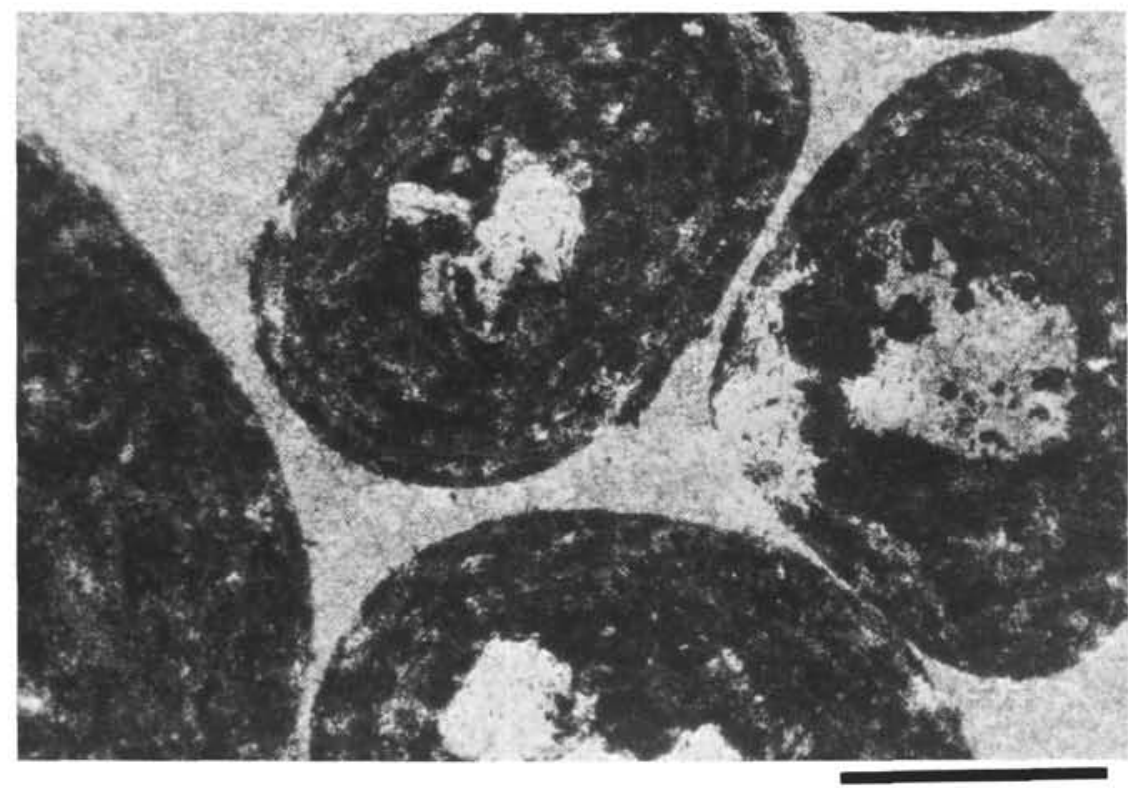

$0.2 \mathrm{~mm}$

Figure 56. Geothite ooids in coccolith lime mudstone. Centers (nucleii) were plucked in slide preparation except one at right which is red-stained coccolith mudstone with red pelletoids. Sample $392 A-4, C C(10 \mathrm{~cm})$. Sub-bottom depth 90.1 meters. Thin section, plane light.

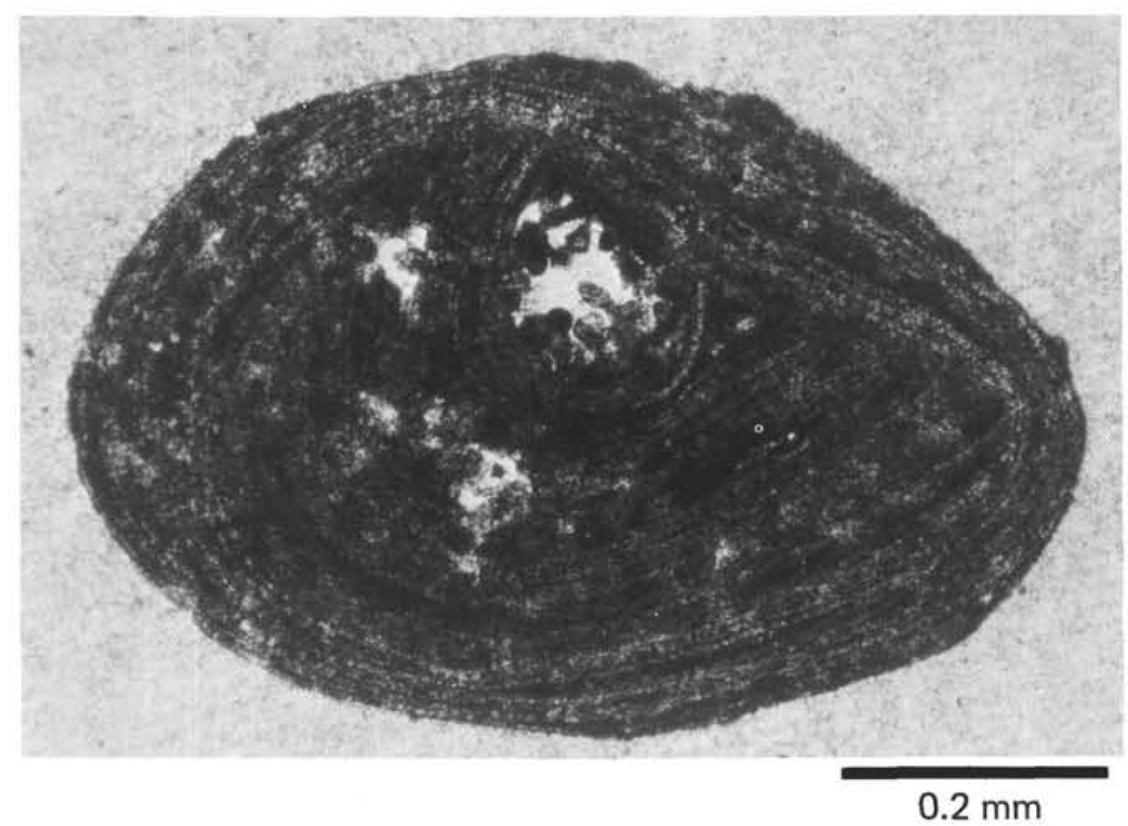

Figure 57. Goethite ooid coating on broken goethite ooid in coccolith mudstone matrix. Nucleus of broken ooid appears to have been a composite pelletoid grain with mud matrix, but the red pelletoids very likely were formed by in situ alteration. Sample 392-1-1, $143 \mathrm{~cm}$. Sub-bottom depth 49 meters. Thin section, plane light. 


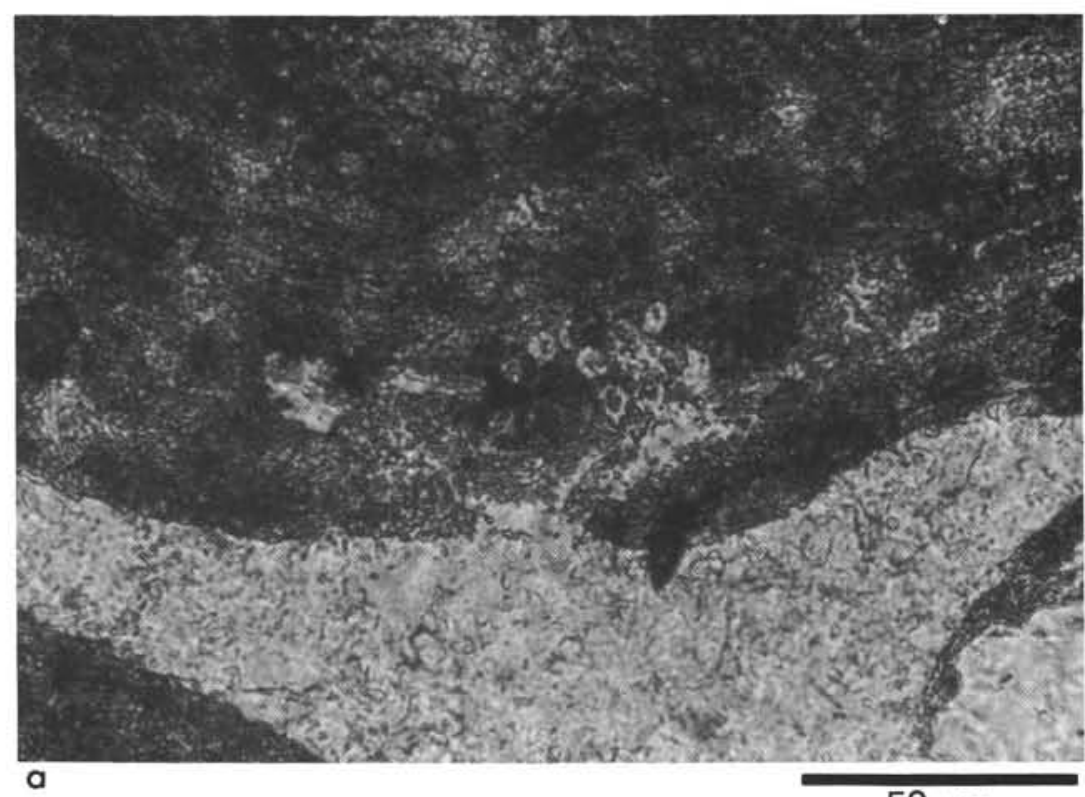

$50 \mu \mathrm{m}$

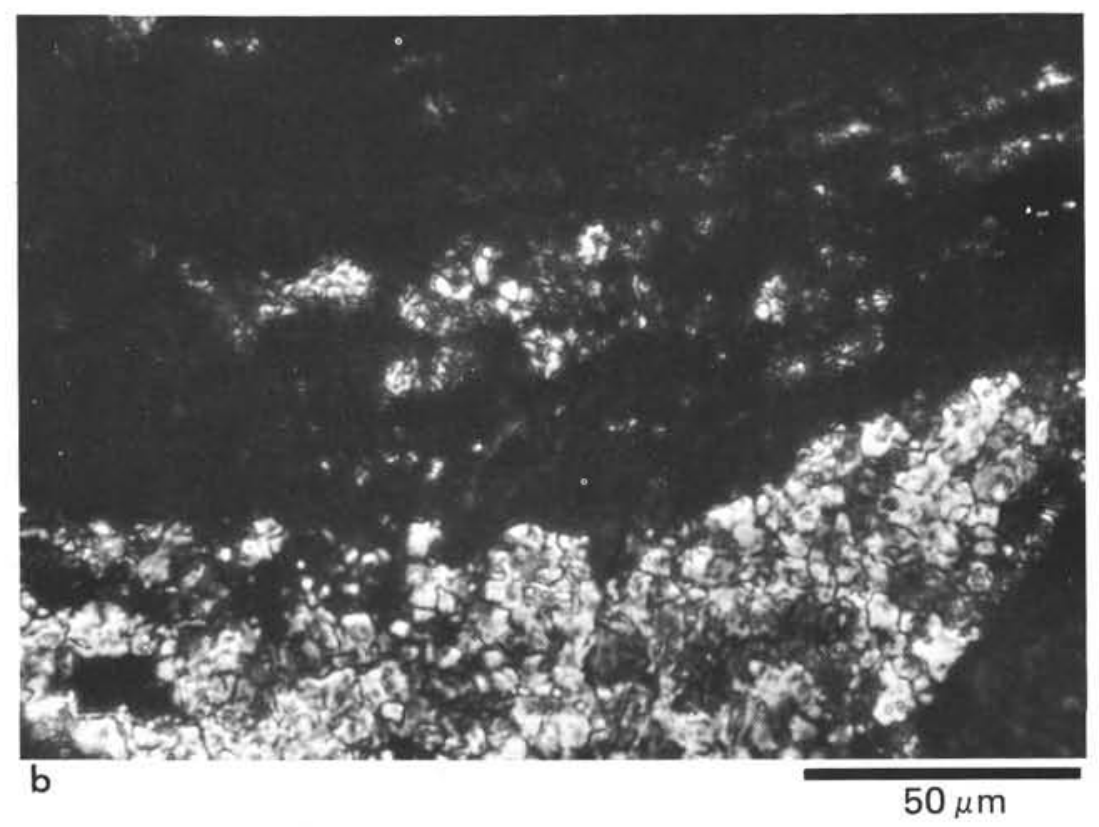

Figure 58. Coccoliths within bands of goethite ooid. (a) Thin section, plane light. Detail of top center ooid in Figure 56. Apparent rupture in ooid shell results from plucking in slide preparation. (b) Polarized light shows characteristic refraction pattern of coccoliths. 


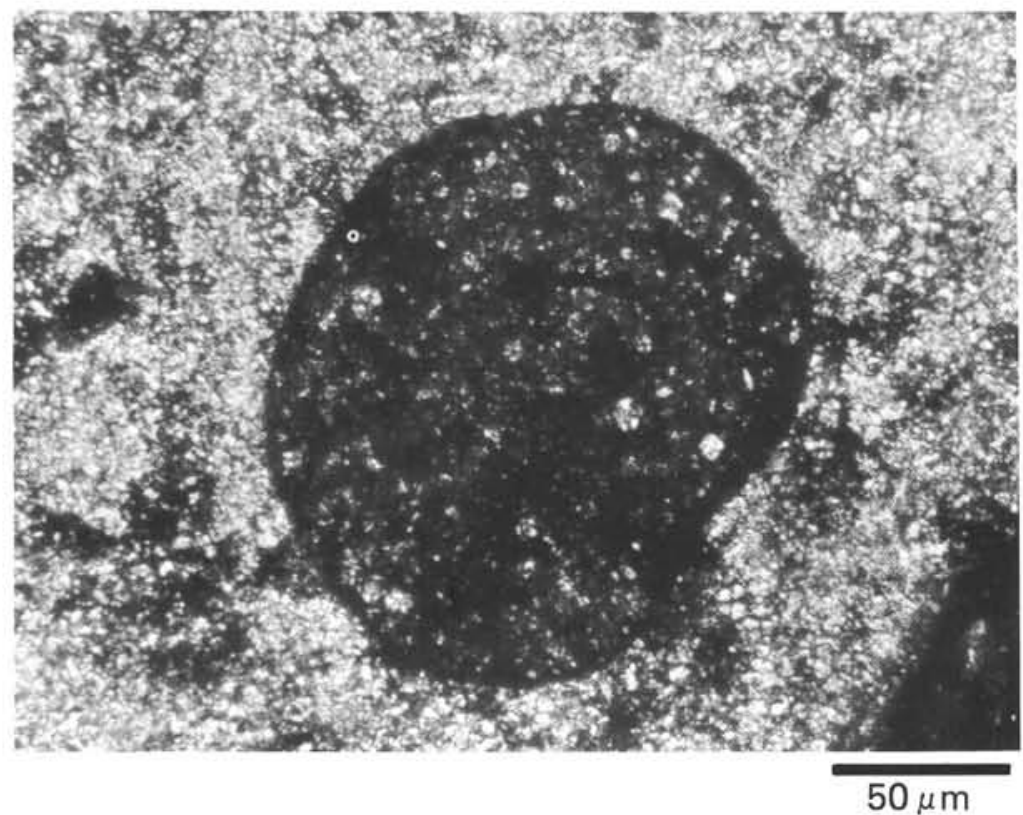

Figure 59. Coccoliths within small goethite ooid in coccolith lime mudstone. Sample 392-1-1, $143 \mathrm{~cm}$. Sub-bottom depth 49 meters. Thin section, cross-polarized light.

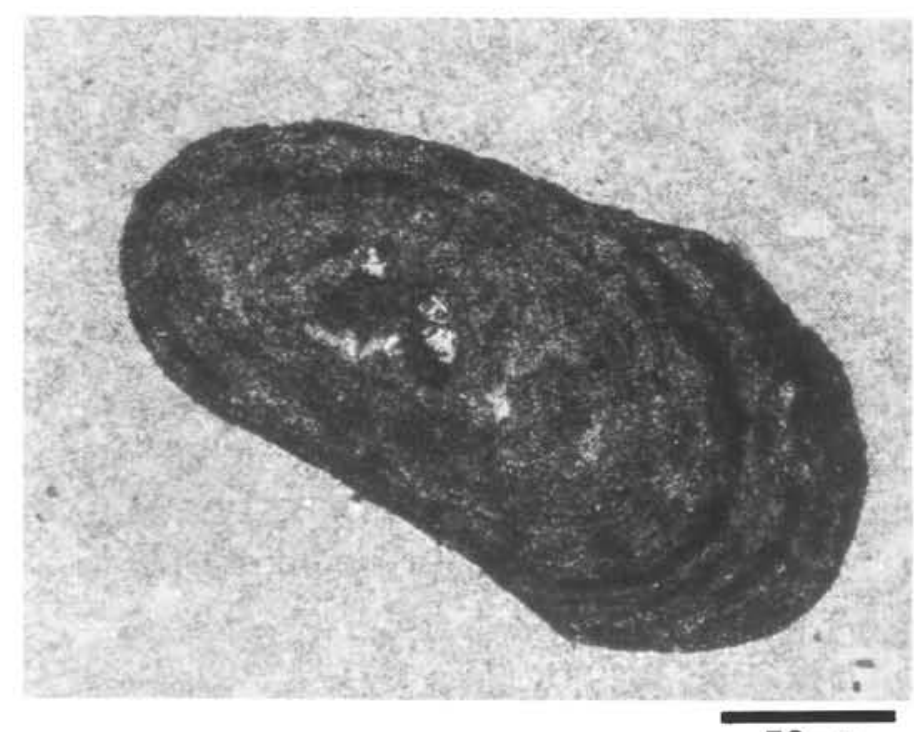

$50 \mu \mathrm{m}$

Figure 60. Asymmetric goethite ooid with truncated laminae. Matrix is coccolith lime mudstone. Sample 392-1-1, 143 cm. Sub-bottom depth 49 meters. Thin section, plane light. 
P. ENOS, T. FREEMAN
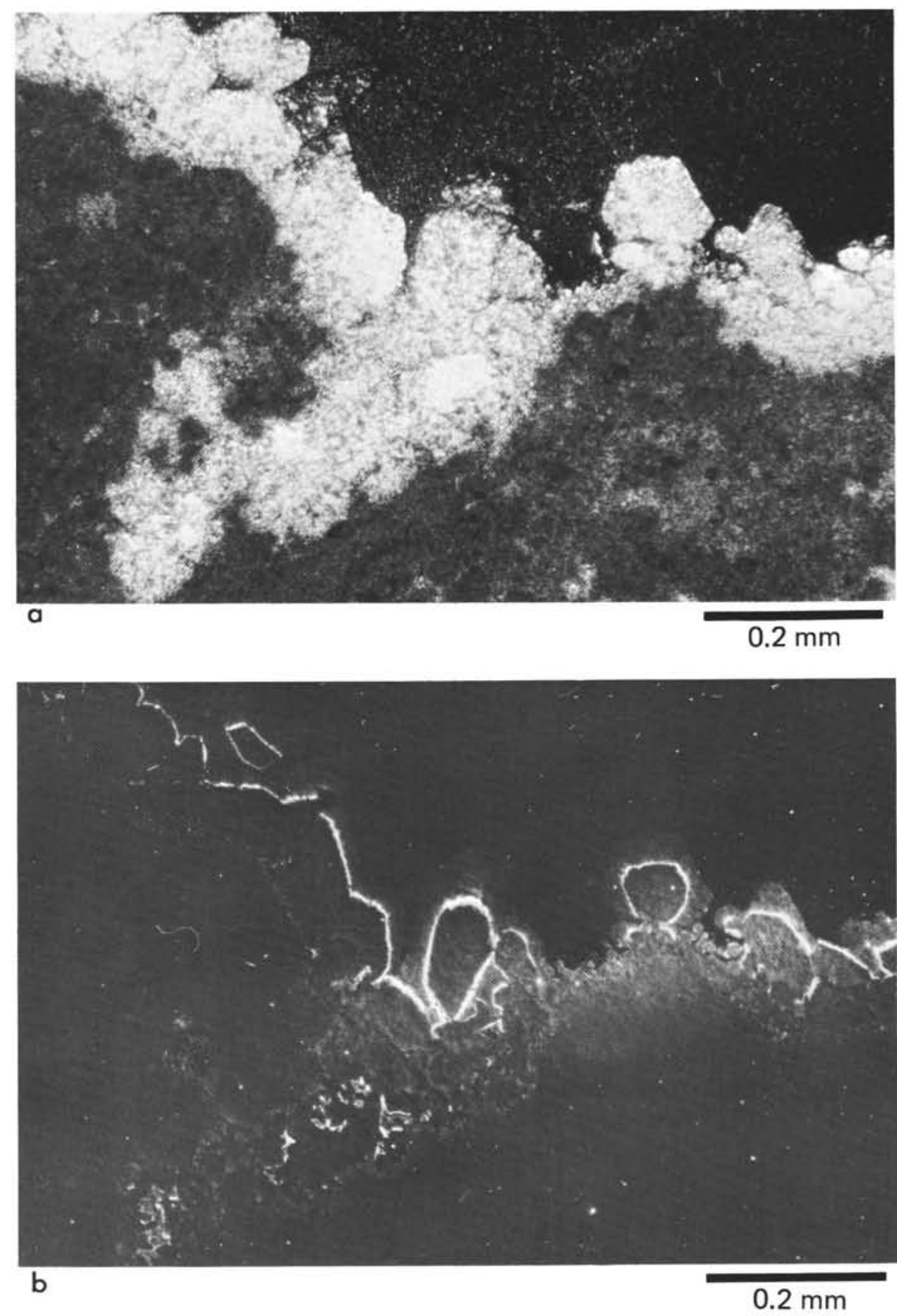

Figure 61. Cathode luminescence in cements of skelmoldic limestone. (a) Equant cement at edge of vug. Thin section, cross-polarized light. (b) Luminescence in same crystals, confined to thin red-luminescing band in outer portions of the crystal, but not at the extremeties. Sample 392A-27, CC. Sub-bottom depth 288 meters. Orientation unknown. 


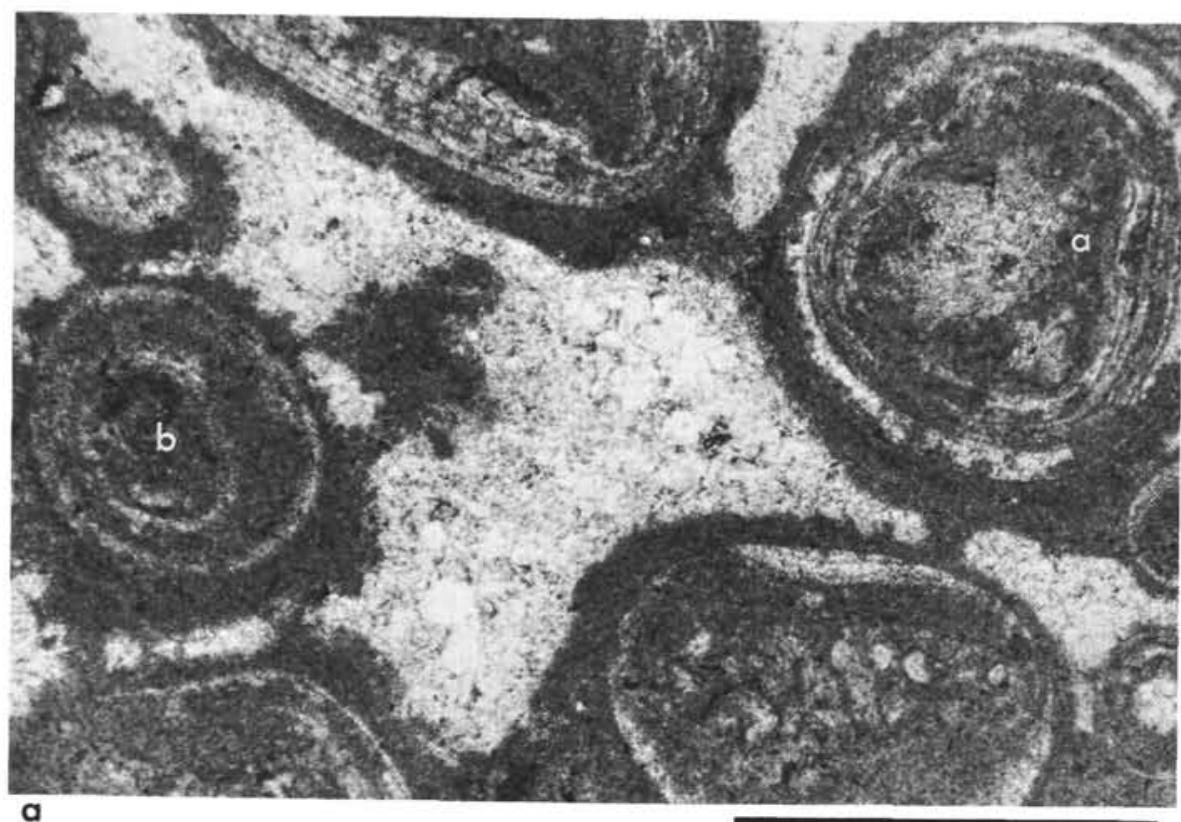

$0.5 \mathrm{~mm}$

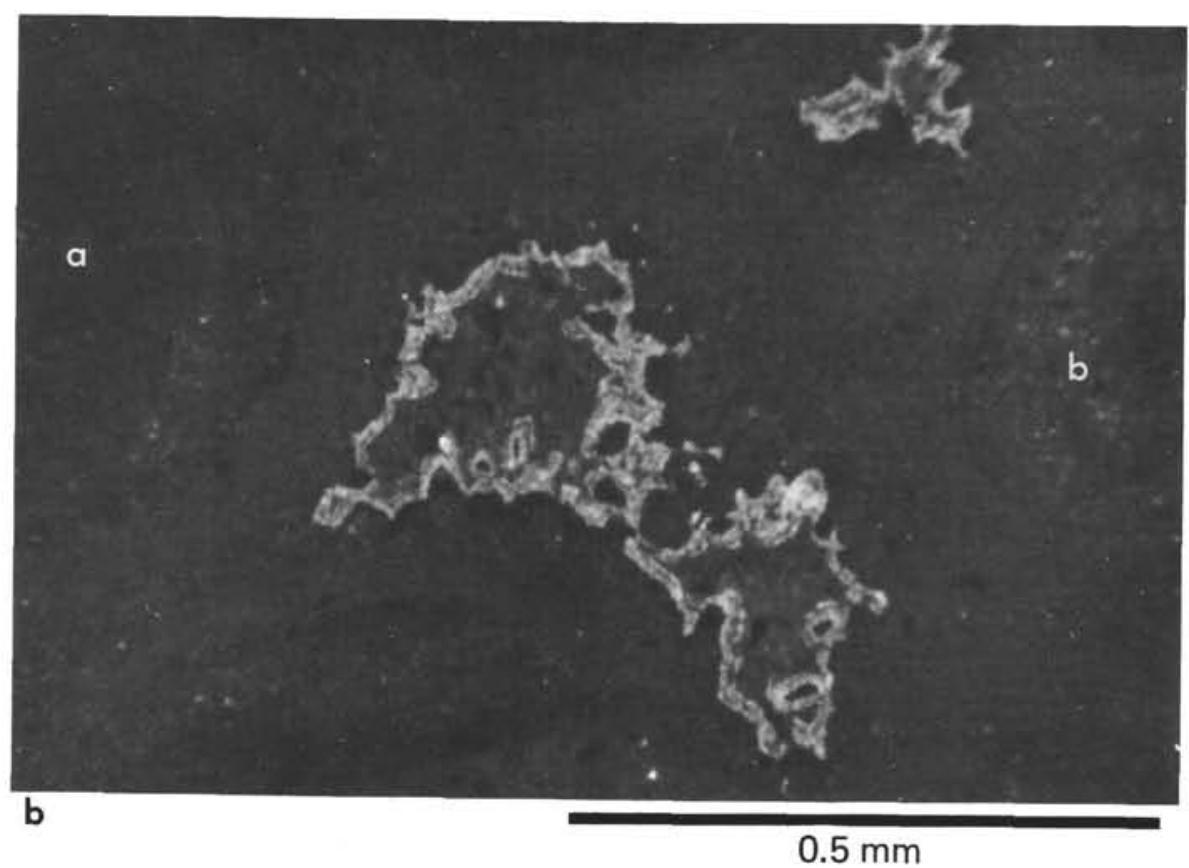

Figure 62. Luminescence in cements of oolitic limestone. (a) Cement filling intergranular pore space in oolitic grainstone, overlying diagenetic sediment. Thin section, plane light. (b) Luminescence in cement; banded red luminescence within the cloudy cement. Earliest and latest cements do not luminesce. This photo is reversed from $A$ and at larger scale. For orientation, corresponding grains $a$ and $b$ are identified in each figure. Sample 392A-22-1, $95 \mathrm{~cm}$. Subbottom depth 241.5 meters. 